NIST Technical Note 2077

\title{
The NIST 20 MW Calorimetry Measurement System for Large-Fire Research
}

Rodney A. Bryant Matthew F. Bundy

This publication is available free of charge from:

https://doi.org/10.6028/NIST.TN.2077

National Institute of Standards and Technology U.S. Department of Commerce 
NIST Technical Note 2077

\section{The NIST $20 \mathrm{MW}$ Calorimetry Measurement System for Large-Fire Research}

Rodney A. Bryant Matthew F. Bundy

Fire Research Division

Engineering Laboratory

This publication is available free of charge from:

https://doi.org/10.6028/NIST.TN.2077

December 2019

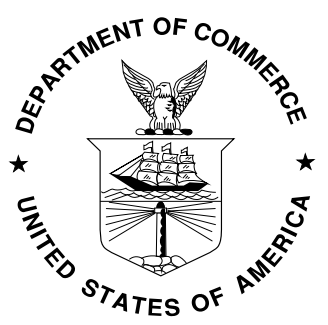

U.S. Department of Commerce Wilbur L. Ross, Jr., Secretary

National Institute of Standards and Technology Walter Copan, NIST Director and Undersecretary of Commerce for Standards and Technology 
Certain commercial entities, equipment, or materials may be identified in this document in order to describe an experimental procedure or concept adequately. Such identification is not intended to imply recommendation or endorsement by the National Institute of Standards and Technology, nor is it intended to imply that the entities, materials, or equipment are necessarily the best available for the purpose.

National Institute of Standards and Technology Technical Note 2077 Natl. Inst. Stand. Technol. Tech. Note 2077, 76 pages (December 2019) CODEN: NTNOEF

This publication is available free of charge from: https://doi.org/10.6028/NIST.TN.2077 


\begin{abstract}
The National Fire Research Laboratory is a unique large-fire research facility; able to characterize the response of full-scale building systems to realistic mechanical loading and fire. The facility maintains an infrastructure of measurements necessary for accurately characterizing the heat release rate of fires, a key parameter in predicting fire hazard. This measurement infrastructure includes four oxygen consumption calorimeters to measure the heat released during fire experiments, and a fuel consumption calorimetry system (natural gas burners and flow control) to generate precise amounts of heat release. Both systems have a heat release rate capacity of $20 \mathrm{MW}$, twice the capacity of the previous facility. A rigorous evaluation of the processes for the measurements by oxygen consumption calorimetry and fuel consumption calorimetry has resulted in significant improvements in measurement uncertainty when compared to previous versions of the facility. Measurement agreement between the two independent systems has been demonstrated and provides evidence that NFRL's system of heat release rate measurements for large-scale fire research are the most accurate and highly characterized of their kind. The methodology, hardware, and performance of the large-fire calorimeters and natural gas flow system are described here to provide technical guidance on achieving accurate heat release measurements to laboratories with the mission of accurate large-scale fire testing.
\end{abstract}

\title{
Keywords
}

Heat Release Rate; Calorimetry; Oxygen Consumption; Fuel Consumption; Large-Fire Measurements. 


\section{Table of Contents}

1. Introduction .............................................................................................................................. 1

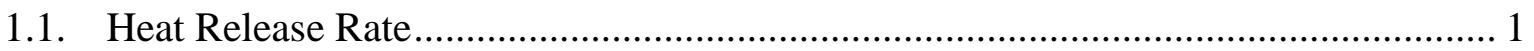

2. Calorimetry Measurement Models ........................................................................ 4

2.1. Oxygen Consumption Calorimetry …………………………………………... 4

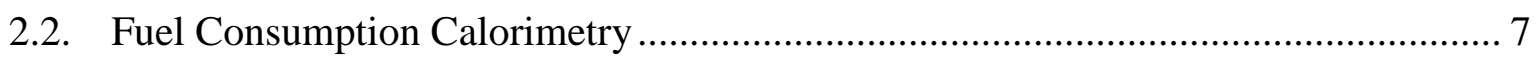

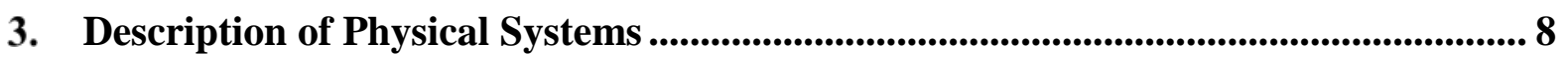

3.1. Oxygen Consumption Calorimetry …………………..................................... 9

3.1.1. Exhaust Hoods and Ducts............................................................................ 9

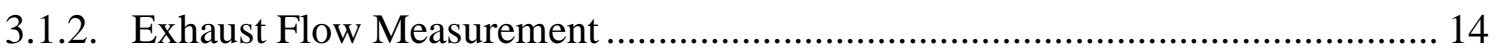

3.1.3. Gas Sampling and Conditioning.................................................................... 19

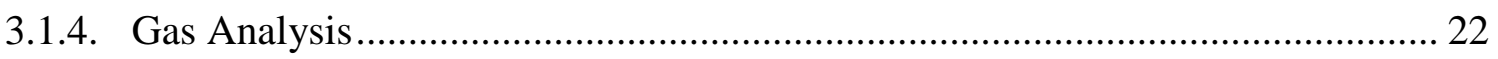

3.2. Fuel Consumption Calorimetry (Natural Gas) ………………………………….... 23

3.2.1. Natural Gas Burners ................................................................................. 24

3.2.2. Natural Gas Flow Measurement and Flow Control............................................ 26

3.2.3. Natural Gas Analysis ..................................................................................... 28

4. Performance ......................................................................................................................... 32

4.1. Measurement Uncertainty ………………………........................................ 32

4.1.1. Oxygen Consumption Calorimetry .............................................................. 32

4.1.2. Fuel Consumption Calorimetry (Natural Gas) .................................................... 38

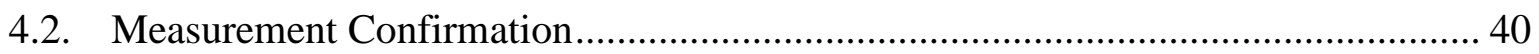

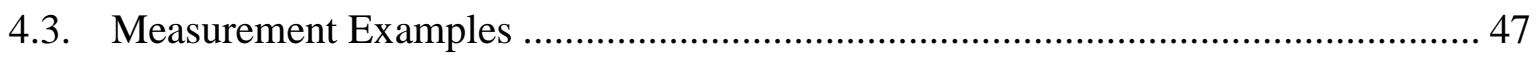

4.4. Measurement Delays and Alignment .................................................................... 49

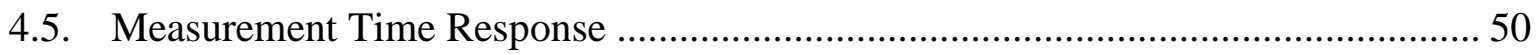

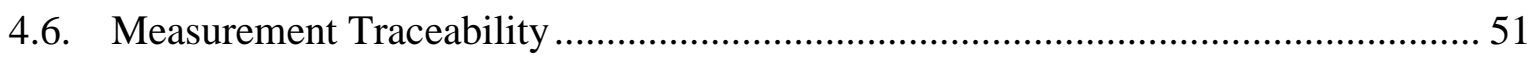

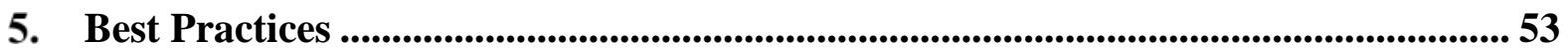

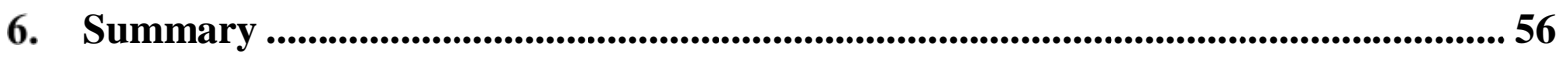

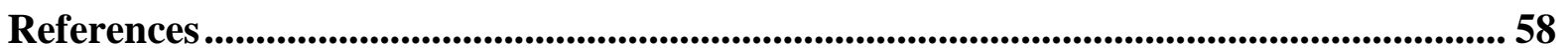

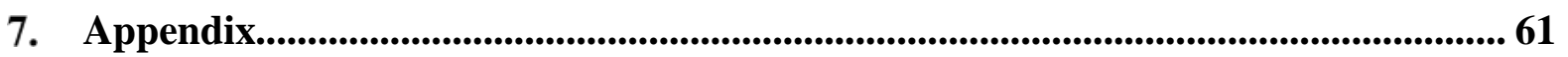

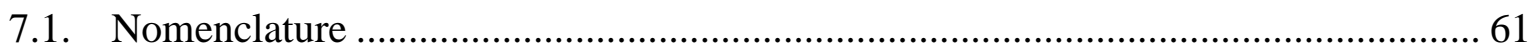

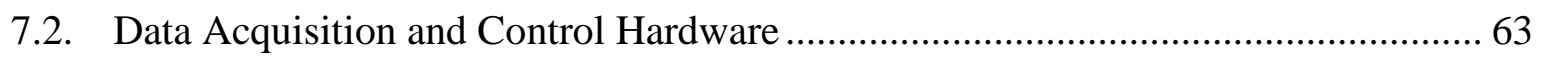

7.3. Rotational Distribution of Chord Measurements in NFRL's Exhaust Ducts............. 64

7.4. Uncertainty Budgets for Select Measurement Components...................................... 65 


\section{List of Tables}

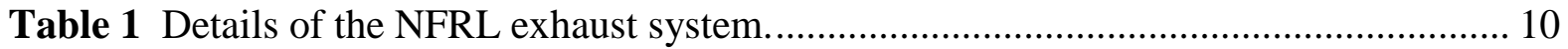

Table 2 Calorimeter hood dimensions and reference distances as described by Figure 3... 11

Table 3 Characterizing details for the averaging pitot probes. Expanded uncertainties are reported for a $95 \%$ confidence interval with a coverage factor $k=2.0$.

Table 4 Flow correction factors for the effective flow measurement by the averaging pitot probes. Expanded uncertainties are reported for a $95 \%$ confidence interval with a coverage factor $\mathrm{k}=2.0$.

Table 5 Effective diameter of NFRL's exhaust ducts. Expanded uncertainties are reported

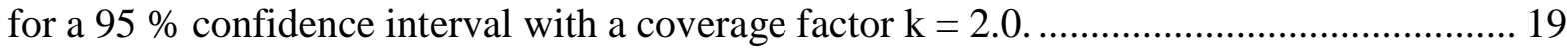

Table 6 Example computation of natural gas properties............................................... 31

Table 7 Summary of measurement uncertainty for NFRL's oxygen consumption calorimeters. Expanded uncertainties are reported.

Table 8 Uncertainty budget for the measurement of heat release rate by oxygen consumption

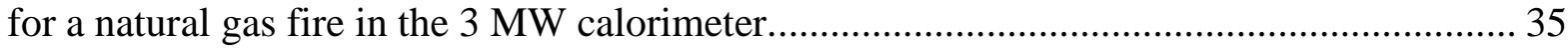

Table 9 Average estimates of measurement repeatability for NFRL's calorimeters............ 37 Table 10 Uncertainty budget for the measurement of exhaust mass flow at the $3 \mathrm{MW}$ Calorimeter.

Table 11 Uncertainty budget for the measurement of heat release rate by fuel consumption at the $8 \mathrm{MW}$ natural gas burner.

Table 12 Summary of traceable measurements for NFRL's oxygen consumption and fuel (natural gas) consumption calorimetry systems.

Table 13 Uncertainty budget for the oxygen volume fraction measurement in the exhaust gas.

Table 14 Uncertainty budget for the carbon dioxide volume fraction measurement in the exhaust gas.

Table 15 Uncertainty budget for the measurement of carbon monoxide volume fraction in the exhaust gas.

Table 16 Uncertainty budget for the measurement of effective gas velocity by the averaging pitot probes in the exhaust duct.

Table 17 Uncertainty budget for the natural gas heat of combustion computed from micro gas chromatograph measurements.

\section{List of Figures}

Figure 1 Conceptual schematic of NFRL's oxygen consumption calorimetry and fuel consumption measurement systems.

Figure 2 Plan view scale drawing of NFRL. Outlines of calorimetry hoods are shown in red and fresh air intake vents are shown in green.

Figure 3 Schematic of hood dimensions as listed in Table 2 ........................................... 12

Figure 4 NFRL exhaust ducts and emissions control system (ECS). ................................ 13

Figure 5 Installation of two averaging pitot probes and the gas sample tube in NFRL's

$1.975 \mathrm{~m}$ exhaust duct. Photograph view is looking upstream............................................ 15 
Figure 6 Locations of chord measurements inside the exhaust ducts as seen looking

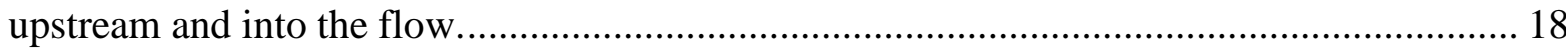

Figure 7 Schematic of exhaust gas sample flow control and conditioning systems............ 20 Figure 8 NFRL's gas analysis instrumentation and sample gas conditioning system (right

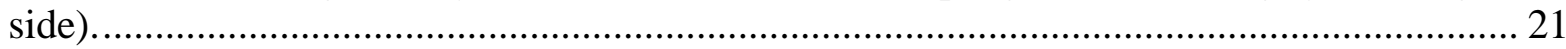

Figure 9 Natural gas tube burner for reference fires up to $8 \mathrm{MW}$.................................. 24

Figure 10 Natural gas tube burner for reference fires up to $20 \mathrm{MW}$............................... 25

Figure 11 Close view of burner tubes and spark ignitor............................................. 26

Figure 12 Schematic of NFRL's system for characterizing and controlling the supply of

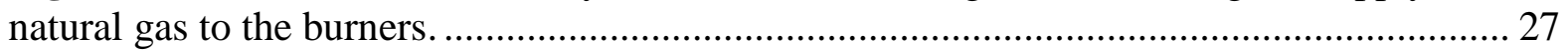

Figure 13 Natural gas delivery for the 20 MW burner. .............................................. 28

Figure 14 Micro gas chromatograph for on-line analysis of NFRL's natural gas supply.... 29 Figure 15 Estimated measurement uncertainty for NFRL's oxygen consumption calorimeters with respect to fuel source: natural gas (NG) or generic combustibles (GC). Expanded uncertainties are reported.

Figure 16 Component measurement uncertainty contribution for the case of a natural gas (NG) fire in the $10 \mathrm{MW}$ calorimeter. Component measurements contributing less than $0.5 \%$ are not shown. 36

Figure 17 Component measurement uncertainty contribution for the case of a generic combustibles (GC) fire in the $10 \mathrm{MW}$ calorimeter. Component measurements contributing less than $0.5 \%$ are not shown.

Figure 18 Estimated measurement uncertainty for heat release by fuel consumption for NFRL's natural gas burners. Expanded uncertainties are reported.

Figure 19 Confirmation burn at the $20 \mathrm{MW}$ Calorimeter using the $20 \mathrm{MW}$ natural gas burner.

Figure 20 Time history traces of calorimetry confirmation experiments at the $0.5 \mathrm{MW}$ and $3 \mathrm{MW}$ calorimeters. The natural gas reference burners were used to generate the prescribed fires. Uncertainty bars represent expanded uncertainties.

Figure 21 Time history traces of calorimetry confirmation experiments at the $10 \mathrm{MW}$ and $20 \mathrm{MW}$ calorimeters. The natural gas reference burners were used to generate the prescribed fires. Uncertainty bars represent expanded uncertainties. 43 Figure 22 Comparison of mean values of independent heat release measurements for routine operating conditions at the $0.5 \mathrm{MW}$ and $3 \mathrm{MW}$ calorimeters. Symbols represent exhaust flow conditions, \% of full-scale (FS). Dashed lines represent relative expanded uncertainty of the mean calorimetry measurement by oxygen consumption. 45 Figure 23 Comparison of mean values of independent heat release measurements for routine operating conditions at the $10 \mathrm{MW}$ and $20 \mathrm{MW}$ calorimeters. Symbols represent exhaust flow conditions, \% of full-scale (FS). Dashed lines represent relative expanded uncertainty of the mean calorimetry measurement by oxygen consumption.

Figure 24 Time trace of heat release rate measured at the $20 \mathrm{MW}$ calorimeter for a fully-furnished apartment with exposed cross laminated timber structural members. Uncertainty bar represent expanded uncertainties.

Figure 25 Opposing vertical panels of PMMA, burning at the $3 \mathrm{MW}$ calorimeter. The heat release rate at the time of the photograph was $1.85 \mathrm{MW}$..... 48 Figure 26 Time trace of heat release rate measured at the 3.0 MW calorimeter for verticallyoriented PMMA panels. Uncertainty bars represent expanded uncertainties. 48 
Figure 27 Example of data used for oxygen delay time calculation. The data was generated using the natural gas burner at the $3 \mathrm{MW}$ calorimeter and for a heat release step of $0.54 \mathrm{MW}$ to $1.02 \mathrm{MW}$.

Figure 28 Dynamic response of the $3 \mathrm{MW}$ calorimeter to a pulsing natural gas fire. Pulse widths decrease left to right. Black and green traces are examples of moving averages applied to the data.

Figure 29 Chord length measurements at the measurement stations of the averaging pitot probes for the $3 \mathrm{MW}$ and the $10 \mathrm{MW}$ calorimeters. Dashed lines represent expanded uncertainties.

Figure 30 Chord length measurements at the measurement stations of the averaging pitot probes for the $20 \mathrm{MW}$ calorimeter. Dashed lines represent expanded uncertainties. 64 


\section{Introduction}

The National Institute of Standards and Technology (NIST) has maintained operation of its large-fire facility in Gaithersburg, MD since 1975. In 2015, the facility was expanded in size and capability to enable research on the response of full-scale structural systems to realistic fire and mechanical loads. The newly expanded facility, the National Fire Research Laboratory (NFRL), is one of the most unique fire research facilities in the world.

The primary objective of the NFRL is to safely conduct real-scale fire and structural-fire experiments with the goals of 1) enabling fire model validation studies 2) enabling advances in codes and standards for materials and structures in fire conditions, and 3) supporting building and fire safety investigations and post disaster and failure studies. To meet the technical needs of the NFRL, new measurement methods are developed while existing methods are continually improved. These measurement methods are used to provide reference data for comparison against numerical predictions for component-scale, small-scale, and full-scale assemblies. The newly developed and improved methods also provide motivation and guidance to advance the state-of-the-art for large-fire research and testing.

The NFRL has developed an infrastructure of physical measurements necessary to conduct research to characterize the behavior of structures in a fire. The measurements are supported with the well-quantified estimates of uncertainty. This infrastructure includes measurements of temperature, heat transfer, gas volume fraction, gas flux, strain, force, displacement, high-definition video, and heat release. All are integrated with high-throughput data acquisition tools to record and view the live measurement results.

Experiments in the NFRL are designed to provide the key technical information and data necessary to advance performance-based design of structures exposed to realistic fire conditions. The facility consists of $3000 \mathrm{~m}^{2}$ (32 $\left.300 \mathrm{ft}^{2}\right)$ of laboratory space, containing a strong floor/strong wall combination to support and load structural components. This allows structures ranging in size from small components to large systems, such as buildings up to two stories in height, to be tested under simultaneous mechanical loading and fire exposure. The NFRL maintains four large-fire calorimeters to measure the heat release rate of fires ranging from 0.02 MW to $20 \mathrm{MW}$. In addition, it maintains an emissions control system (ECS) to treat smoke particulates and combustion gases to comply with local environmental requirements. Therefore, building systems can be tested while exposed to growing fires, using natural gas, liquid hydrocarbons, wood cribs, or actual building contents as fuel. The rate of heat release is the primary parameter defining the fire load and the primary measurement capability of the NFRL. This document will describe the methodology, hardware, and performance of NFRL's measurement of heat release rate as conducted with its four large-fire calorimeters and natural gas flow system.

\subsection{Heat Release Rate}

Heat release rate is defined as the enthalpy change per unit time as a result of the conversion of the chemical energy of a fuel to heat in a combustion process. Most commonly the fuel is carbon-based; and the combustion process is one of oxidation, usually by the oxygen in air. Heat release rate is typically reported in kilowatts (kW) or megawatts (MW). Its importance follows from the fact that it is a key predictor of the hazard of a fire, directly controlling the 
rate at which heat and toxic gases build up in a compartment or are buoyantly driven into more remote spaces. [1] It is, in effect, the most pertinent measure of the size of a fire. [2]

Understanding the heat release rate potential of an object or an assembly of objects is essential to estimate the hazard such an object or arrangement could pose if ignited. Fire safety standards and codes of such hazards are based on this understanding. Although substantial progress is being made, the present state of fire growth models is such that the prediction of heat release rate for common room contents such as chairs or beds cannot be fully characterized. Thus, measurements of heat release rate on real objects are still essential. The measured results may be used as input for hazard calculation models such as the Consolidated Model of Fire Growth and Smoke Transport (CFAST) [3] and the Fire Dynamics Simulator (FDS) [4] or for the evaluation of product performance. In either case, accurate heat release rate measurements are essential to meaningful results.

For a simple object made from a pure substance with a known constant heat of combustion the measurement of heat release rate requires only a mass loss rate measurement on the object since the former is proportional to the latter. Mass loss (fuel consumption) is useful if the "object" is a well-defined gas or liquid supplied at a known rate. This is the basis for the confirmation of more general heat release rate calorimeters, where the calorimeter output can be compared with the heat release from a precisely measured flow of a fuel whose heat of combustion is accurately known. In practice the heat of combustion of a complex object is rarely tabulated and in any case is variable for charring materials. Thus, reliance on mass loss to quantify heat release is unreliable for real objects.

Early measurements of heat release rate for real objects focused on the heat output as represented by the temperature of the product gases. An array of thermocouples was positioned in a duct which captured all the gases to measure their average gas temperature [ASTM 1321 (LIFT test); ASTM 906 (OSU calorimeter)]. This approach assumes the flow is adiabatic, a simplifying ideal case. However, the heat emitted from the fire as radiation can be $35 \%$ or more of the total chemical heat release rate. [5] More sophisticated variants of this thermal approach, based on measuring the fuel gas flow rate required to maintain a constant product stream temperature, have the same limitation. [6]

Huggett first suggested a very different approach, now termed oxygen consumption calorimetry. [7] He followed up on the much earlier finding that the amount of heat evolved from most organic materials per unit mass of oxygen consumed in their complete combustion is nearly constant. For example, the heat evolved for butyl alcohol is:

$$
\begin{aligned}
& \mathrm{C}_{4} \mathrm{H}_{9} \mathrm{OH}+6 \mathrm{O}_{2}+6(3.76) \mathrm{N}_{2} \rightarrow 4 \mathrm{CO}_{2}+5 \mathrm{H}_{2} \mathrm{O}+6(3.76) \mathrm{N}_{2} ; \\
& \left(\Delta_{c} \mathrm{H}_{\mathrm{C}_{4} \mathrm{H}_{9} \mathrm{OH}}\right)_{\mathrm{O}_{2}}=-12.79 \mathrm{MJ} / \mathrm{kg}^{1}
\end{aligned}
$$

Thus, the oxygen deficit (relative to ambient air) due to combustion is a measure of the heat released by the burning material.

\footnotetext{
${ }^{1}$ All heat of combustion values reported here are ideal net heating values, also known as lower heating values (LHV); therefore, the water produced by the combustion reaction is in vapor form.
} 
For a wide variety of molecules from pure hydrocarbons, to partially oxygenated species, to partially halogenated species, and a wide variety of polymers and natural materials such as wood and coal, the heat release per unit mass of oxygen falls within a narrow range. Huggett showed that, for most common materials or generic combustibles (GC) containing atoms of carbon $(\mathrm{C})$, hydrogen $(\mathrm{H})$, oxygen $(\mathrm{O})$, and nitrogen $(\mathrm{N})$, the average heat release per unit mass of oxygen is $13.1 \mathrm{MJ} / \mathrm{kg}$ with a standard deviation of $0.35 \mathrm{MJ} / \mathrm{kg}$.

Fire calorimeter methods based on oxygen consumption were developed at NIST in the 1970s and 1980s. The first practical measurement device resulting from this research was known as the Cone Calorimeter. [8] The Cone Calorimeter is used to study material flammability for specimens smaller than $100 \mathrm{~cm}^{2}$ and producing heat release up to $10 \mathrm{~kW}$. The Cone Calorimeter has been commercialized, standardized, and widely adopted as a research, development, and standard testing methodology. At the same time a full-scale open calorimeter was developed for furniture-sized items. The 'Furniture Calorimeter' was used to study fires up to $1 \mathrm{MW}$ in size. [9] These early calorimeters used primitive computer data collection systems and were labor intensive to operate. In the early 2000s NIST added a 3 MW and $10 \mathrm{MW}$ calorimeter, made significant upgrades to the data acquisition, computer control, and measurement hardware, and added an improved emissions control system. [10]

Around the same time, other laboratories began expanding their capabilities to study large-scale fires. Factory Mutual Global built a facility with a $20 \mathrm{MW}$ calorimeter based on the measurement principle of carbon dioxide and carbon monoxide production. [11] The Bureau of Alcohol, Tobacco and Firearms (ATF) built a facility able to accommodate fires up to 14 MW. [12] Both Underwriters Laboratories, Inc. (UL) and the Korea Institute of Civil Engineering and Building Technology (KICT) constructed facilities capable of handling 10 MW fires. [13, 14] ATF, UL, and KICT all implemented the measurement principle of oxygen consumption calorimetry in their facilities, with ATF and KICT adopting many of the measurement strategies and procedures from NIST guidance. [15] 


\section{Calorimetry Measurement Models}

The primary measurement capability of the NFRL is the measure of heat release by 1) the principle of oxygen consumption calorimetry and 2) the principle of fuel consumption calorimetry (consumption of natural gas). The following text describes the model used to infer heat release from a system of measurements that comprise NFRL's four oxygen consumption calorimeters for large-fire measurements. The simplifying assumptions that allow for practical utilization of the model are also described. Since the NFRL has the capability to precisely generate prescribed amounts of chemically released heat utilizing a natural gas delivery and burner system. The model used to infer heat release from fuel consumption calorimetry, specifically the consumption of natural gas, is also described.

\subsection{Oxygen Consumption Calorimetry}

Sensenig built the first working apparatus based on oxygen consumption (OC) calorimetry. [16] Heat release rate, $\dot{Q}_{\mathrm{OC}}$, was inferred from the measured oxygen $\left(\mathrm{O}_{2}\right)$ deficit in the flow of a hood that captured the fire plume as shown in the following equation:

$$
\dot{Q}_{\mathrm{OC}}=\left(\Delta_{\mathrm{c}} H_{\text {fuel }}\right)_{\mathrm{O}_{2}} \dot{V}_{\mathrm{e}} X_{\mathrm{O}_{2}}^{\mathrm{o}} \theta
$$

where

$$
\theta=\frac{X_{\mathrm{O}_{2}}^{\mathrm{o}}-X_{\mathrm{O}_{2}}}{X_{\mathrm{O}_{2}}^{\mathrm{o}}}
$$

with $X_{\mathrm{O}_{2}}^{\mathrm{o}}$ being the oxygen volume fraction in the ambient air, $X_{\mathrm{O}_{2}}$ the oxygen volume fraction in the duct after the captured smoke plume (and any excess air) is well-mixed, $\dot{V}_{\mathrm{e}}$ is the measured volume flow in the exhaust duct, and $\left(\Delta_{\mathrm{c}} H_{\text {fuel }}\right)_{\mathrm{O}_{2}}$ is the heat of combustion per unit volume of oxygen consumed (e.g., $\mathrm{MJ} / \mathrm{m}^{3}$ ). This simplified equation is approximate since it neglects other gases that are present such as water vapor and carbon dioxide. The equation does convey, however, the role of the primary variables: exhaust duct flow and oxygen depletion.

Equation (2) may be rewritten on a mass basis as follows:

$$
\dot{Q}_{\mathrm{OC}}=\left(\Delta_{\mathrm{c}} H_{\text {fuel }}\right)_{\mathrm{O}_{2}}\left(\dot{m}_{\mathrm{O}_{2}}^{\mathrm{o}}-\dot{m}_{\mathrm{O}_{2}}\right)
$$

Where $\left(\Delta_{\mathrm{c}} H_{\text {fuel }}\right)_{\mathrm{O}_{2}}$ is the heat of combustion per unit mass of oxygen, $\dot{m}_{\mathrm{O}_{2}}^{0}$ is the mass flow of oxygen in the duct prior to the fire test, and $\dot{m}_{\mathrm{O}_{2}}$ is the mass flow of oxygen in the duct during the fire test.

For an open system only the exhaust flow, which includes the flow of incoming air and combustion products, is measured. It is necessary to relate the measured exhaust flow to the incoming air flow. Therefore, it is useful to define the oxygen depletion factor, $\phi$, as the fraction of incoming air that is depleted of its oxygen. 


$$
\phi=\frac{\dot{m}_{\mathrm{O}_{2}}^{\mathrm{o}}-\dot{m}_{\mathrm{O}_{2}}}{\dot{m}_{\mathrm{O}_{2}}^{\mathrm{o}}}
$$

In relating the mass flow of air into the system to the mass flow in the duct, the assumption is employed that nitrogen is not involved in the combustion process and therefore the nitrogen flow is constant. Nitrogen analysis is not performed so its volume fraction is replaced using the assumption that only nitrogen $\left(\mathrm{N}_{2}\right)$, oxygen $\left(\mathrm{O}_{2}\right)$, carbon dioxide $\left(\mathrm{CO}_{2}\right)$, carbon monoxide (CO) and water $\left(\mathrm{H}_{2} \mathrm{O}\right)$ are present. This substitution is most accurate if all the other gas species are measured. Accurate water analysis is difficult, so it is typically approximated based on the humidity of the incoming air. Using the substitution for nitrogen, $\phi$ is expressed in terms of the measured volume fractions of the gas species.

$$
\phi=\frac{X_{\mathrm{O}_{2}}^{\mathrm{o}}\left(1-X_{\mathrm{CO}_{2}}-X_{\mathrm{CO}}\right)-X_{\mathrm{O}_{2}}\left(1-X_{\mathrm{CO}_{2}}^{\mathrm{o}}\right)}{\left(1-X_{\mathrm{O}_{2}}-X_{\mathrm{CO}_{2}}-X_{\mathrm{CO}}\right) X_{\mathrm{O}_{2}}^{\mathrm{o}}}
$$

It is apparent in Eq. (1) that the combustion process of hydrocarbon fuels can result in a greater number of moles of products than reactants. Parker[17] defines a chemical expansion factor as follows:

$$
\alpha=1+X_{\mathrm{O}_{2}}^{\mathrm{o}}(\beta-1)
$$

where $\beta$ is the ratio of the moles of combustion products to the moles of oxygen consumed. In the case of hydrocarbon fuels the average value of $\alpha$ is 1.10 .

The number of moles in the fraction of air depleted of its oxygen is replaced by an equal or greater number of moles of combustion products (second term of the equation below). Therefore, the mass flow of air into the system, $\dot{m}_{\text {air }}$, may be related to the measured mass flow of exhaust gas, $\dot{m}_{\mathrm{e}}$, by the following relation:

$$
\frac{\dot{m}_{\mathrm{e}}}{M_{\mathrm{e}}}=\frac{\dot{m}_{\mathrm{air}}}{M_{\mathrm{air}}}(1-\phi)+\frac{\dot{m}_{\mathrm{air}}}{M_{\mathrm{air}}} \phi \alpha
$$

Assuming the molecular weight of the exhaust gas is approximately equal to the molecular weight of the incoming air $\left(M_{\mathrm{e}} \approx M_{\text {air }}\right.$ ), the mass flow of the incoming oxygen is expressed as:

$$
\dot{m}_{\mathrm{O}_{2}}^{\mathrm{o}}=\dot{m}_{\mathrm{air}} X_{\mathrm{O}_{2}, \text { inc }}^{\mathrm{o}} \frac{M_{\mathrm{O}_{2}}}{M_{\mathrm{air}}}=\frac{\dot{m}_{\mathrm{e}}}{1+\phi(\alpha-1)} X_{\mathrm{O}_{2}, \text { inc }}^{\mathrm{o}} \frac{M_{\mathrm{O}_{2}}}{M_{\mathrm{air}}}
$$

Paramagnetic oxygen analyzers require the water to be removed from the sampled gas, therefore a correction must be made to the ambient oxygen volume fraction measurement.

$$
X_{\mathrm{O}_{2}, \text { inc }}^{\mathrm{o}}=\left(1-X_{\mathrm{H}_{2} \mathrm{O}}^{\mathrm{o}}\right) X_{\mathrm{O}_{2}}^{\mathrm{o}}
$$

Using Eq. (5), (9), and (10), Eq. (4) may be rewritten as follows with $\phi$, as described in Eq. (6), representing the case where $\mathrm{O}_{2}, \mathrm{CO}_{2}$, and $\mathrm{CO}$ are measured while $\mathrm{H}_{2} \mathrm{O}$ is removed from the sampled gas:

$$
\dot{Q}_{\mathrm{OC}}=\left(\Delta_{\mathrm{c}} H_{\text {fuel }}\right)_{\mathrm{O}_{2}} \phi \frac{\dot{m}_{\mathrm{e}}}{1+\phi(\alpha-1)}\left(1-X_{\mathrm{H}_{2} \mathrm{O}}^{\mathrm{o}}\right) X_{\mathrm{O}_{2}}^{\mathrm{o}} \frac{M_{\mathrm{O}_{2}}}{M_{\mathrm{air}}}
$$


Incomplete combustion, especially $\mathrm{CO}$ formation, often occurs in fires and $\mathrm{CO}$ formation yields only about half as much heat per unit mass of $\mathrm{O}_{2}$ consumed as does $\mathrm{CO}_{2}$ formation. Huggett points out that even if the $\mathrm{CO}$ concentration is $10 \%$ of the $\mathrm{CO}_{2}$ concentration, the effect on the net heat released per mass $\mathrm{O}_{2}$ consumed is small. However, flame retardants frequently boost $\mathrm{CO}$ formation, and oxygen-starved burning, as in flashover conditions, does so as well. Often $\mathrm{CO}$ formation may exceed $10 \%$ of $\mathrm{CO}_{2}$ formation. In general, it is recommended to measure $\mathrm{CO}$ and correct the heat release rate for its formation as shown in the following equation:

$$
\begin{aligned}
\dot{Q}_{\mathrm{OC}}= & {\left[\left(\Delta_{\mathrm{c}} H_{\text {fuel }}\right)_{\mathrm{O}_{2}} \phi-\left(\left(\Delta_{\mathrm{c}} H_{\mathrm{CO}}\right)_{\mathrm{O}_{2}}-\left(\Delta_{c} H_{\text {fuel }}\right)_{\mathrm{O}_{2}}\right) \frac{1-\phi}{2} \frac{X_{\mathrm{CO}}}{X_{\mathrm{O}_{2}}}\right] } \\
& \frac{\dot{m}_{\mathrm{e}}}{1+\phi(\alpha-1)}\left(1-X_{\mathrm{H}_{2} \mathrm{O}}^{\mathrm{o}}\right) X_{\mathrm{O}_{2}}^{\mathrm{o}} \frac{M_{\mathrm{O}_{2}}}{M_{\mathrm{air}}}
\end{aligned}
$$

where

$\left(\Delta_{\mathrm{c}} H_{\text {fuel }}\right)_{\mathrm{O}_{2}}=$ heat of combustion (LHV) of hydrocarbon fuel per unit mass oxygen, $\mathrm{MJ} / \mathrm{kg}$

$\left(\Delta_{\mathrm{c}} H_{\mathrm{CO}}\right)_{\mathrm{O}_{2}}=$ heat of combustion of carbon monoxide per unit mass oxygen, $\mathrm{MJ} / \mathrm{kg}$

$\phi=$ oxygen depletion factor

$\dot{m}_{\mathrm{e}}=$ mass flow rate in exhaust duct, $\mathrm{kg} / \mathrm{s}$

$\alpha=$ combustion products expansion factor

$M_{i}=$ molecular weight of gas $i, \mathrm{~kg} / \mathrm{kmole}$

$X_{i}=$ volume fraction of exhaust gas $i, \mathrm{~L} / \mathrm{L}$

$X_{i}^{\mathrm{o}}=$ volume fraction of ambient gas $i, \mathrm{~L} / \mathrm{L}$

The algebraic complexity of Eq. (12), compared to Eq. (2) or (4), arises from a more thorough treatment of the mass balances (and elemental balances) on the species between the fire, where they are generated, and the instruments where they are measured. Parker [17] and Parker and Janssens [18] discuss the details of the heat release rate calculation based on the extent to which the duct gas flow is characterized, i.e., whether one measures only $\mathrm{O}_{2}$ or also includes $\mathrm{CO}, \mathrm{CO}_{2}$ and water. The NIST calorimeter system measures $\mathrm{O}_{2}, \mathrm{CO}$ and $\mathrm{CO}_{2}$; a correction is made for ambient humidity as an estimate of the water concentration in the incoming air. The heat release rate is not corrected for the soot yield ${ }^{2}$. Details concerning the input measurement quantities for Eq. (12) are discussed in later sections.

\footnotetext{
${ }^{2}$ A first order thermodynamic analysis indicates that for highly sooting toluene flames the effect on the heat of combustion is less than the uncertainty in the heat of combustion per $\mathrm{kg} \mathrm{O}_{2}$ for an unknown fuel.
} 
It is important to realize that the oxygen deficit in the duct flow, even in large fires, is typically small. This is a consequence of the need to prevent overheating of the exhaust duct and to allow completion of the combustion reactions before the fire plume enters the duct. Thus the best one can do with regard to capturing the plume is draw it and no other diluting air into the duct inlet at the top of the hood. [19] However, fire plumes are already quite diluted at the flame tips [20] and, as a result, one can expect an oxygen reduction only from $21 \%$ by volume to about $19 \%$. Rarely is it possible to capture the plume in this manner, so additional plume dilution is the norm. An implication of this is that the oxygen meter needs to have high resolution if the inferred heat release rate is to be precise. Hence, the oxygen volume fraction and exhaust duct flow are the two measurements in need of greatest attention.

\subsection{Fuel Consumption Calorimetry}

The heat release measurement for a pure substance with a known constant heat of combustion, $\Delta_{\mathrm{c}} H_{\text {fuel }}$, and known combustion efficiency, $\eta_{\text {fuel }}$, requires only a measurement of the rate of consumption of the substance by the fire, therefore the rate of mass loss, $\dot{m}_{\text {fuel }}$.

$$
\dot{Q}_{\mathrm{FC}}=\dot{m}_{\text {fuel }} \Delta_{\mathrm{c}} H_{\text {fuel }} \eta_{\text {fuel }}
$$

Fuel consumption (FC) for solids or finite amounts of liquids may be determined by continuously monitoring the decrease in mass during the burning period. For a continuous supply of gas or liquid, consumption is determined by monitoring the flow of fuel to the burning process. The supply rate may be on a volume basis, as is the case for ideal gases, and hence the formulation for heat release becomes

$$
\dot{Q}_{\mathrm{FC}}=\dot{V}_{\text {fuel }} \Delta_{\mathrm{c}} H_{\text {fuel }}^{\text {id }} \eta_{\text {fuel }}
$$

Where $\Delta_{\mathrm{c}} H_{\text {fuel }}^{\text {id }}$ is now the volumetric heat of combustion of the ideal gas at specified conditions and $\dot{V}_{\text {fuel }}$ is the volume flow of the gas at the same conditions. This fuel consumption formulation is utilized to measure heat release at NFRL's natural gas burners. Details concerning the fuel consumption calorimetry measurement, Eq. (14), are discussed in later sections. 


\section{Description of Physical Systems}

Several major systems in the NFRL make it possible to measure characterizing details of fires, generate prescribed fires, and safely remove the products of the fire from the facility. These systems, shown in Figure 1, are the oxygen consumption calorimetry, fuel (natural gas) consumption calorimetry, and exhaust and emissions control systems. In addition, there is the large physical space and mechanical systems that make it possible to safely conduct large-scale fire experiments within the facility. The following sections will describe the oxygen consumption and fuel consumption calorimetry systems in greater detail, as these independent yet complementary systems are essential components of NFRL's capability to quantitatively characterize a fire - uncontrolled or prescribed.

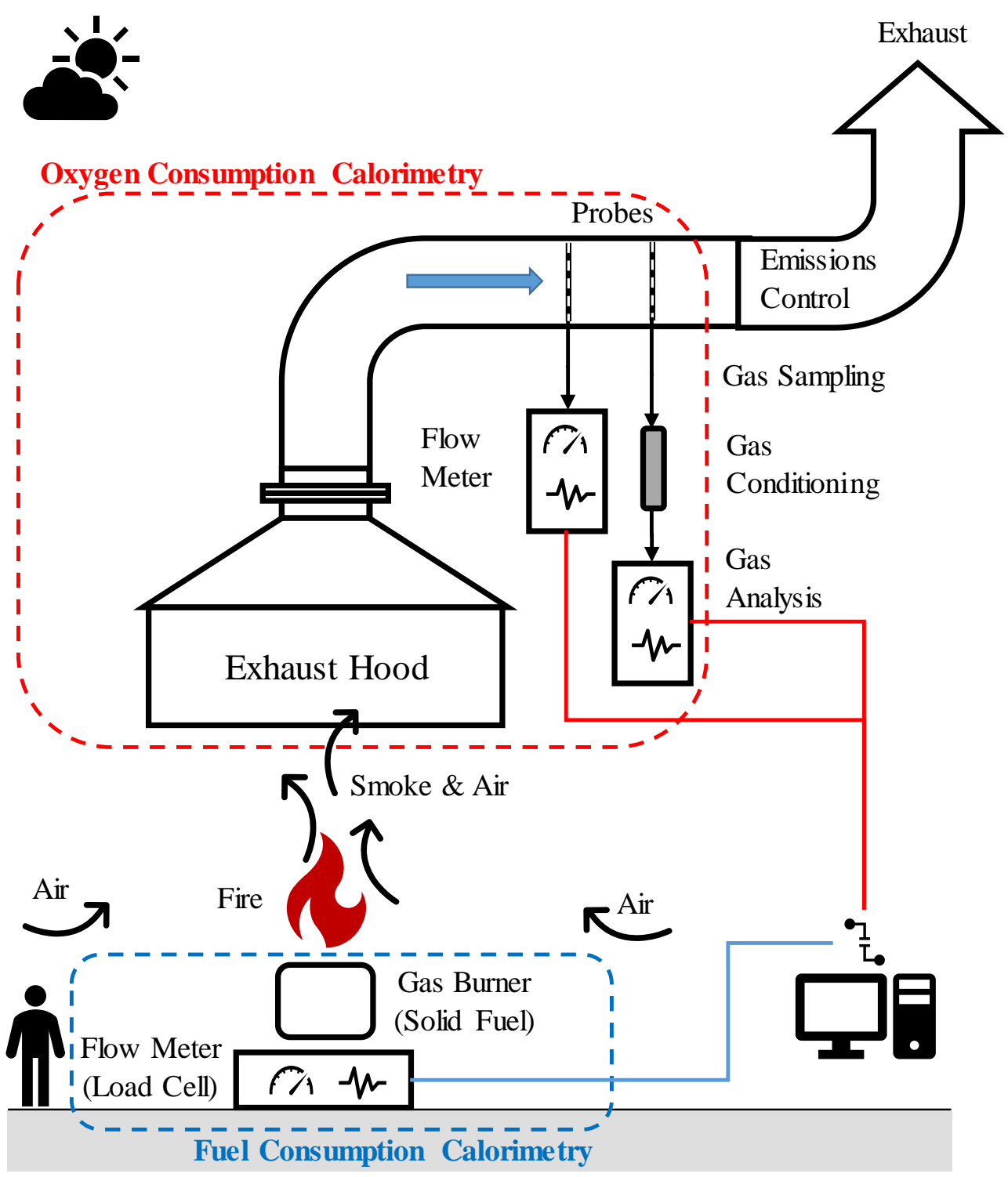

Figure 1 Conceptual schematic of NFRL's oxygen consumption calorimetry and fuel consumption measurement systems. 


\subsection{Oxygen Consumption Calorimetry}

\subsubsection{Exhaust Hoods and Ducts}

The NFRL utilizes large canopy exhaust hoods to capture the fire effluents for quantification of the heat release as a function of time. The insulated steel hoods are suspended above the test floor and serviced by large exhaust ducts that transport the combustion products to an emissions control system (ECS) for conditioning before release into the atmosphere. The facility has 4 canopy hoods, each denoted by its fire capacity: $0.5 \mathrm{MW}, 3 \mathrm{MW}, 10 \mathrm{MW}$, and 20 MW. Each hood is equipped with side skirts to improve smoke capture. The height above the test floor with side skirts (and without side skirts) is listed in Table 2. Retractable side skirts (ZetexPlus Fabric) are installed on the 20 MW hood and can be deployed at variable heights. The side skirts are constructed from a silica-based cloth rated up to $1089 \mathrm{~K}$ (1500 deg F). The 0.5 MW hood is supported by legs resting on the test floor. A plan view of the NFRL lab space is shown in the Figure 2. Three large rollup doors separate the two high bay fire testing areas. The high bay lab containing the $20 \mathrm{MW}$ hood is $1750 \mathrm{~m}^{2}$ in area and $25000 \mathrm{~m}^{3}$ in volume. This space was designed to withstand a continuous $20 \mathrm{MW}$ fire for up to four hours. The high bay space containing the 3 smaller hoods is $700 \mathrm{~m}^{2}$ in area and $6100 \mathrm{~m}^{3}$ in volume. The outline of each of the four calorimetry hoods is shown in red and the fresh air intake vents are outlined in green. These vents supply the make-up air from outside the laboratory needed to operate the hoods at full capacity. There are eight independently controlled intake vents that are used for the $20 \mathrm{MW}$ hood. The top of these vent openings is located $9.26 \mathrm{~m}$ above the floor. There are five independent vents used to supply fresh air for the $0.5 \mathrm{MW}, 3 \mathrm{MW}$, and $10 \mathrm{MW}$ hoods. The vents can be used to balance and minimize cross air currents in the lab. 


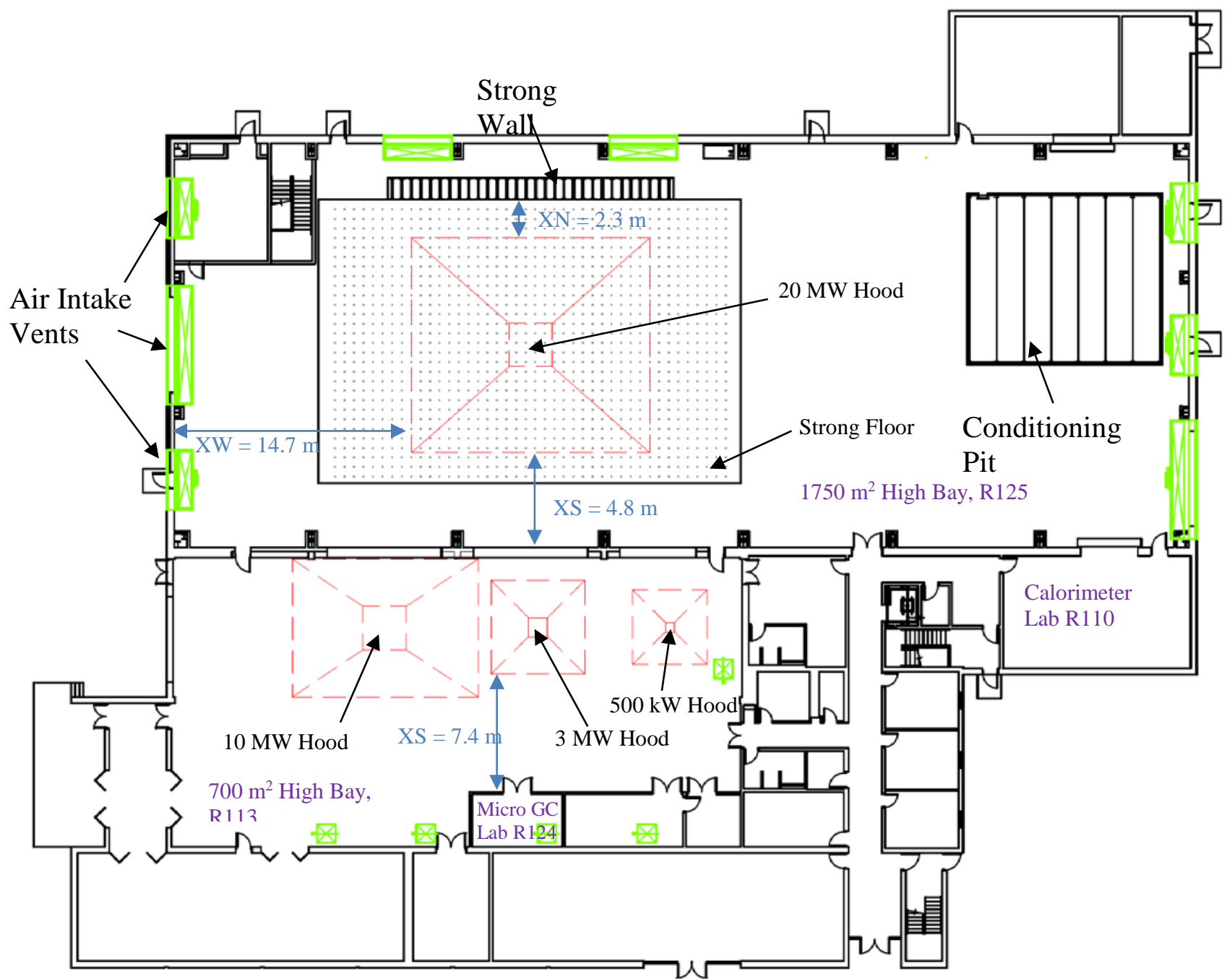

Figure 2 Plan view scale drawing of NFRL. Outlines of calorimetry hoods are shown in red and fresh air intake vents are shown in green.

Table 1 Details of the NFRL exhaust system.

\begin{tabular}{lrrc}
\hline Canopy Hood & $\begin{array}{r}\text { Duct I.D. at } \\
\text { Measurement } \\
\text { Section, } \mathbf{~ m}\end{array}$ & $\begin{array}{r}\text { Flow Capacity, } \\
\mathbf{k g} / \mathbf{s}\left(\mathbf{m}^{3} / \mathbf{m i n}\right)\end{array}$ & $\begin{array}{c}\text { Fire Capacity, } \\
\text { MW }\end{array}$ \\
& 0.483 & $4.1(190)$ & 0.5 \\
\hline $3.1 \times 3.2$ & 1.975 & $27.5(1275)$ & 3.0 \\
$6.1 \times 6.1$ & 1.975 & $54.9(2550)$ & 10 \\
$8.4 \times 12.4$ & 2.424 & $110(5100)$ & 20 \\
$13.8 \times 15.4$ & & & \\
\hline
\end{tabular}


The $3 \mathrm{MW}$ and $10 \mathrm{MW}$ hoods share an exhaust duct with inside diameter (ID) of $1.975 \mathrm{~m}$. The $20 \mathrm{MW}$ hood is serviced by a $2.424 \mathrm{~m}$ ID duct, while a $0.483 \mathrm{~m}$ ID duct (which feeds into the $1.975 \mathrm{~m}$ duct) services the $0.5 \mathrm{MW}$ hood. Both large ducts, $1.975 \mathrm{~m}$ and $2.424 \mathrm{~m}$, run along the roof of the facility and transport the combustion products from the fire to the ECS, Figure 4. The ducts are wrapped with $0.152 \mathrm{~m}$ (6 in) of mineral wool fiber insulation between the roof exit and the ECS. Upstream of the ECS, measurements of gas volume fraction, temperature, and velocity are made at instrumentation stations to determine heat release. The layout of the roof ducts was designed to provide more than 10 diameters of straight run to create a well-developed flow field at the instrument measurement stations.

Flow is pulled through the exhaust system by induced draft fans near the end of the system, therefore the operating pressure in the ducts is slightly below atmospheric. The system has a volume flow capacity of approximately $5100 \mathrm{~m}^{3} / \mathrm{min}$ (at standard conditions) or a mass flow capacity of approximately $110 \mathrm{~kg} / \mathrm{s}$. The exhaust flow capacity at each hood sets the limits on maximum fire capacity for each hood as shown in Table 1. Maximum fire size for the NFRL is $20 \mathrm{MW}$.

Table 2 Calorimeter hood dimensions and reference distances as described by Figure 3.

\begin{tabular}{lrrrr}
\hline Dimension, m & 0.5 MW & 3 MW & 10 MW & 20 MW \\
\hline H1, Skirt Height & 1.802 & 3.056 & 4.931 & 6.435 \\
H2, Hood Height & 2.327 & 4.514 & 6.385 & 12.462 \\
H3, Inlet Height & 4.134 & 5.964 & 8.710 & 15.340 \\
DIN, Inlet Diameter & 0.477 & 1.510 & 1.955 & 2.428 \\
LEW, Length East West & 3.085 & 6.127 & 12.365 & 15.373 \\
LNS, Length North South & 3.244 & 6.145 & 8.422 & 13.834 \\
XN, Distance to North Wall & 5.100 & 2.146 & 1.042 & 2.334 \\
XS, Distance to South Wall & 7.397 & 7.405 & 9.832 & 4.760 \\
XE, Distance to East Wall & 4.515 & 9.909 & 16.246 & 34.004 \\
XW, Distance to West Wall & 28.596 & 20.040 & 7.453 & 14.676 \\
\hline
\end{tabular}



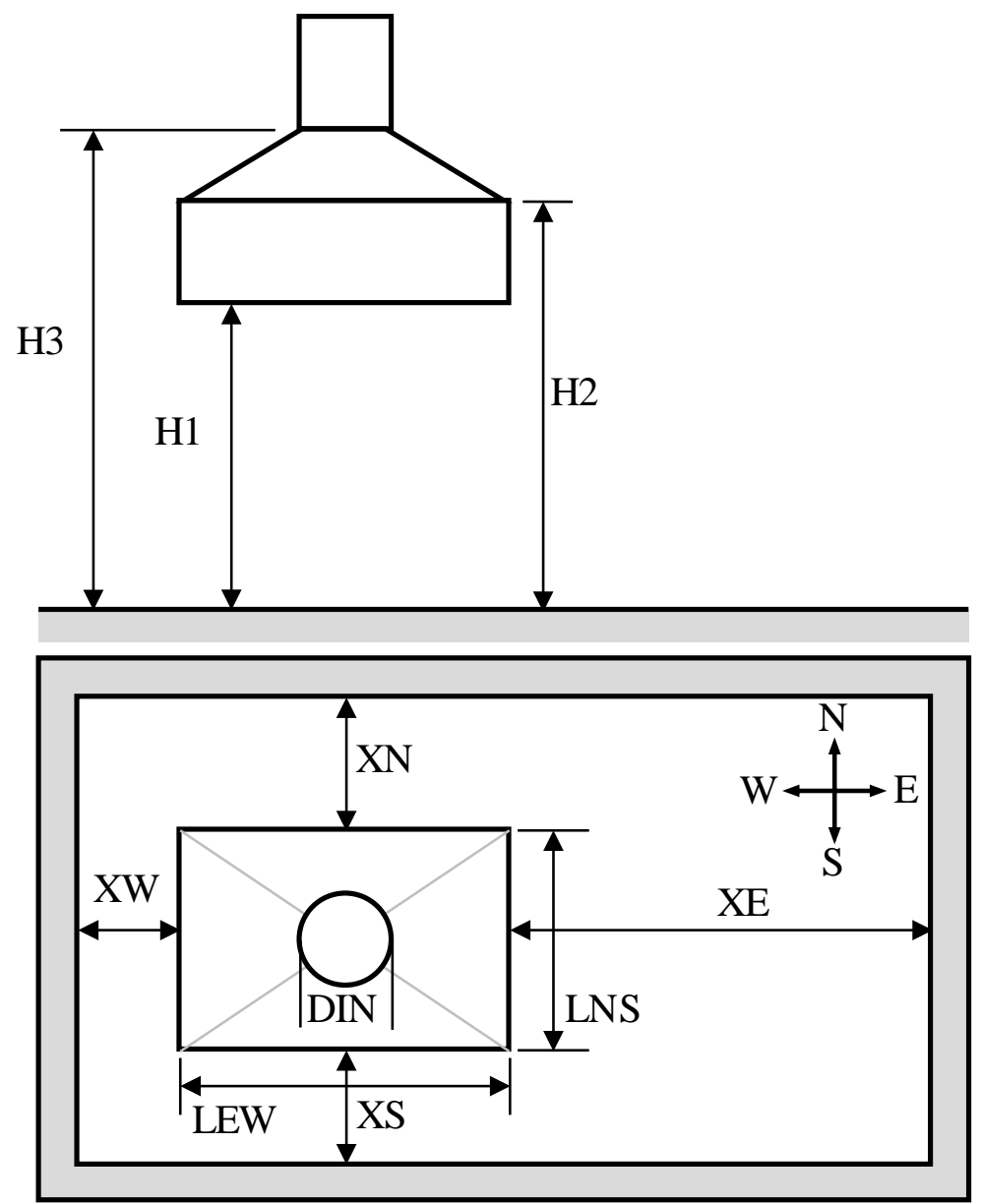

Figure 3 Schematic of hood dimensions as listed in Table 2. 


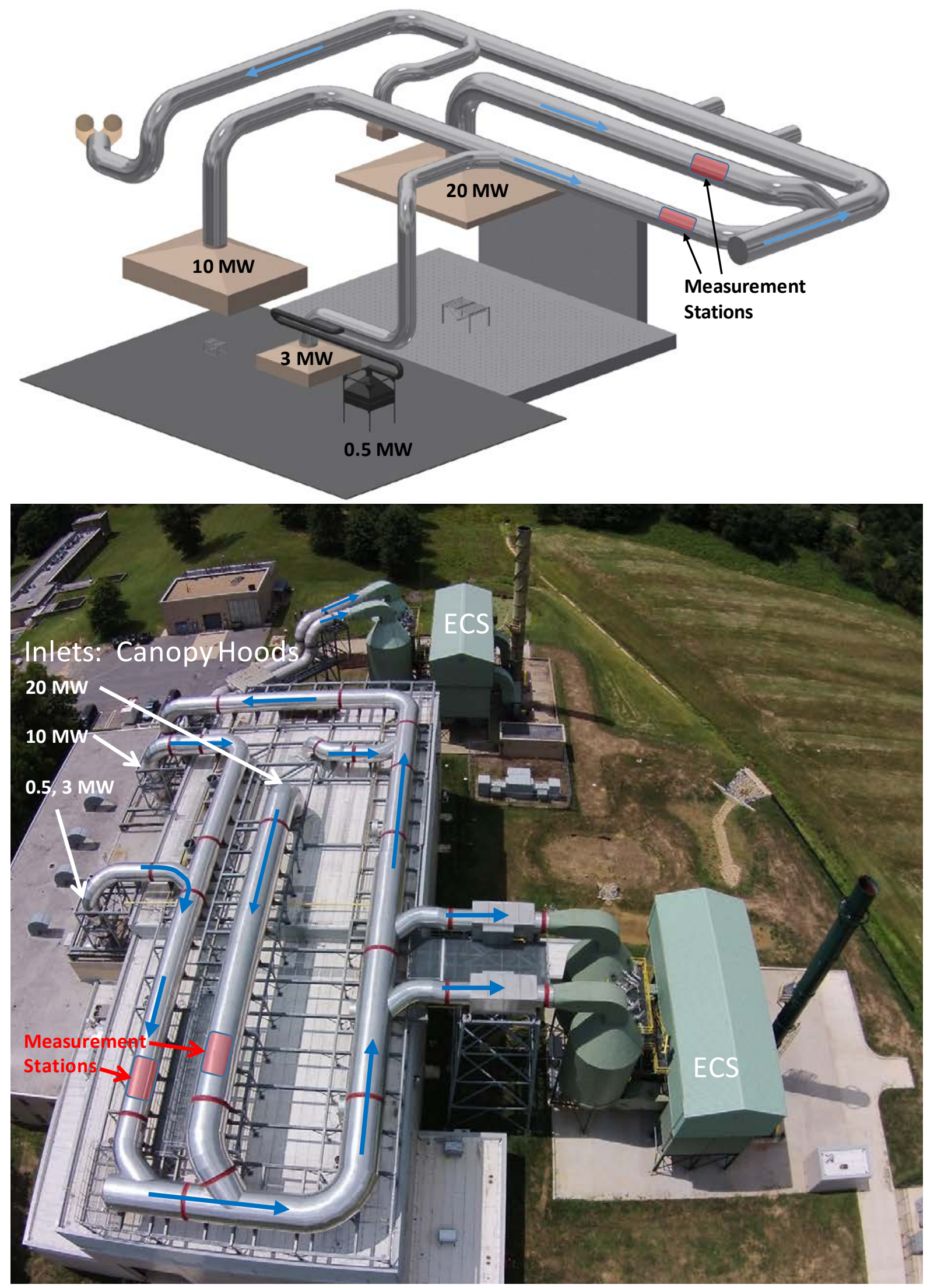

Figure 4 NFRL exhaust ducts and emissions control system (ECS). 


\subsubsection{Exhaust Flow Measurement}

Mass flow through the exhaust ducts is determined using pressure-based flow instrumentation and temperature measurements, and computed as:

$$
\dot{m}_{\mathrm{e}}=\rho_{\mathrm{e}} V_{\mathrm{eff}} \frac{\pi D_{\mathrm{eff}}^{2}}{4}
$$

Where the effective velocity, $V_{\text {eff }}$, of the exhaust flow is determined using an averaging pitot probe equipped with a pair of Type $\mathrm{K}$ thermocouples. Temperature measurements from the thermocouples are used to infer the average density of the exhaust gas, $\rho_{\mathrm{e}}$, assuming an ideal gas. The effective inner diameter of the duct, $D_{\text {eff }}$, is computed from a series of chord measurements made inside each exhaust duct.

\subsubsection{Average Flow Velocity - Averaging Pitot}

The flow sensors used in the exhaust ducts are a tee-shaped averaging pitot style probe (Rosemont 485 Annubar) ${ }^{3}$. The probes are made of 316 stainless steel and have a width of $2.6924 \mathrm{~cm}$. Three probe lengths are used to match the inner diameter of the exhaust ducts, $0.483 \mathrm{~m}, 1.975 \mathrm{~m}$ and $2.424 \mathrm{~m}$. Two averaging pitot probes (A and B) are installed in the $1.975 \mathrm{~m}$ duct and the $2.424 \mathrm{~m}$ duct. The two probes are installed $45^{\circ}$ relative to horizontal and with an orientation off-set of $90^{\circ}$ relative to each probe as shown in Figure 5. The separation distance for the two-probe installation is at least 1 duct diameter. A single averaging pitot probe (A) and thermocouple pair are installed vertically in the $0.483 \mathrm{~m}$ duct.

Flow across the averaging pitot induces a differential pressure, $\Delta P$, integrated along the length of the device; hence the name averaging pitot. This differential pressure is measured with a high-precision capacitance manometer (MKS 220D Baratron) and used to compute the average flow velocity, $V_{\mathrm{e}, i}$, at the device $i(i=\mathrm{A}$ or $\mathrm{B})$.

$$
V_{\mathrm{e}, i}=K_{\mathrm{a}, i} \sqrt{\frac{2 \Delta P_{i}}{\rho_{\mathrm{e}, i}}}
$$

The flow coefficient, $K_{\mathrm{a}}$, for the probe was determined using the following equation from the manufacturer's reference guide. [21]

$$
K_{\mathrm{a}}=\frac{\left(1-C_{2} B\right)}{\sqrt{1-C_{1}\left(1-C_{2} B\right)^{2}}}
$$

The probe blockage factor, $B$, is defined as the ratio of the probe face area to the area of the duct cross section. The constants $C_{1}=-1.4920$ and $C_{2}=1.4179$ are based on the probe width. Blockage factors and the resulting flow coefficients for the 3 probes are listed in Table 3 . The

\footnotetext{
${ }^{3}$ Certain commercial entities, equipment, or materials may be identified in this document in order to describe an experimental procedure or concept adequately. Such identification is not intended to imply recommendation or endorsement by the National Institute of Standards and Technology, nor is it intended to imply that the entities, materials, or equipment are necessarily the best available for the purpose.
} 
manufacturer quotes an expanded uncertainty of $0.75 \%$ for the flow coefficients when the Reynolds number $(R e)$ for the flow over the probe is greater than 12500.

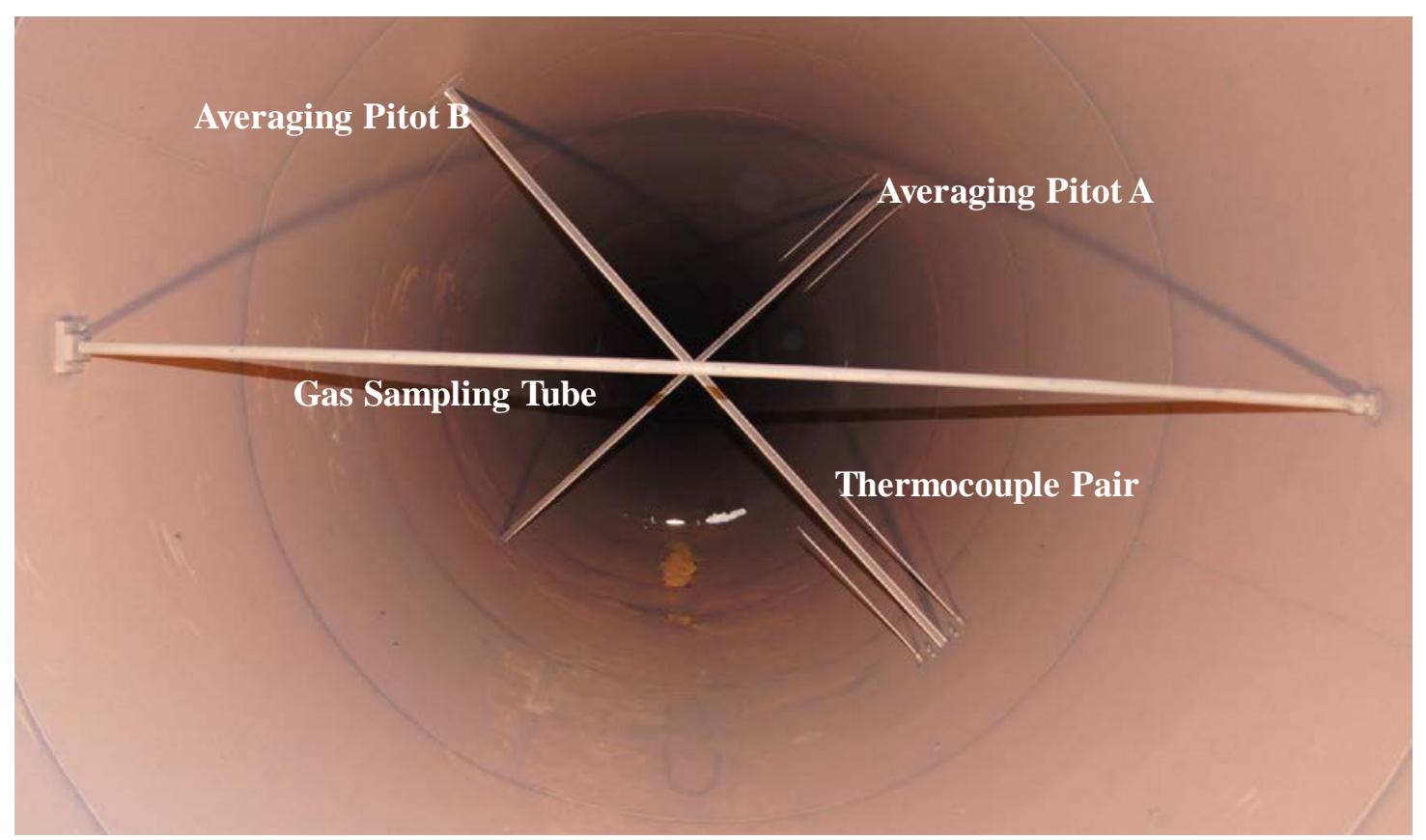

Figure 5 Installation of two averaging pitot probes and the gas sample tube in NFRL's $1.975 \mathrm{~m}$ exhaust duct. Photograph view is looking upstream.

Table 3 Characterizing details for the averaging pitot probes. Expanded uncertainties are reported for a $95 \%$ confidence interval with a coverage factor $\mathrm{k}=2.0$.

\begin{tabular}{lcccc}
\hline Probe Length, $\boldsymbol{m}$ & $\boldsymbol{B}$ & $\boldsymbol{K}_{\mathbf{a}}$ & Minimum Re & Hood \\
\hline 0.48 & 0.0707 & $0.6055 \pm 0.0045$ & 12500 & $0.5 \mathrm{MW}^{*}$ \\
1.97 & 0.0174 & $0.6271 \pm 0.0047$ & 12500 & $3 \mathrm{MW}$ \\
& & & & $10 \mathrm{MW}$ \\
2.42 & 0.0141 & $0.6283 \pm 0.0047$ & 12500 & $20 \mathrm{MW}$ \\
\hline
\end{tabular}

*Averaging pitot A only; all other hoods utilize two averaging pitot probes, A and B.

A gas expansion factor can be used to account for local density changes in the fluid around the probe. A thermal expansion factor can be used to account for the change in cross sectional duct area as the duct material expands with increased temperature. The gas expansion factor was determined to be 0.997 and 0.999 for duct geometry and normal operating flow condition. The thermal expansion factor was estimated to range from 1.000 (cold flow) to 1.005 at $200{ }^{\circ} \mathrm{C}$. 
The manufacturer provided flow coefficient, Eq. (17), is for a fully-developed turbulent pipe flow, therefore a flow that is symmetrical in all directions across the pipe. Any asymmetry in the flow due to upstream disturbances will introduce error in the flow measurement. If asymmetry exists, an in-line calibration of the probe is recommended to correct the flow measurement. More than 10 diameters of straight run exist upstream of each flow measurement location to allow for well-developed flow at the measurement station. Flow conditioning, such as screens, straightening tubes, or disturbance plates, has not been implemented. The two averaging pitot probes (A and B), installed as shown in Figure 5, did not measure the same gas velocity for some flow cases. Whenever the ratio of the velocity, $V_{\mathrm{e}, \mathrm{A}} / V_{\mathrm{e}, \mathrm{B}}$, deviates from unity, asymmetric flow is suspected. Therefore in-line calibrations of the probes were conducted. The correction factor, $C_{\mathrm{f}}$, for the flow velocity was determined from the in-line calibration and applied to compute the effective velocity for the measurement station.

$$
V_{\mathrm{eff}}=C_{\mathrm{f}}\left(V_{\mathrm{e}, \mathrm{A}}+V_{\mathrm{e}, \mathrm{B}}\right) / 2
$$

Table 4 Flow correction factors for the effective flow measurement by the averaging pitot probes. Expanded uncertainties are reported for a $95 \%$ confidence interval with a coverage factor $\mathrm{k}=2.0$.

\begin{tabular}{ll}
\hline Hood / Path & $\begin{array}{l}\text { Flow Correction } \\
\text { Factor, } \boldsymbol{C}_{\mathbf{f}}\end{array}$ \\
\hline $0.5 \mathrm{MW}^{*}$ & $1.033 \pm 0.029$ \\
$3 \mathrm{MW}$ & $1.028 \pm 0.029$ \\
$10 \mathrm{MW}$ & $1.055 \pm 0.034$ \\
$20 \mathrm{MW}$ & $1.042 \pm 0.032$ \\
\hline
\end{tabular}

*Averaging pitot A only; all other hoods/paths utilize two averaging pitot probes, A and B.

Flow correction factors for each exhaust hood (or flow path) are listed in Table 4 along with estimates of expanded uncertainty. ${ }^{4}$ To determine the correction factors, in-line calibrations were performed using the tracer gas dilution method (TGDM), as described by ASTM Standard E20229-99. [22] The tracer gas dilution method is a volumetric, or whole field, method for measuring flow. When compared to the averaging pitot probes, it is a completely independent measurement technique and insensitive to non-ideal flow characteristics such as flow asymmetry. The technique, as applied in the NFRL, and the analysis to estimate the uncertainty of the measurement are described in detail in reference [23].

\footnotetext{
${ }^{4}$ Unless otherwise stated, all uncertainty values are reported as expanded uncertainty, for a 95\% confidence interval with a coverage factor $k=2.0$
} 


\section{Differential Pressure}

High-precision capacitance manometers (MKS 220D Baratron) are used to measure the differential pressure due to flow at each averaging pitot probe. The instruments have a range of $0 \mathrm{~Pa}$ to $1333.2 \mathrm{~Pa}$ ( 0 torr to 10 torr) and the instrument voltage, $V_{\Delta P_{i}}$, is converted to differential pressure using the following relation.

$$
\Delta P_{i}=C_{\Delta P_{i}} 133.32\left(V_{\Delta P_{i}}-V_{\Delta P_{i}}^{\text {zero }}\right)
$$

The nominal scaling factor for the devices is $133.32 \mathrm{~Pa} /$ Volt. However, to improve the accuracy of the measurement, the devices are periodically calibrated, against an in-house working standard for pressure. This calibration correction, $C_{\Delta P, i}$, is applied and the relative expanded uncertainty of the differential pressure measurement is estimated to be 0.006 . Prior to each experiment a hydraulic zero is applied to each transducer. Therefore, the transducers are isolated from any flow or buoyancy-induced pressure differential and a zero-offset voltage, $V_{\Delta P_{i}}^{\text {zero }}$, is determined.

\subsubsection{Gas Density}

Gas density at each averaging pitot probe $(i=\mathrm{A}$ or $\mathrm{B})$ is derived as follows:

$$
\rho_{\mathrm{e}, i}=\frac{P_{\mathrm{amb}} M_{\mathrm{e}}}{R T_{\mathrm{e}, i}}
$$

Each probe is equipped with two bare-bead thermocouples, type $\mathrm{K}$, to provide measured estimates of gas temperature in the exhaust duct, $T_{\mathrm{e}, \mathrm{A}}=\left(T_{\mathrm{e}, \mathrm{A} 1}+T_{\mathrm{e}, \mathrm{A} 2}\right) / 2$ and $T_{\mathrm{e}, \mathrm{B}}=\left(T_{\mathrm{e}, \mathrm{B} 1}+T_{\mathrm{e}, \mathrm{B} 2}\right) / 2$. The relative expanded uncertainty for the gas temperature measurement is estimated to be 0.010 . This estimate includes the relative standard uncertainty for the bead temperature as stated by the manufacturer, 0.0038 , and the relative standard error from the contribution of radiative heat transfer with the surroundings, 0.0035. The error contribution from radiative heat transfer was estimated as the rectangular distribution of 6 thermocouple measurements at 6 locations in the exhaust duct, and with two different bead sizes. Both were combined in quadrature.

The ambient pressure, $P_{\mathrm{amb}}$, inside the facility is measured with a digital barometer (Vaisala PTB220) with an expanded uncertainty of $103 \mathrm{~Pa}$. The molecular weight, $M_{\mathrm{e}}$, of the exhaust gas is assumed to be equal to that of the dry ambient air, $28.97 \pm 0.10 \mathrm{~kg} / \mathrm{kmole}$. The exhaust ducts are designed to pull a large amount of air, significantly more air than required for complete combustion. Therefore, this assumption is applied, since the combustion products of the fire are only a small contribution to the total mass of the exhaust gases.

\subsubsection{Effective Duct Diameter}

Accurate determination of the diameter of each exhaust duct is required for exhaust mass flow measurements and ultimately calorimetry. Measurements of chord length were conducted at the locations of the averaging pitot probes and at various inclinations to generate an accurate profile of the duct geometry. Using a laser distance meter (Leica DISTO D8) and a digital 
inclinometer, radial points were projected and marked on the inside surface of the exhaust ducts at increments of $22.5^{\circ}$, Figure 6.

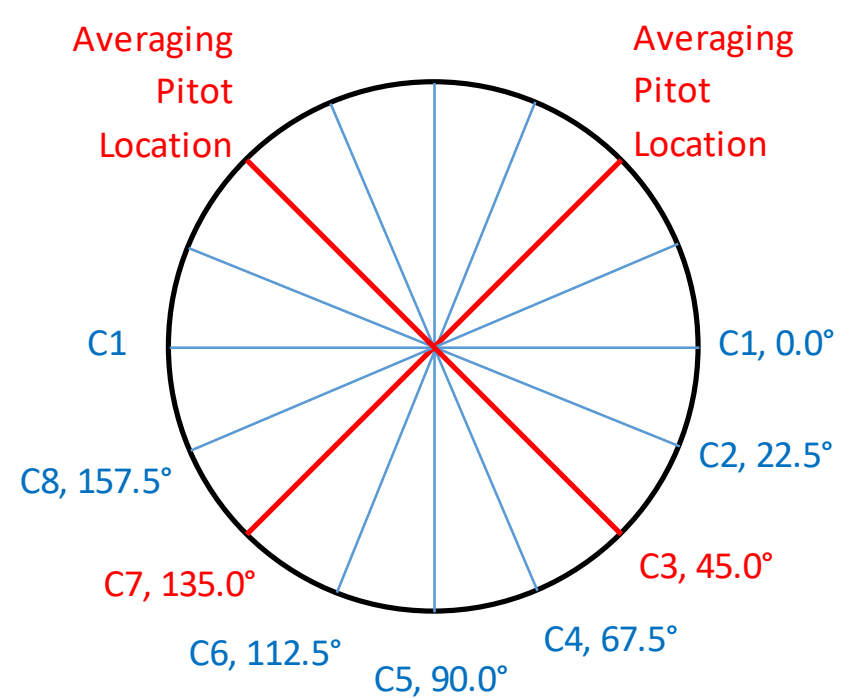

Figure 6 Locations of chord measurements inside the exhaust ducts as seen looking upstream and into the flow.

The cross-sectional area of the duct is determined based on its effective diameter, $D_{\text {eff, for flow }}$ analysis (hydraulic diameter). It is defined as the diameter of a circle with the same crosssectional area as the nearly circular duct. The effective diameter is determined as the average length of the measured chords at the two planes containing the averaging pitot probes. Effective duct diameters along with their expanded uncertainty estimates are listed in Table 5. The uncertainty estimates account for the standard error of the mean and the most conservative of instrument accuracy or instrument resolution. The variation of chord lengths about the rotational positions is shown in the Appendix, Figure 29 and Figure 30. The results show that the large ducts are not perfect circles. 
Table 5 Effective diameter of NFRL's exhaust ducts. Expanded uncertainties are reported for a $95 \%$ confidence interval with a coverage factor $\mathrm{k}=2.0$.

\begin{tabular}{lcc}
\hline Hood / Path & $\begin{array}{l}\text { No. Chord } \\
\text { Measurements }\end{array}$ & $\boldsymbol{D}_{\text {eff, }} \mathbf{m}$ \\
\hline $0.5 \mathrm{MW}$ & 4 & $0.483 \pm 0.004$ \\
$3 \mathrm{MW}, 10 \mathrm{MW}$ & 16 & $1.975 \pm 0.005$ \\
$20 \mathrm{MW}$ & 16 & $2.424 \pm 0.009$ \\
\hline
\end{tabular}

\subsubsection{Gas Sampling and Conditioning}

The gas sample conditioning system is shown below, in Figure 7. Each of the exhaust ducts contains a perforated tube to extract a spatially-integrated gas sample for analysis. The sample tube for the two larger ducts consists of a $12.7 \mathrm{~mm}$ (OD) stainless steel tube mounted horizontally across the inside of the duct with $3.2 \mathrm{~mm}$ diameter holes facing downstream of the flow and spaced every $5 \mathrm{~cm}$. The small 0.483 duct used for the $0.5 \mathrm{MW}$ calorimeter contains a single $9.5 \mathrm{~mm}$ (OD) sample tube with $3.2 \mathrm{~mm}$ diameter holes spaced every $2.5 \mathrm{~cm}$. A 9.5 $\mathrm{mm}(\mathrm{OD})$ stainless steel tube is used to transfer approximately $40 \mathrm{~L} / \mathrm{min}$ of exhaust gas from the duct to the gas analyzers located in the instrumentation room. The sample transfer tube lengths for the three different duct sample locations are $34.5 \mathrm{~m}$ for the $0.5 \mathrm{MW}$ calorimeter, $29.5 \mathrm{~m}$ for the $3 \mathrm{MW}$ and $10 \mathrm{MW}$ calorimeter, and $34.0 \mathrm{~m}$ for the $20 \mathrm{MW}$ calorimeter. The heated duct sample pump and metering valve, located in the instrumentation room (R110 in Figure 2), are used to control the sample flow rate. High pressure air (690 kPa) is used to purge the gas sample tubes for 30 seconds each test day. All gas sampling pumps, valves and conditioning equipment are digitally controlled to allow remote computer operation from different locations in the lab.

The dry sample pump is used to draw a $5 \mathrm{~L} / \mathrm{min}$ sample stream from the $40 \mathrm{~L} / \mathrm{min}$ exhaust gas stream. That sample steam is conditioned to remove particles and water before entering the gas analyzers. High efficiency particle filters and multistage dryers, consisting of two Nafion membrane tube dryers (PermaPure MiniGASS MG-1228W and PermaPure PD-200T-72SS) and a small desiccant tube indicator (Drierite 26930), were used to condition the sample to a dryness of less than $100 \mu \mathrm{L} / \mathrm{L}(100 \mathrm{ppmv})$ of water or less than $-45^{\circ} \mathrm{C}$ dew point temperature. This drying system has several advantages over traditional ice traps and desiccant tubes. The membrane style dryers can run continuously with no loss in drying efficiency when there is a continuous supply of dry purge air. The NFRL has an in-house compressor that supplies dry air at $690 \mathrm{kPa}(100 \mathrm{psig})$. The house air uses a refrigerant dryer and oil filter. A regenerative desiccant dryer lowers the purge air dew point to $-73{ }^{\circ} \mathrm{C}$ for use by both membrane tube dryers. The membrane dryers have smaller volume than other water traps and they do not remove other organic gases that may be of interest. The initial cost of these dryers is greater, but the operational and long-term maintenance costs are negligible. Figure 8 provides a photograph of the gas conditioning rack and the gas analysis rack. 
The sample flow rate to the gas analyzers is regulated using a precision electronic mass flow controller. Several balancing valves and rotameters are used to set the flow to each of the three gas analyzers. The analyzers for $\mathrm{CO}_{2}$ and $\mathrm{CO}$ require approximately $1.0 \mathrm{~L} / \mathrm{min}$ of gas flow each and the $\mathrm{O}_{2}$ analyzer requires approximately $0.2 \mathrm{~L} / \mathrm{min}$. The remaining flow is vented to the atmosphere.

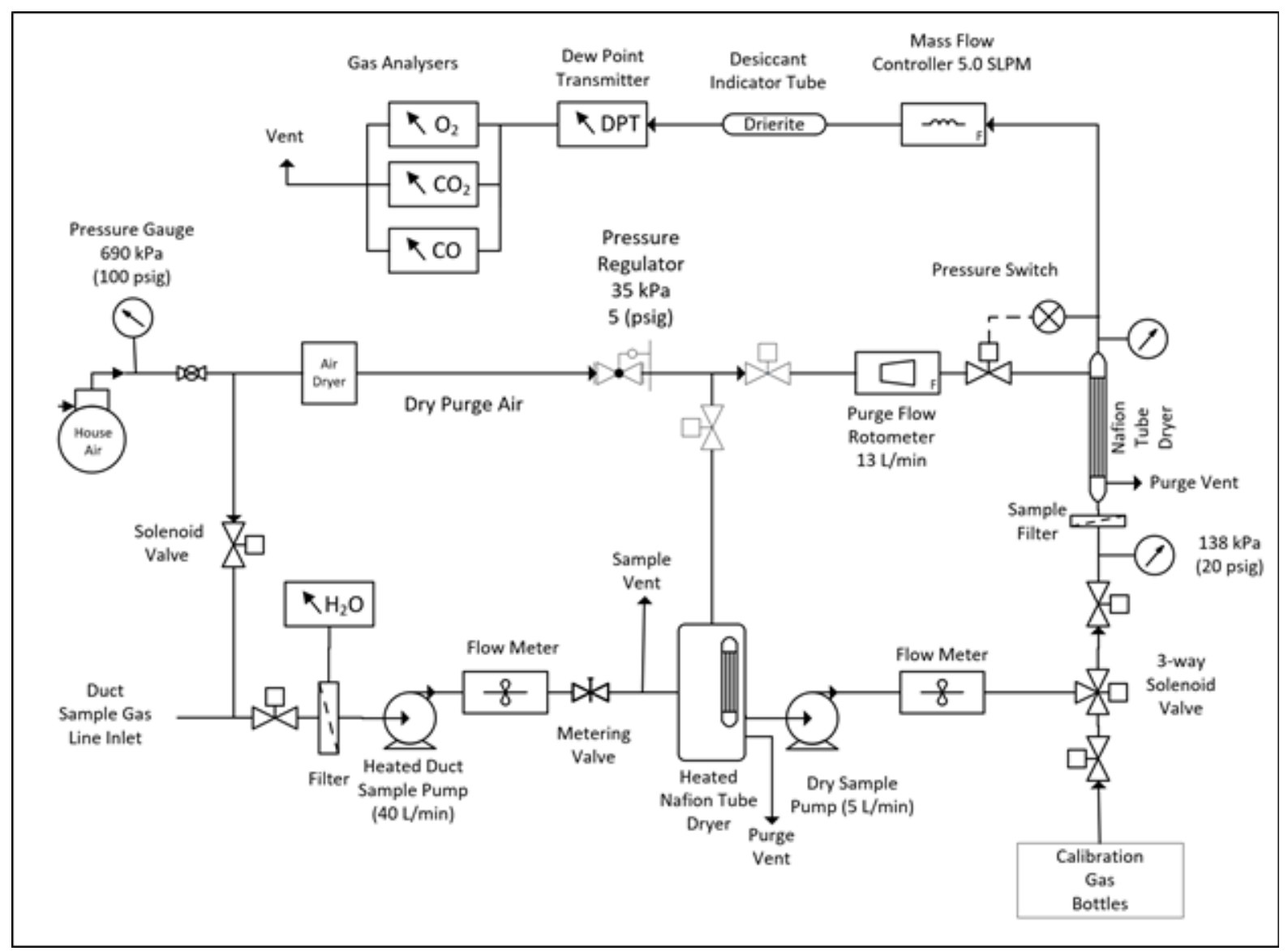

Figure 7 Schematic of exhaust gas sample flow control and conditioning systems. 


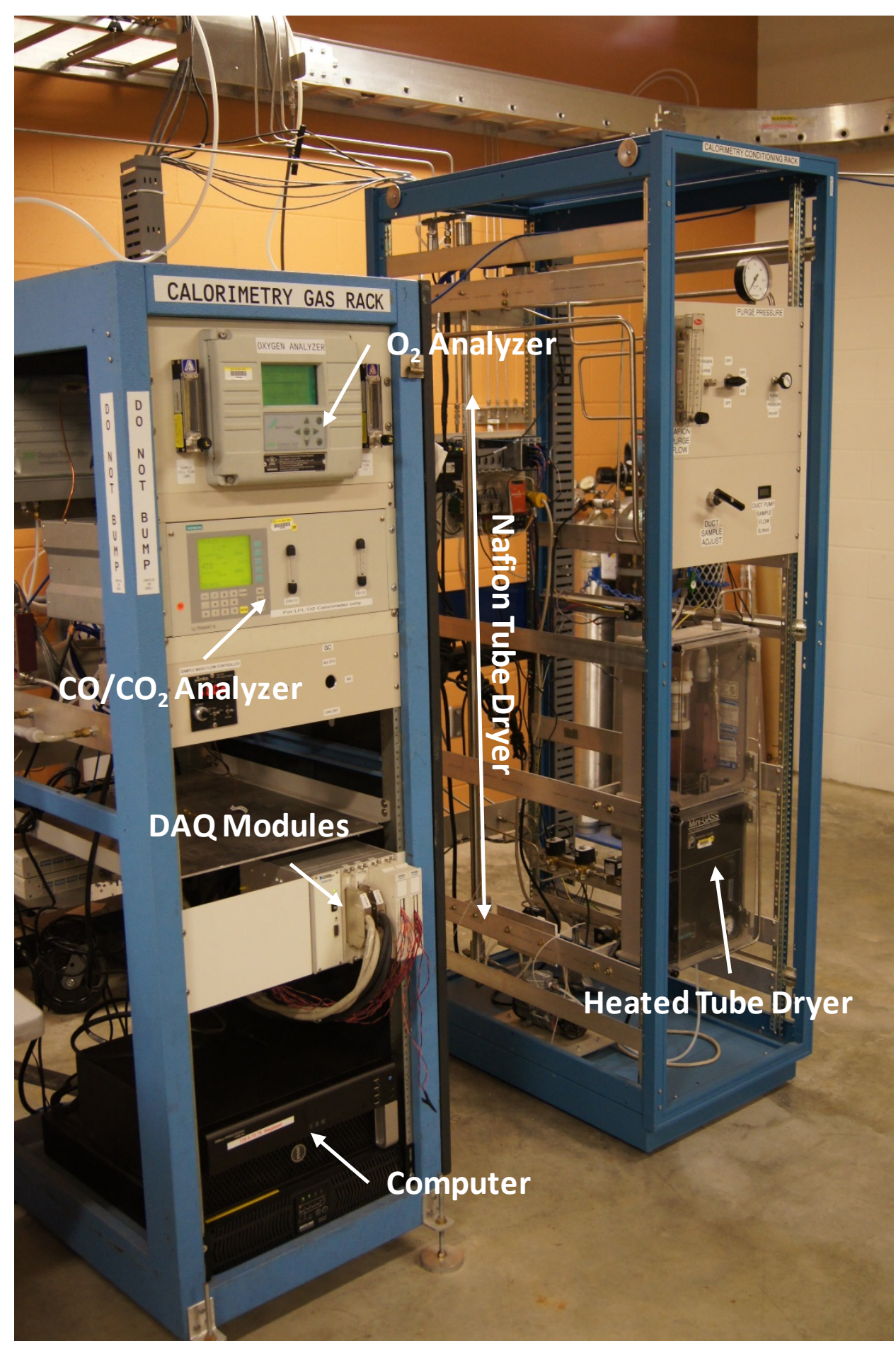

Figure 8 NFRL's gas analysis instrumentation and sample gas conditioning system (right side). 


\subsubsection{Gas Analysis}

\subsubsection{Oxygen Analyzer}

Oxygen volume fraction, $X_{\mathrm{O}_{2}}$, is measured using a paramagnetic oxygen transmitter (Servomex OxyExact 2223) paired with an optional control unit (Servomex 2210), Figure 8. The oxygen transmitter is equipped with internal pressure compensation. The voltage response of the oxygen transmitter, $V_{\mathrm{O}_{2}}$, is converted to oxygen volume fraction using the following equation:

$$
X_{O_{2}}=\frac{X_{\mathrm{O}_{2}}^{\text {span }}}{V_{\mathrm{O}_{2}}^{\text {span }}-V_{\mathrm{O}_{2}}^{\text {zero }}}\left(V_{\mathrm{O}_{2}}-V_{\mathrm{O}_{2}}^{\text {zero }}\right)
$$

The amount of oxygen consumed by the fire or the change of the oxygen volume fraction from ambient, $\Delta X_{\mathrm{O}_{2}}$, is computed as:

$$
\Delta X_{\mathrm{O}_{2}}=\frac{X_{\mathrm{O}_{2}}^{\text {span }}}{V_{\mathrm{O}_{2}}^{\text {span }}-V_{\mathrm{O}_{2}}^{\text {zero }}}\left(V_{\mathrm{O}_{2}}-V_{\mathrm{O}_{2}}^{\mathrm{o}}\right)
$$

where superscripts indicate values when the instrument is measuring the "span" gas, the "zero" gas, or ambient air, "o". Two-point calibrations are performed prior to each test using highaccuracy calibration gases to span and zero the instrument. The span gas has a nominal oxygen volume fraction of $0.21000 \pm 0.00021$ with a balance of nitrogen, while ultra-high-purity nitrogen (0.999 99) is used for the zero gas. Manufacturer specifications for the instrument state that it has a repeatability of \pm 0.00020 over the range of $0 \%$ to $21 \% \mathrm{O}_{2}$. However, for the sampling and data acquisition (DAQ) configuration implemented (See Appendix, Section 7.2 ), a repeatability of \pm 0.000005 was achieved using a stable gas source. The response time of the analyzer is less than $7 \mathrm{~s}$.

\subsubsection{Carbon Dioxide Analyzer}

Carbon dioxide volume fraction, $X_{\mathrm{CO}_{2}}$, is measured using a nondispersive infrared (NDIR) analyzer (Seimens Ultramat 6E), Figure 8. The voltage response of the NDIR analyzer, $V_{\mathrm{CO}_{2}}$, is converted to $\mathrm{CO}_{2}$ volume fraction using the following equation:

$$
X_{\mathrm{CO}_{2}}=\frac{X_{\mathrm{CO}_{2}}^{\text {span }}}{V_{\mathrm{CO}_{2}}^{\text {span }}-V_{\mathrm{CO}_{2}}^{\text {zero }}}\left(V_{\mathrm{CO}_{2}}-V_{\mathrm{CO}_{2}}^{\text {zero }}\right)
$$

The amount of $\mathrm{CO}_{2}$ produced by the fire or the net $\mathrm{CO}_{2}$ volume fraction, $\Delta X_{\mathrm{CO}_{2}}$, is computed as:

$$
\Delta X_{\mathrm{CO}_{2}}=\frac{X_{\mathrm{CO}_{2}}^{\mathrm{span}}}{V_{\mathrm{CO}_{2}}^{\mathrm{span}_{2}}-V_{\mathrm{CO}_{2}}^{\mathrm{zero}}}\left(V_{\mathrm{CO}_{2}}-V_{\mathrm{CO}_{2}}^{\mathrm{o}}\right)
$$

Two-point calibrations are performed prior to each test using high-accuracy calibration gases to span and zero the instrument. The span gas has a nominal $\mathrm{CO}_{2}$ concentration of $0.010000 \pm 0.000025$ and nominal CO concentration of $0.001000 \pm 0.000002$, with a balance of nitrogen. Ultra-high-purity nitrogen $(0.99999)$ is used for the zero gas. 
Manufacturer specifications for the instrument state that it has a repeatability of less than $1.0 \%$ of the selected measurement range. For the sampling and DAQ configuration described in this report, a repeatability of 0.000001 was achieved when using a stable gas source. Response time of the instrument can vary from $0.5 \mathrm{~s}$ to $100 \mathrm{~s}$, depending on the analyzer's electronic time constant and length of the sample cell. For the configuration described here the response time is estimated to be less than $12 \mathrm{~s}$.

\subsubsection{Carbon Monoxide Analyzer}

Carbon monoxide volume fraction, $X_{\mathrm{CO}}$, and carbon dioxide volume fraction are measured simultaneously using the same NDIR analyzer, Figure 8 . The voltage response of the NDIR analyzer, $V_{\mathrm{CO}}$, is converted to $\mathrm{CO}$ volume fraction using the following equation:

$$
X_{\mathrm{CO}}=\frac{X_{\mathrm{CO}}^{\mathrm{span}}}{V_{\mathrm{CO}}^{\mathrm{span}}-V_{\mathrm{CO}}^{\mathrm{zero}}}\left(V_{\mathrm{CO}}-V_{\mathrm{CO}}^{\mathrm{o}}\right)
$$

Two-point calibrations for $\mathrm{CO}$ and $\mathrm{CO}_{2}$ are performed simultaneously using the high-accuracy calibration gases described previously for the $\mathrm{CO}_{2}$ analyzer. Repeatability and response time estimates are also similar.

\subsubsection{Water Analyzers}

The water content in the exhaust gas sample stream is determined at several locations using thin film capacitive detectors. Water in the ambient air is measured at fixed location inside the lab (Vaisala Model HMT 331). The water content in the gas sample line (labeled $\mathrm{H}_{2} \mathrm{O}$ in Figure 7) is measured inside a heated enclosure on the clean side of a particle filter housing and upstream of the main sample pump (Vaisala Model HMT 337). The manufacturer stated accuracy of these two devices is $1 \%$ in the range of $0 \% \mathrm{RH}$ to $90 \% \mathrm{RH}$ and $1.7 \%$ in the range of $90 \% \mathrm{RH}$ to $100 \% \mathrm{RH}$ and the $90 \%$ response time is $20 \mathrm{~s}$. The dry gas sample water content (labeled DPT in Figure 7) is measured after the multi-stage drying process at a location upstream of the gas analyzers (Vaisala Dewpoint Transmitter Model DRYCAP DMT242 ). This thin film polymer sensor measures dew point in the range from $-60{ }^{\circ} \mathrm{C}$ to $60^{\circ} \mathrm{C}$ with an accuracy of $2{ }^{\circ} \mathrm{C}$ and $90 \%$ response time of $10 \mathrm{~s}$.

The water volume fraction in ambient air is used directly in the heat release rate formulation (Eq. (12)). The water measured in the sample line is not directly used to calculate heat release rate but instead used to verify adequate drying efficiency. The observed water removal efficiency of this system is better than $99.5 \%$. For example, if the volume fraction of water in the sample line is $1.5 \%$ then the water concentration at the gas analyzers would be less than $75 \mu \mathrm{L} / \mathrm{L}(75 \mathrm{ppmv})$. The dry gas dew point temperature is continuously monitored, and a warning indication is given if the volume fraction increases above $200 \mu \mathrm{L} / \mathrm{L}$ ( $200 \mathrm{ppmv})$.

\subsection{Fuel Consumption Calorimetry (Natural Gas)}

Natural gas, supplied by the local utility company, is often used in the NFRL as a fuel to simulate real fires. The NFRL has multiple burners that are used to provide prescribed heat output for a fire test or to confirm the accuracy of the oxygen consumption calorimetry system. The heat output of the burners is computed using the following equation: 


$$
\dot{Q}_{\mathrm{FC}}=\frac{\dot{V}_{\mathrm{NG}, \mathrm{bc}} \Delta_{\mathrm{c}} H_{\mathrm{NG}}^{\mathrm{id}} \eta_{\mathrm{NG}}}{Z_{\mathrm{NG}}}
$$

Where $\dot{V}_{\mathrm{NG}, \mathrm{bc}}$ is the volume flow rate of the natural gas computed at the same base conditions (bc) as the ideal net heating value $\Delta_{\mathrm{c}} H_{\mathrm{NG}}^{\mathrm{id}}$, and the compressibility factor, $Z_{\mathrm{NG}}$, and $\eta_{\mathrm{NG}}$ is the combustion efficiency. For the natural gas burners described in the following sections, $\mathrm{CO}$ could not be detected in the exhaust stream, hence complete carbon conversion is assumed. The combustion efficiency is $1.0000 \pm 0.0030$. [24] The uncertainty of this value was estimated using the detection limits of the $\mathrm{CO}$ analyzer.

\subsubsection{Natural Gas Burners}

NFRL has two reference (confirmation) burners that are used to verify the calorimetry measurement. It also has other burners designed to meet specific project needs by generating prescribed fire conditions. These burners are typically sand, gravel, or line and box style burners. The reference burners are tube burners - a $1.5 \mathrm{~m}$ tube burner for fires up to $8 \mathrm{MW}$, shown in Figure 9, and a $2 \mathrm{~m}$ tube burner for fires up to $20 \mathrm{MW}$, shown in Figure 10. Both burners have two pilot tubes controlled by a computer activated relay and electric solenoid valve. The $8 \mathrm{MW}$ burner has 4 main tube banks and the $20 \mathrm{MW}$ burner has 5 main tube banks. The main tube banks are opened and closed using solenoid valves. The burners are equipped with a spark ignition system near each pilot tube, as shown in Figure 11 . An ultraviolet/infrared (UV/IR) flame detector is used to prevent accidental release of flammable gas. If the burner flame is not detected a safety shutoff valve is activated.

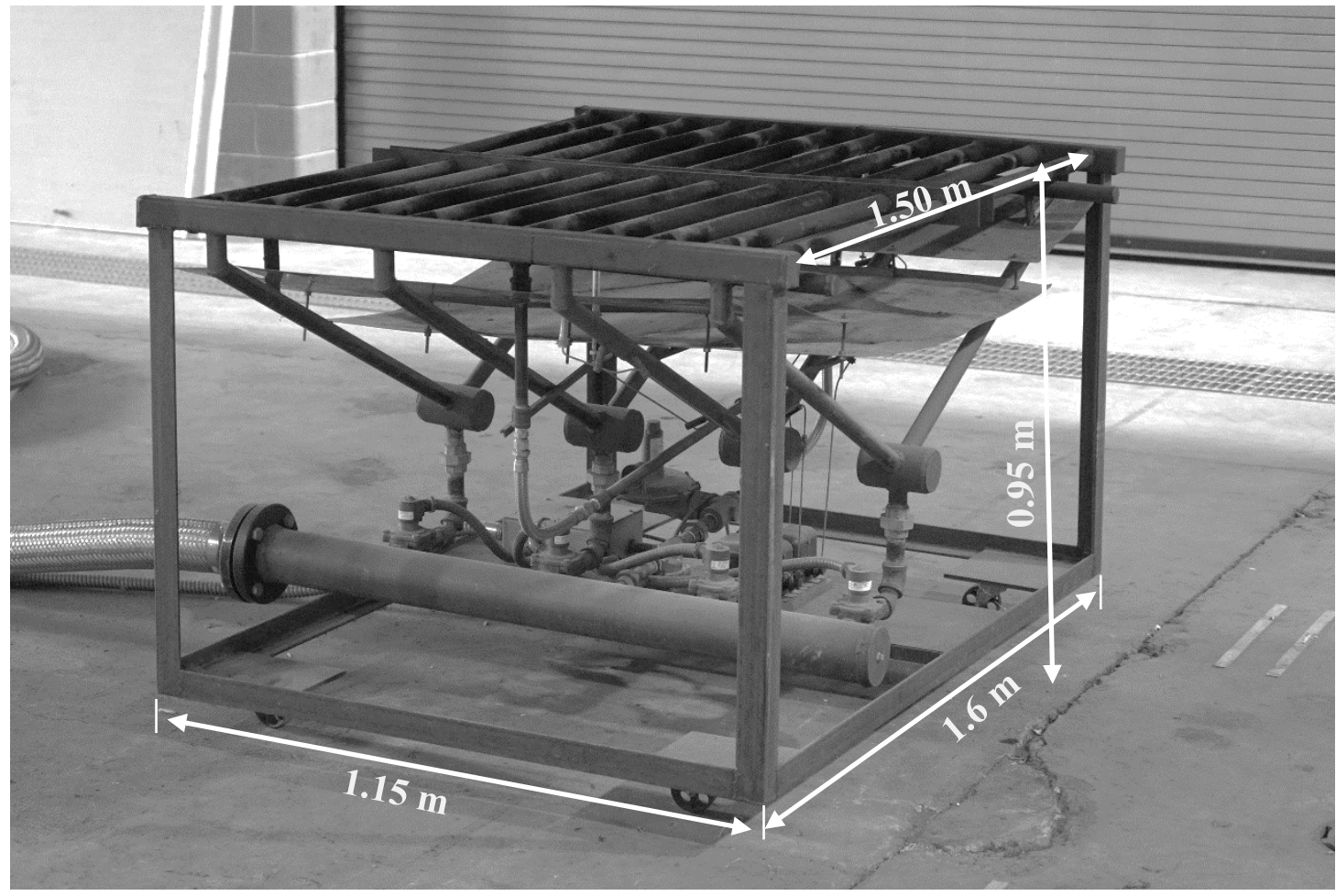

Figure 9 Natural gas tube burner for reference fires up to $8 \mathrm{MW}$. 
The tube burners are designed to provide optimal air entrainment for highly efficient combustion. The main burner tubes for each burner are $33 \mathrm{~mm}$ in diameter and perforated with $3 \mathrm{~mm}$ diameter holes facing upward and spaced every $25 \mathrm{~mm}$. The $8 \mathrm{MW}$ burner has 11 main $1.5 \mathrm{~m}$ long tubes spaced at $11 \mathrm{~cm}$ and the tube bed is $95 \mathrm{~cm}$ above the lab floor. The outer frame of the $8 \mathrm{MW}$ burner is $1.15 \mathrm{~m}$ by $1.6 \mathrm{~m}$. The $20 \mathrm{MW}$ burner has 20 main $2 \mathrm{~m}$ long tubes spaced at $11.5 \mathrm{~cm}$ and the tube bed is $1.25 \mathrm{~m}$ above the lab floor. The outer frame of the $20 \mathrm{MW}$ burner is $2.5 \mathrm{~m}$ by $2.2 \mathrm{~m}$. Operation, control, and monitoring of the burners are executed from NFRL's DAQ and Control system.

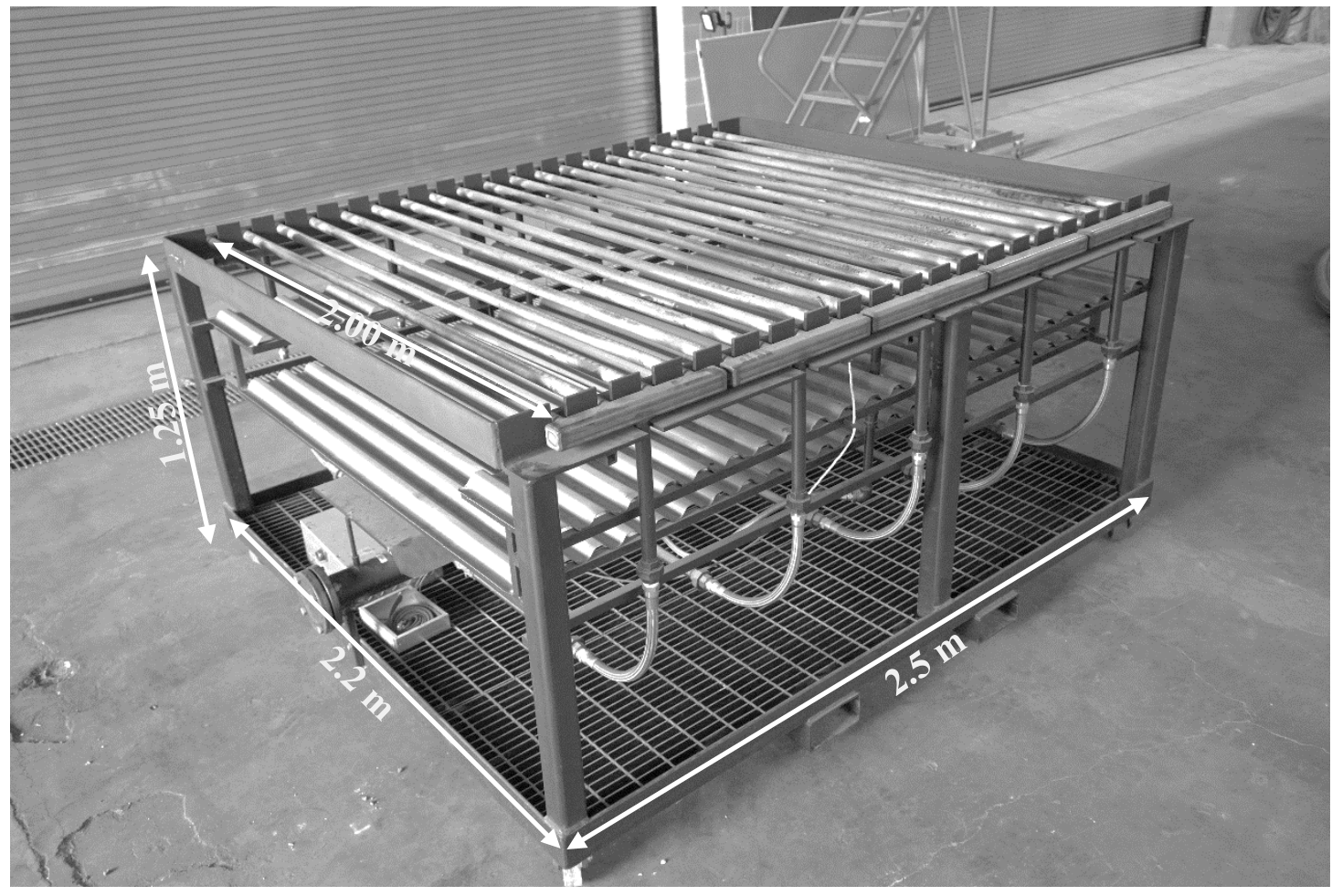

Figure 10 Natural gas tube burner for reference fires up to $20 \mathrm{MW}$. 


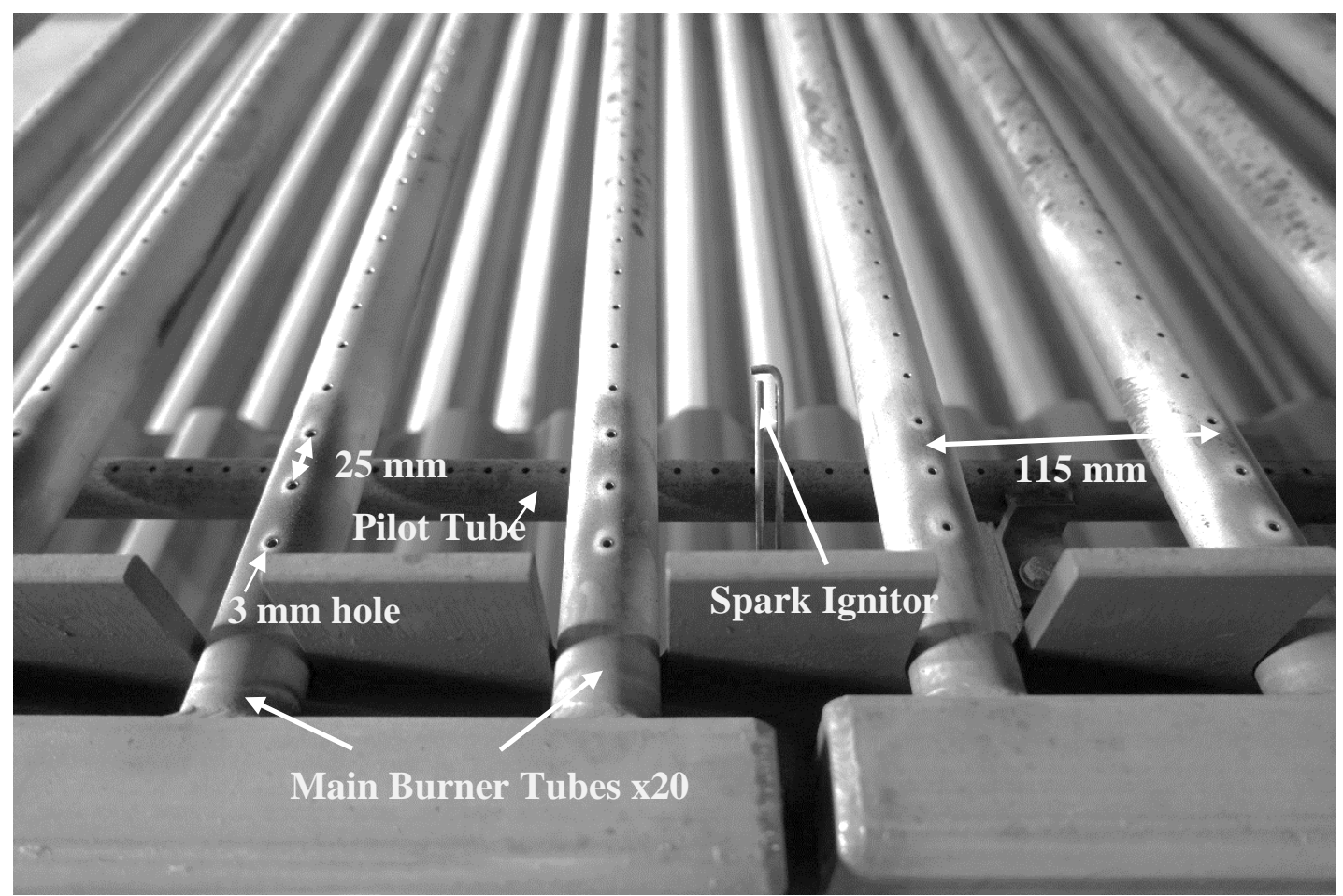

Figure 11 Close view of burner tubes and spark ignitor.

\subsubsection{Natural Gas Flow Measurement and Flow Control}

A high-precision gas control and measurement system is used to supply the natural gas burners. The fuel delivery system was designed to provide fuel gas flow for fires ranging from $50 \mathrm{~kW}$ up to $20 \mathrm{MW}$. A schematic of the fuel delivery system is shown in Figure 12. The main gas line to the building is sized to provide a flow of natural gas capable of generating a sustained $20 \mathrm{MW}$ fire while also supplying the 4 duct burners (pre-heaters) used by the emission control system. As the natural gas supply enters the building, it is regulated from $345 \mathrm{kPa}$ (50 psig) above atmospheric pressure down to $138 \mathrm{kPa}$ (20 psig) above atmospheric pressure. The regulator is designed with a safety shutoff that activates with a sudden pressure drop from a large gas leak. Two natural gas flow trains supply the reference burners - a $10.2 \mathrm{~cm}$ (4 in) gas line supplies the $8 \mathrm{MW}$ burner at a pressure of $103 \mathrm{kPa}$ (15 psig) above atmospheric pressure, and a $12.7 \mathrm{~cm}$ (5 in) gas line supplies the $20 \mathrm{MW}$ burner at a pressure of $138 \mathrm{kPa}$ (20 psig) above atmospheric pressure.

Control of the flow of natural gas to each burner is performed using a pneumatic actuated v-notch ball valve for each train (8 MW burner: TrimTeck Optimux OpVEE CL150 2, 20 MW burner: TrimTeck Optimux OpVEE CL150 3). Both control valves have a turndown ratio of 200:1 and a $63 \%$ response time of 1 second. This fast response time is needed to characterize the calorimeter response time and to allow simulation of fast-growing fires. The valve position feedback measurement accuracy is $1 \%$. The setup position repeatability is better than $3 \%$. The valve is positioned using a computer controlled analog output signal from NFRL's DAQ and Control system. Measurement of the volume flow of natural gas is performed by a positive displacement flow meter (8 MW burner: Instromet IRM-A 15M-125, 20 MW burner: ElsterInstromet IRM-3 DUO-38M), equipped with a frequency pulse counter (Pepper \& Fuchs KD2UFC-Ex1.D), two thermistor temperature probes, and two pressure transducers. The 
temperature and pressure probes are located at the inlet and outlet of the gas flow meter to characterize the condition of the gas as it passes through the meter. Volume flow at the gas meter is derived from measurements of pulse frequency, $f_{\mathrm{NG}}$, gas pressure, $P_{\mathrm{NG}}$, and gas temperature, $T_{\mathrm{NG}}$, and adjusted to base conditions using the following equation:

$$
\dot{V}_{\mathrm{NG}, \mathrm{bc}}=\frac{f_{\mathrm{NG}}}{K_{\mathrm{m}}} \frac{P_{\mathrm{NG}}}{P_{\mathrm{NG}, \mathrm{bc}}} \frac{T_{\mathrm{NG}, \mathrm{bc}}}{T_{\mathrm{NG}}}
$$

Where $K_{\mathrm{m}}$ is the calibrated frequency factor for the flow meter. The volume flow measurement has an expanded uncertainty of $0.19 \%$. [25] Figure 13 shows a photograph of the portion of the system that supplies the $20 \mathrm{MW}$ burner.

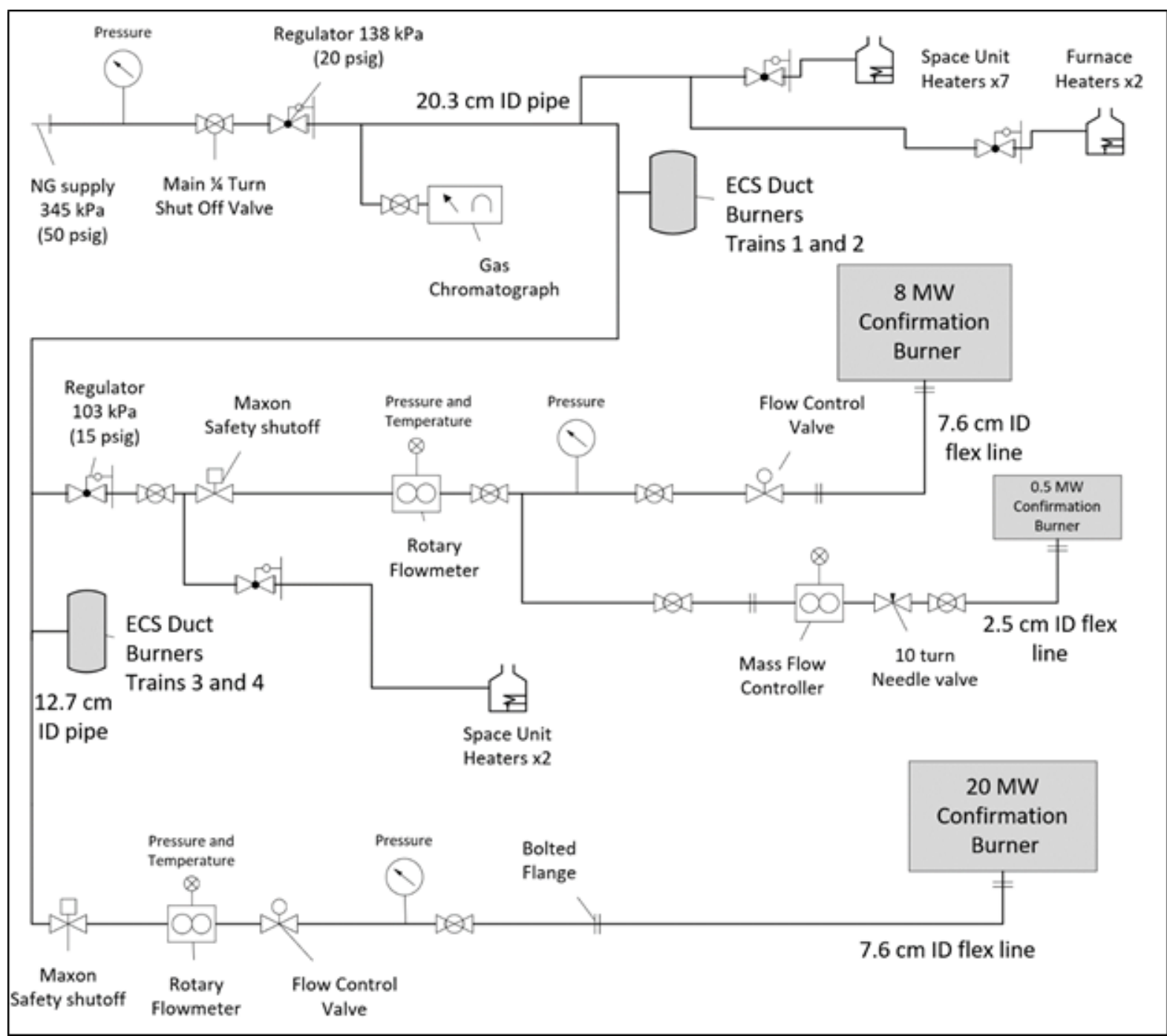

Figure 12 Schematic of NFRL's system for characterizing and controlling the supply of natural gas to the burners. 


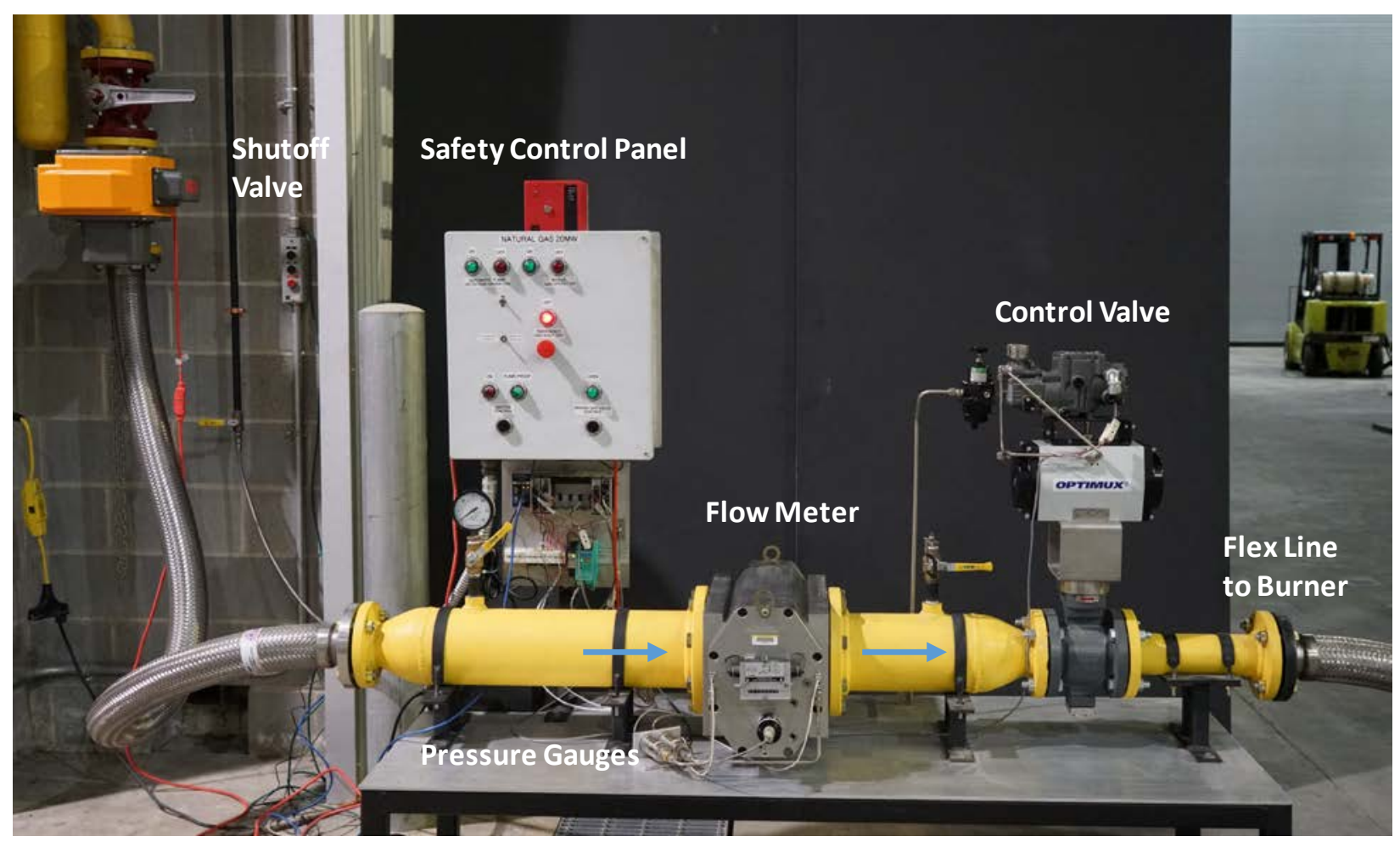

Figure 13 Natural gas delivery for the 20 MW burner.

\subsubsection{Natural Gas Analysis}

Whenever a fire is generated with natural gas as the primary fuel, the composition of the natural gas is determined using on-line chromatography. Natural gas is continuously sampled from the main supply line as it enters the building and sent to a gas chromatograph (INFICON Fusion micro gas chromatograph) for analysis, Figure 14. The gas chromatograph (GC) is equipped with two columns specifically designed for natural gas analysis and a micro Thermal Conductivity Detector ( $\mu$ TCD). It provides gas composition measurements, $X_{i}$, every 5 min, delivering on-line results. Energy content (Ideal Net Heating Value), molecular weight, gas compressibility, and molecular carbon fraction of natural gas are all computed from the composition measurements following the procedures described in GPA 2172 and ASTM D3588 - 98. [26, 27] Computations are for base conditions of $P_{\mathrm{bc}}=101.325 \mathrm{kPa}$ (14.696 psia) and $T_{\mathrm{bc}}=288.7 \mathrm{~K}(60 \mathrm{~F})$ as defined by ASTM D3588 -98. The physical properties of natural gas are taken from GPA 2145-09 for the same base conditions. [28] 


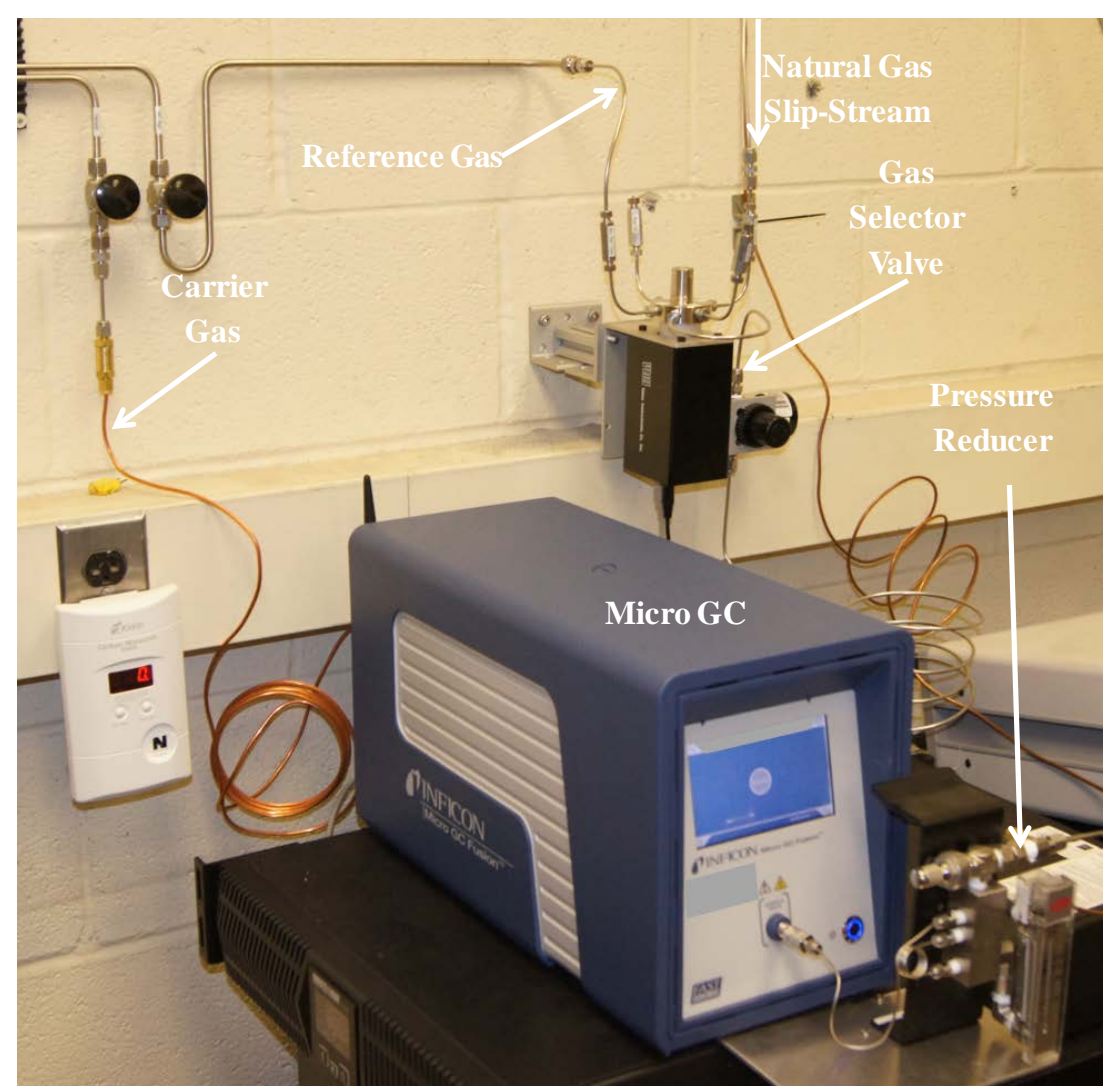

Figure 14 Micro gas chromatograph for on-line analysis of NFRL's natural gas supply.

The ideal net heating value, $\Delta_{\mathrm{c}} H_{\mathrm{NG}}^{\mathrm{id}}$, of the natural gas sample is defined as the summation of the product of the volume fraction, $X_{i}$, and the ideal net heating value of each pure component $i$ in the mixture, $\Delta_{\mathrm{c}} H_{i}^{\mathrm{id}}$.

$$
\Delta_{\mathrm{c}} H_{\mathrm{NG}}^{\mathrm{id}}=\sum_{i=1}^{N} X_{i} \Delta_{\mathrm{c}} H_{i}^{\mathrm{id}}
$$

The net heating value, or lower heating value (LHV), is used when all the water remains in the ideal gas state. This is the assumed case for the high temperature combustion gases in the NFRL exhaust ducts. The ideal gross heating value, or higher heating value (HHV), is used when all the water formed by the reaction condenses to liquid.

Similarly, the molecular weight, $M_{\mathrm{NG}}$, carbon fraction, $X_{\mathrm{C}, \mathrm{NG}}$, and summation factor, $\sqrt{\beta}{ }_{\mathrm{NG}}$, for the natural gas sample are computed using the following equations:

$$
\begin{gathered}
M_{\mathrm{NG}}=\sum_{i=1}^{N} X_{i} M_{i} \\
X_{\mathrm{C}, \mathrm{NG}}=\sum_{i=1}^{N} X_{i} n_{\mathrm{C}, i} \\
\sqrt{\beta}_{\mathrm{NG}}=\sum_{i=1}^{N} X_{i} \sqrt{\beta_{i i}}
\end{gathered}
$$


If complete combustion is assumed, all carbon atoms are converted to carbon dioxide. With this assumption, the carbon fraction can be used to predict how much carbon dioxide is generated by the natural gas fire. The summation factor is used to compute the compressibility factor, $Z$, which subsequently is used to correct gas quantities computed under ideal gas conditions to real gas conditions. The compressibility factor is a complicated function of pressure, temperature and virial coefficients for each pure component in the gas mixture. NIST REFPROP [29] is often used to perform this rigorous computation however ASTM D 3588 provides an approximation which achieves better than $99.96 \%$ agreement with REFPROP and requires less computational effort.

$$
Z_{\mathrm{NG}}(T, P)=1-P\left(\sum_{i=1}^{N} X_{i} \sqrt{\beta_{i i}}\right)^{2}
$$

The summation factor for each component, $\sqrt{\beta_{i i}}$, , is provided in GPA 2145-09. This factor is sensitive to temperature and can be corrected for real temperature conditions.

$$
\begin{gathered}
\sqrt{\beta_{i i}}=\sqrt{\frac{B_{i i}}{R T}} \\
{\sqrt{\beta_{i i}}}_{\text {real }}=\sqrt{\beta_{i i}} \sqrt{\frac{T_{\mathrm{bc}}}{T_{\text {real }}}}
\end{gathered}
$$

Using the corrected summation factor, the compressibility factor at real conditions can be computed.

$$
\begin{aligned}
& Z_{\mathrm{NG}}\left(T_{\text {real }}, P_{\text {real }}\right)=1-P_{\text {real }}\left(\sum_{i=1}^{N} X_{i} \sqrt{\beta_{i i}} \text { real }\right)^{2} \\
& Z_{\mathrm{NG}}\left(T_{\text {real }}, P_{\text {real }}\right)=1-P_{\text {real }} \frac{T_{\mathrm{bc}}}{T_{\text {real }}}\left(\sum_{i=1}^{N} X_{i} \sqrt{\beta_{i i}}\right)_{\mathrm{bc}}^{2}
\end{aligned}
$$


Table 6 Example computation of natural gas properties.

\begin{tabular}{|c|c|c|c|c|c|c|c|c|c|}
\hline Component & $\begin{array}{r}X_{i} \\
\text { Norm }\end{array}$ & $\begin{array}{c}\Delta_{\mathrm{c}} H_{i}^{\mathrm{id}} \\
\mathrm{MJ} / \mathrm{m}^{3}\end{array}$ & $\begin{array}{c}M_{i} \\
\mathrm{~kg} / \mathrm{kmol}\end{array}$ & $n_{\mathrm{C}, i}$ & $\begin{array}{r}\sqrt{\beta_{i i}} \\
1 / \text { psia }\end{array}$ & $\begin{array}{l}X_{i} \Delta_{\mathrm{c}} H_{\mathrm{i}}^{\mathrm{id}} \\
\mathrm{MJ} / \mathrm{m}^{3}\end{array}$ & $\begin{array}{c}X_{i} M_{i} \\
\mathrm{~kg} / \mathrm{kmol}\end{array}$ & $X_{i} n_{\mathrm{C}, i}$ & $\begin{array}{l}X_{i} \sqrt{\beta_{i i}} \\
\text { 1/psia }\end{array}$ \\
\hline Methane & 0.9661 & 33.883 & 16.0425 & 1 & 0.0116 & 32.733 & 15.498 & 0.9661 & 0.0112 \\
\hline Ethane & 0.0278 & 60.311 & 30.069 & 2 & 0.0238 & 1.679 & 0.8369 & 0.05566 & 0.0007 \\
\hline Propane & 0.00147 & 86.251 & 44.096 & 3 & 0.0347 & 0.127 & 0.06473 & 0.00440 & 0.0001 \\
\hline i-Butane & 0.000077 & 111.792 & 58.122 & 4 & 0.0441 & 0.009 & 0.00446 & 0.00031 & 0.0000 \\
\hline n-Butane & 0.000129 & 112.179 & 58.122 & 4 & 0.0470 & 0.014 & 0.00748 & 0.00051 & 0.0000 \\
\hline i-Pentane & 0.0000128 & 137.821 & 72.149 & 5 & 0.0576 & 0.002 & 0.00092 & 0.000063 & 0.0000 \\
\hline n-Pentane & 0.0000041 & 138.003 & 72.149 & 5 & 0.0606 & 0.001 & 0.00029 & 0.000020 & 0.0000 \\
\hline $\begin{array}{l}\text { Hexanes } \\
\left(\mathrm{C}^{+}+\right)\end{array}$ & 0.00072 & 177.055 & 93.189 & 6.7 & 0.0864 & 0.128 & 0.06714 & 0.004827 & 0.0001 \\
\hline Nitrogen & 0.002583 & 0.000 & 28.013 & 0 & 0.0044 & 0.000 & 0.07236 & 0.0 & 0.0000 \\
\hline $\begin{array}{l}\text { Carbon } \\
\text { Dioxide }\end{array}$ & 0.00112 & 0.000 & 44.0010 & 1 & 0.0195 & 0.000 & 0.04920 & 0.001118 & 0.0000 \\
\hline Summation & & & & & & 34.69 & 16.60 & 1.0330 & 0.0121 \\
\hline
\end{tabular}




\section{Performance}

\subsection{Measurement Uncertainty}

Estimates of measurement uncertainty were evaluated using the approximate methods described in the ISO GUM. [30] Measurement processes that were based on input measurements, $x_{i}$, were modeled as an output quantity, y:

$$
y=y\left(x_{1}, x_{2}, x_{3}, \ldots, x_{N}\right)
$$

In the case that all input quantities, $x_{i}$, are uncorrelated, the relative combined standard uncertainty is given by

$$
\frac{u_{\mathrm{c}}(y)}{y}=\sqrt{\sum_{i=1}^{N}\left(s_{i} \frac{u\left(x_{i}\right)}{x_{i}}\right)^{2}}
$$

Where $u\left(x_{i}\right)$ is the standard uncertainty for each input, and $s_{i}$ is the associated dimensionless sensitivity coefficient given by

$$
s_{i}=\frac{\partial y}{\partial x_{i}} \frac{x_{i}}{y}
$$

Equation (38) provides the propagation of uncertainty from each instrument and input parameter into the measurement model, Eq. (37). The results of the uncertainty propagation were also verified using a Monte Carlo Analysis as performed by the NIST Uncertainty Machine (https://uncertainty.nist.gov/). [31]

The uncertainty analysis also included an evaluation of the precision of the integrated system as a whole. This was performed by providing each calorimeter with a steady fire input using the natural gas burners and acquiring enough data to compute statistics of the measured heat release, specifically the standard deviation, $\sigma_{\text {sys }}$, or repeatability of the measurement system. The repeatability of the measurement system was included in the analysis to estimate the combined standard uncertainty. Steady state experiments were conducted over the full range of operating conditions to characterize the system's repeatability.

For this analysis, the relative expanded uncertainty for a single point in time is given as:

$$
\frac{U(y)}{y}=k \frac{u_{\mathrm{c}}(y)}{y}
$$

Where $k=2.0$, is the coverage factor for the $95 \%$ confidence interval.

\subsubsection{Oxygen Consumption Calorimetry}

The measurement uncertainty for NFRL's system of oxygen consumption calorimeters ranges from $4 \%$ to $13 \%$ as shown in Figure 15 . The uncertainty depends on which calorimeter is utilized as well as the fuel source for the fire. Burning a fuel like natural gas will result in lower uncertainty estimates for calorimetry measurements because the constant for heat release per unit mass of oxygen is known with great accuracy for natural gas. Heat release measurements in the larger calorimeters will result in higher uncertainty estimates due to the lower precision for the larger systems. There is enough overlap of the measurement ranges of 
calorimeters to allow some flexibility in choosing a calorimeter for a specific fire study and optimized performance. The previous uncertainty estimate for the $3 \mathrm{MW}$ calorimeter, conducted in 2003, was $11 \%$ for natural gas fires. [32] Current estimates are on the order of $4 \%$; demonstrating better than a factor of 2.5 reduction in measurement uncertainty for the $3 \mathrm{MW}$ calorimeter. These improvements were achieved through more accurate span gas mixtures for the oxygen measurement, better accuracy in the duct diameter measurement, better flow measurement devices, and in-situ calibrations of the flow.

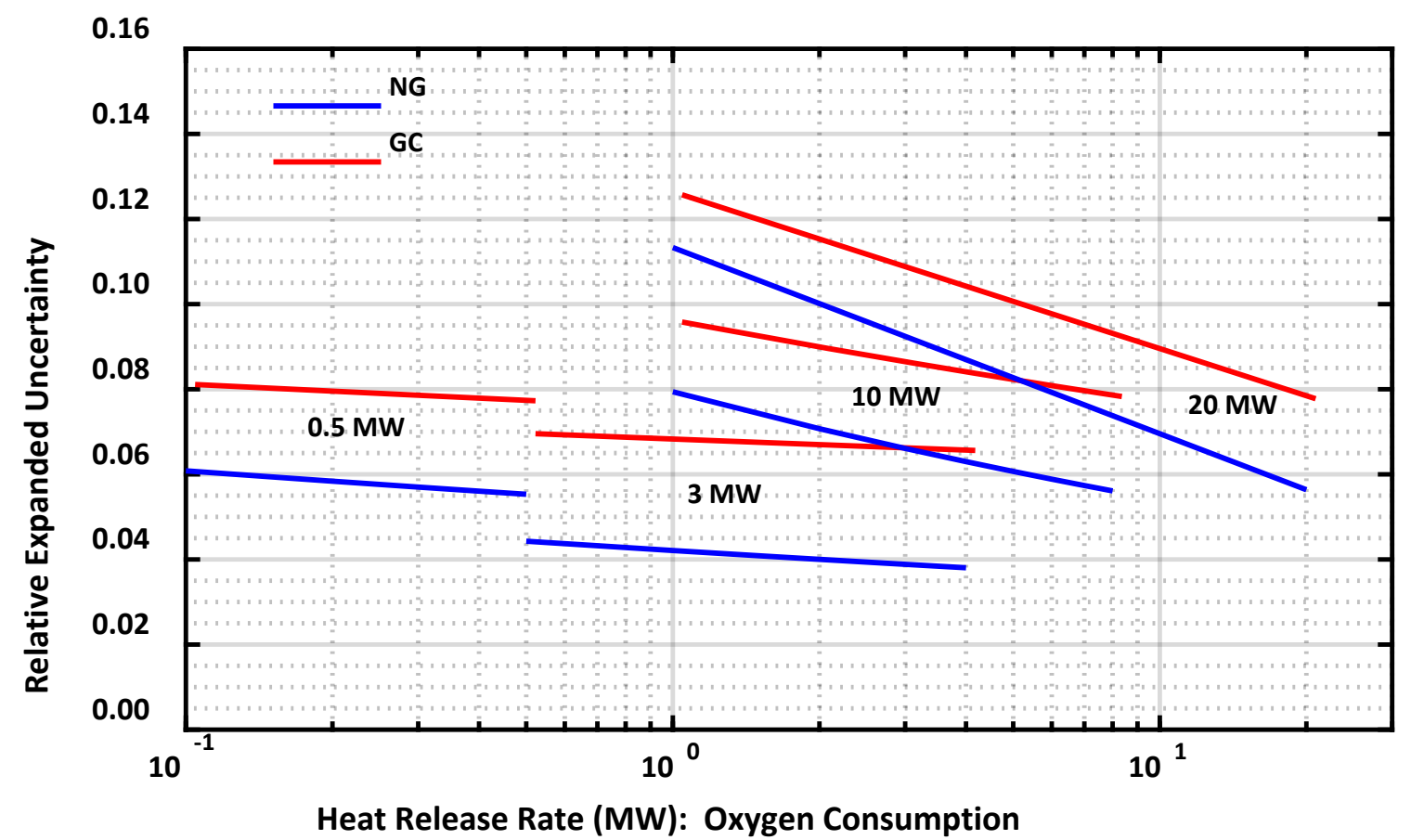

Figure 15 Estimated measurement uncertainty for NFRL's oxygen consumption calorimeters with respect to fuel source: natural gas (NG) or generic combustibles (GC). Expanded uncertainties are reported.

Estimates of measurement uncertainty are almost constant over the operating range of the $0.5 \mathrm{MW}$ and $3 \mathrm{MW}$ calorimeters. However, the $10 \mathrm{MW}$ and $20 \mathrm{MW}$ calorimeters have a greater range of measurement uncertainty. Figure 15 is intended as a resource for users of NFRL's calorimeters to assign uncertainty values to their heat release rate measurements. Table 7 is a summary of the figure, listing average uncertainty and the range of uncertainty for each calorimeter. It is intended as a resource for those users not requiring the detail of Figure 15. 
Table 7 Summary of measurement uncertainty for NFRL's oxygen consumption calorimeters. Expanded uncertainties are reported.

\begin{tabular}{lcc}
\hline & \multicolumn{2}{c}{$\begin{array}{c}\text { Natural Gas Fire } \\
\text { (Generic Combustibles Fire) }\end{array}$} \\
\hline Calorimeter & $\begin{array}{c}\text { Range } \\
\boldsymbol{U} / \dot{\boldsymbol{Q}}_{\text {oc }}\end{array}$ & $\begin{array}{c}\text { Average } \\
\boldsymbol{U} / \dot{\boldsymbol{Q}}_{\text {oc }}\end{array}$ \\
\hline \multirow{2}{*}{$0.5 \mathrm{MW}$} & 0.055 to 0.061 & 0.058 \\
& $(0.077$ to 0.081$)$ & $(0.079)$ \\
$3.0 \mathrm{MW}$ & 0.038 to 0.044 & 0.041 \\
& $(0.066$ to 0.070$)$ & $(0.068)$ \\
$10 \mathrm{MW}$ & 0.056 to 0.079 & 0.068 \\
& $(0.079$ to 0.096$)$ & $(0.087)$ \\
$20 \mathrm{MW}$ & 0.056 to 0.113 & 0.082 \\
& $(0.078$ to 0.126$)$ & $(0.098)$ \\
\hline
\end{tabular}

The uncertainty analysis utilizes the formulation of the oxygen consumption calorimetry measurement, Eq. (12), as the measurement model, $y$. The analysis includes the instrument voltage responses, $V_{\mathrm{i}}$, for some of the component measurements such as gas volume fraction: $X_{\mathrm{O}_{2}}, X_{\mathrm{CO}_{2}}, X_{\mathrm{CO}}$, etc. Since some of these component measurements share a span gas, reducing the equations to voltage responses reduces the correlation introduced through the shared span gas and the possible double counting of uncertainty. [33] An uncertainty budget for a natural gas fire at the $3 \mathrm{MW}$ calorimeter, Table 8, demonstrates the accounting of component uncertainty estimates and their contribution to the combined standard uncertainty. 
Table 8 Uncertainty budget for the measurement of heat release rate by oxygen consumption for a natural gas fire in the $3 \mathrm{MW}$ calorimeter.

\begin{tabular}{|c|c|c|c|c|}
\hline Measurement / Parameter, $x_{i}$ & Value & $u\left(x_{i}\right) / x_{i}$ & $s_{i}$ & $\begin{array}{r}\% \\
\text { Contribution }\end{array}$ \\
\hline$\left(\Delta_{\mathrm{c}} H_{\text {fuel }}\right)_{\mathrm{O}_{2}}(\mathrm{MJ} / \mathrm{kg})$ & 12.540 & 0.0016 & 1.00 & 0.7 \\
\hline$\left(\Delta_{\mathrm{c}} H_{\mathrm{CO}}\right)_{\mathrm{O}_{2}}(\mathrm{MJ} / \mathrm{kg})$ & 17.690 & 0.00057 & -0.00 & 0.0 \\
\hline$\alpha(-)$ & 1.105 & 0.043 & -0.06 & 1.5 \\
\hline$M_{\mathrm{O}_{2}}(\mathrm{~kg} / \mathrm{kmol})$ & 32.000 & 0.000 & 1.00 & 0.0 \\
\hline$M_{\text {air }}(\mathrm{kg} / \mathrm{kmol})$ & 28.970 & 0.00035 & -1.00 & 0.0 \\
\hline$\dot{m}_{\mathrm{e}}(\mathrm{kg} / \mathrm{s})$ & 13.49 & 0.015 & 1.00 & 57.7 \\
\hline$X_{\mathrm{O}_{2}}^{\text {span }}(\mathrm{L} / \mathrm{L})$ & 0.21259 & 0.00052 & 1.25 & 0.1 \\
\hline$V_{\mathrm{O}_{2}}^{\text {span }}$ (volts) & 4.19228 & 0.000024 & -1.25 & 0.0 \\
\hline$V_{\mathrm{O}_{2}}^{\text {zero }}$ (volts) & 0.00886 & 0.014 & 0.00 & 0.0 \\
\hline$V_{\mathrm{O}_{2}}$ (volts) & 3.94290 & 0.000025 & -23.48 & 0.1 \\
\hline$V_{\mathrm{O}_{2}}^{\mathrm{o}}$ (volts) & 4.13007 & 0.000024 & 24.73 & 0.1 \\
\hline$X_{\mathrm{CO}_{2}}^{\text {span }}(\mathrm{L} / \mathrm{L})$ & 0.010223 & 0.0012 & -0.13 & 0.0 \\
\hline$V_{\mathrm{CO}_{2}}^{\mathrm{span}}$ (volts) & 1.70399 & 0.00011 & 0.12 & 0.0 \\
\hline$V_{\mathrm{CO}_{2}}^{\text {zero }}$ (volts) & -0.001835 & -0.051 & 0.00 & 0.0 \\
\hline$V_{\mathrm{CO}_{2}}$ (volts) & 0.95344 & 0.00020 & -0.13 & 0.0 \\
\hline$V_{\mathrm{CO}_{2}}^{\mathrm{o}}$ (volts) & 0.06740 & 0.0028 & 0.01 & 0.0 \\
\hline$X_{\mathrm{CO}}^{\mathrm{span}}(\mathrm{L} / \mathrm{L})$ & 0.0010025 & 0.0010 & 0.00 & 0.0 \\
\hline$V_{\mathrm{CO}}^{\text {span }}$ (volts) & 1.62500 & 0.00031 & 0.00 & 0.0 \\
\hline$V_{\mathrm{CO}}^{\text {zero }}$ (volts) & -0.01307 & -0.031 & 0.00 & 0.0 \\
\hline$V_{\mathrm{CO}}$ (volts) & -0.01260 & -0.040 & 0.00 & 0.0 \\
\hline$X_{\mathrm{H}_{2} \mathrm{O}}^{\mathrm{o}}(\mathrm{L} / \mathrm{L})$ & 0.01844 & 0.010 & -0.02 & 0.0 \\
\hline$\sigma_{\text {sys }}$ & - & 0.012 & 1.00 & 39.8 \\
\hline$\dot{Q}_{\mathrm{OC}}(\mathrm{MW})$ & 1.928 & \multicolumn{3}{|c|}{$\begin{array}{c}\boldsymbol{u}_{\mathrm{c}} / \dot{\boldsymbol{Q}}_{\mathrm{OC}}=\mathbf{0 . 0 1 9 7} \\
\boldsymbol{U} / \dot{\boldsymbol{Q}}_{\mathrm{OC}}=\mathbf{0 . 0 3 9}\end{array}$} \\
\hline
\end{tabular}


In the case of a fire from a well characterized fuel like natural gas, most of the uncertainty in the heat release measurement can be attributed to the repeatability of the system, $\sigma_{\text {sys }}$, and the mass flow measurement of the exhaust gas, $\dot{m}_{\mathrm{e}}$. Figure 16 demonstrates this for the case of natural gas fires measured at the $10 \mathrm{MW}$ calorimeter. For this case, measurement repeatability contributes $52 \%$ to $87 \%$ to the uncertainty, while mass flow contributes $13 \%$ to $45 \%$. Measurement repeatability improves for larger fires and larger exhaust flows, and therefore its contribution to uncertainty decreases for these conditions. The significant contribution from the mass flow measurement confirms the importance of achieving accurate exhaust flow measurements for large-scale calorimetry. For the case of fires generated by generic combustibles such as building components and furniture, the uncertainty of the heat of combustion value, $\left(\Delta_{\mathrm{c}} H_{\mathrm{GC}}\right)_{\mathrm{O}_{2}}$, is much greater and so is its contribution. The parameter becomes significant, contributing $24 \%$ to $53 \%$ to the uncertainty as shown in Figure 17. Measurement repeatability and exhaust mass flow continue to be significant contributors for the case of generic combustibles.

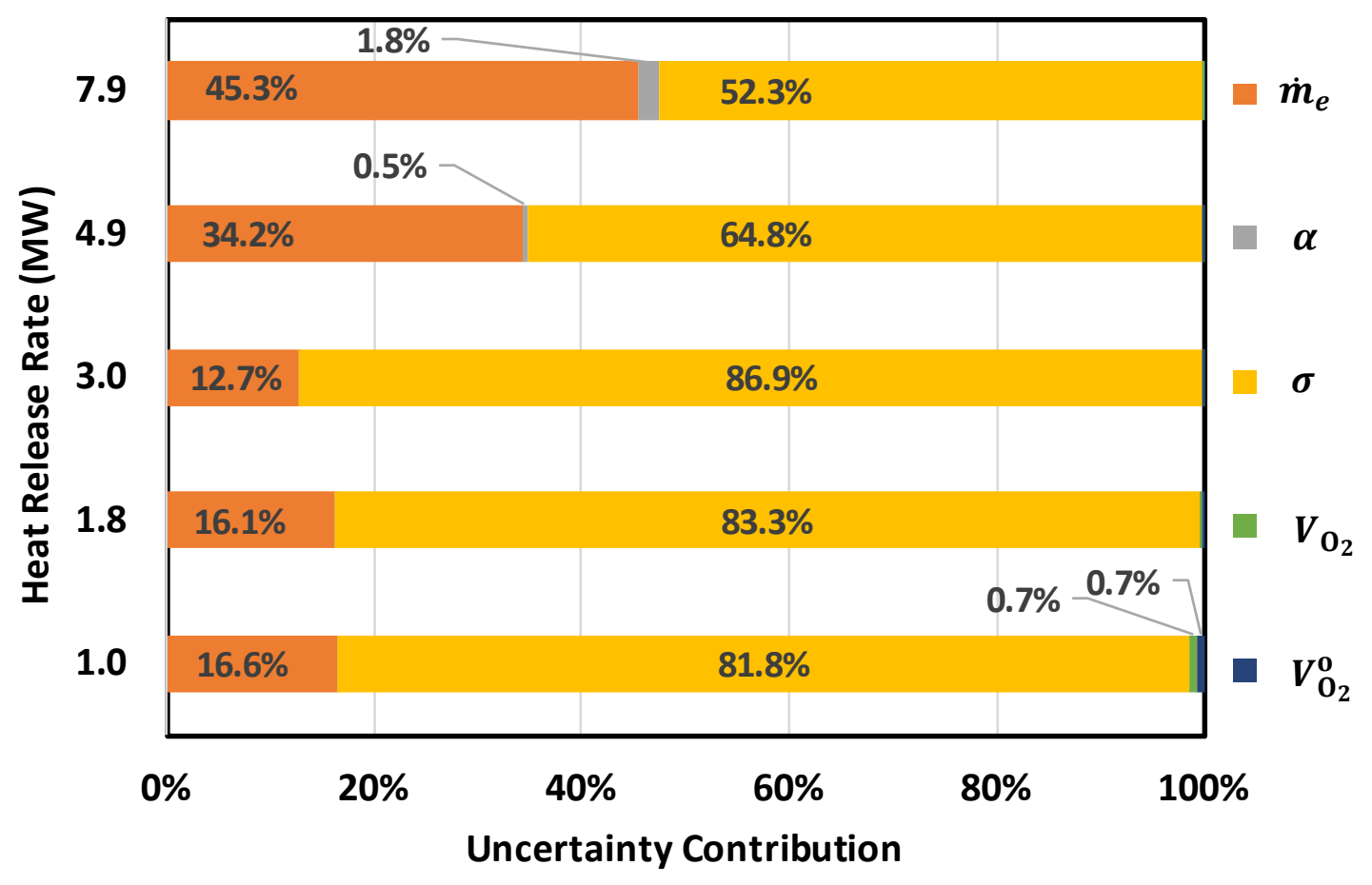

Figure 16 Component measurement uncertainty contribution for the case of a natural gas (NG) fire in the $10 \mathrm{MW}$ calorimeter. Component measurements contributing less than $0.5 \%$ are not shown. 


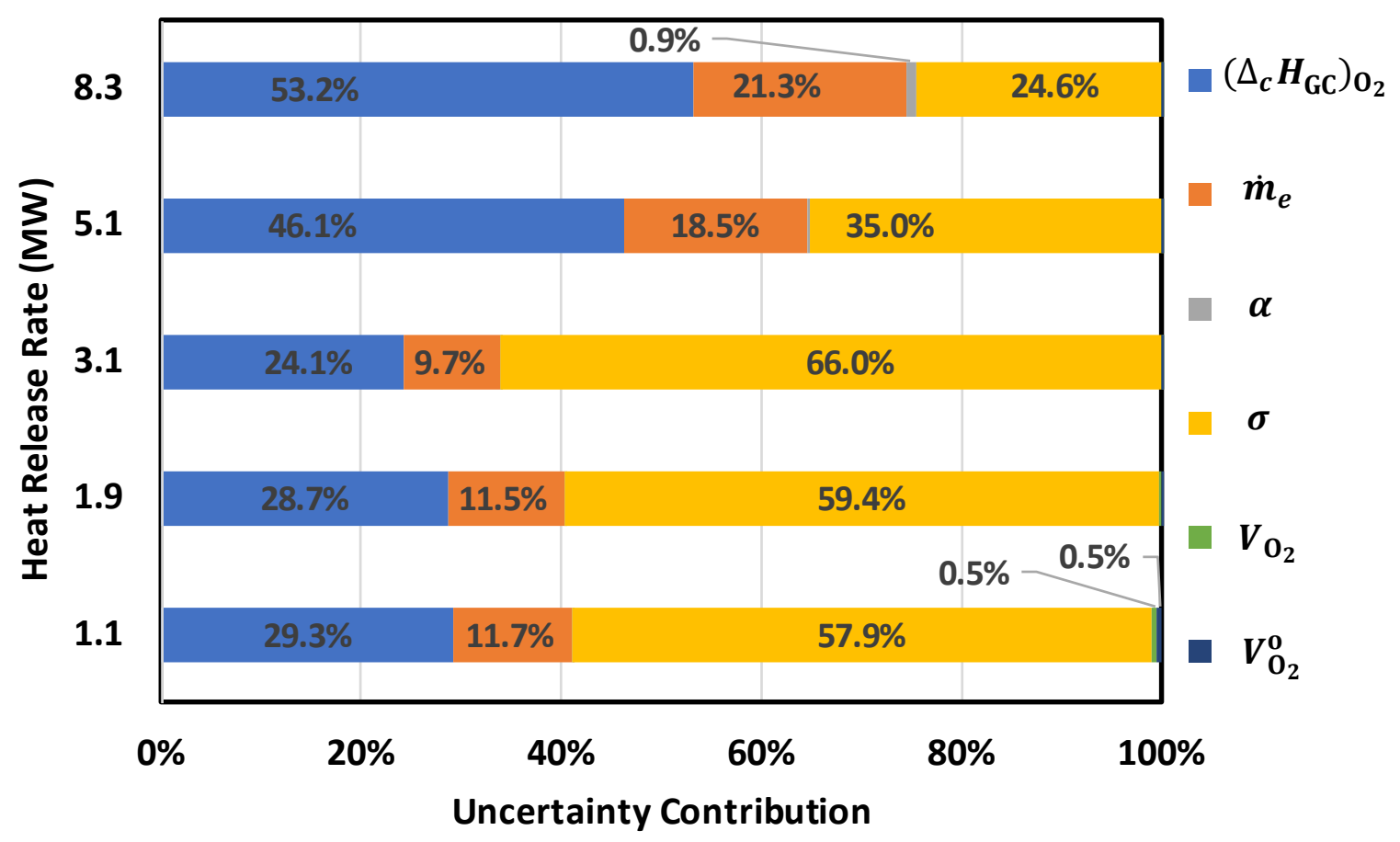

Figure 17 Component measurement uncertainty contribution for the case of a generic combustibles (GC) fire in the $10 \mathrm{MW}$ calorimeter. Component measurements contributing less than $0.5 \%$ are not shown.

The standard deviation of a measurement for a steady input is a measure of the precision of an instrument. The greater the standard deviation the lower the precision or repeatability. Table 9 lists the relative standard deviation for each calorimeter. In general, precision decreases as the size and capacity of the calorimeter increases. However, within the operating range of a specific calorimeter, there is greater precision for larger fires. This is seen in Figure 16 and Figure 17, where there is less contribution from measurement repeatability for the largest fire. It is also apparent in Figure 15 for the $10 \mathrm{MW}$ and $20 \mathrm{MW}$ calorimeters, where the uncertainty decreases as fire size increases.

Table 9 Average estimates of measurement repeatability for NFRL's calorimeters.

\begin{tabular}{lc}
\hline Calorimeter & $\begin{array}{r}\text { Repeatability } \\
\boldsymbol{\sigma}_{\text {sys }} / \dot{\boldsymbol{Q}}_{\text {oc }}\end{array}$ \\
\hline $0.5 \mathrm{MW}$ & 0.024 \\
$3.0 \mathrm{MW}$ & 0.014 \\
$10 \mathrm{MW}$ & 0.029 \\
$20 \mathrm{MW}$ & 0.037 \\
\hline
\end{tabular}


As stated previously, the mass flow measurement of the exhaust gas also contributes significantly to the measurement uncertainty of the heat release rate measurement. Further examination of the uncertainty budget for the measurement of mass flow, Table 10, shows that the flow correction factor, $C_{\mathrm{f}}$, and the effective diameter of the duct, $D_{\mathrm{eff}}$, are significant contributors to its combined uncertainty. Considerable care and attention were devoted to the accurate determination of both parameters.

Table 10 Uncertainty budget for the measurement of exhaust mass flow at the $3 \mathrm{MW}$ Calorimeter.

\begin{tabular}{lrrrr}
\hline $\begin{array}{l}\text { Measurement / Parameter, } \\
\boldsymbol{x}_{\boldsymbol{i}}(\mathbf{U n i t s})\end{array}$ & Value & $\boldsymbol{u}\left(\boldsymbol{x}_{\boldsymbol{i}}\right) / \boldsymbol{x}_{\boldsymbol{i}}$ & $\boldsymbol{s}_{\boldsymbol{i}}$ & $\begin{array}{r}\text { \% } \\
\text { Contribution }\end{array}$ \\
\hline$C_{\mathrm{f}}(-)$ & 1.028 & 0.014 & 1.0 & 88.3 \\
$K_{\mathrm{a}}(-)$ & 0.6271 & 0.0038 & 1.0 & 6.2 \\
$D_{\mathrm{eff}}(\mathrm{m})$ & 1.9753 & 0.0013 & 2.0 & 2.8 \\
$R(\mathrm{~J} / \mathrm{kmol} \mathrm{K})$ & 8314.47 & 0.0000 & -0.5 & 0.0 \\
$M_{\mathrm{air}}(\mathrm{kg} / \mathrm{kmol})$ & 28.97 & 0.0035 & 0.5 & 1.3 \\
$P_{\mathrm{amb}}(\mathrm{Pa})$ & 100762 & 0.00051 & 0.5 & 0.0 \\
$\Delta P_{\mathrm{A}}(\mathrm{Pa})$ & 27.162 & 0.0030 & 0.25 & 0.3 \\
$\Delta P_{\mathrm{B}}(\mathrm{Pa})$ & 25.442 & 0.0030 & 0.25 & 0.2 \\
$T_{\mathrm{e}, \mathrm{A} 1}(\mathrm{~K})$ & 396.8 & 0.0051 & -0.13 & 0.2 \\
$T_{\mathrm{e}, \mathrm{A} 2}(\mathrm{~K})$ & 396.6 & 0.0051 & -0.13 & 0.2 \\
$T_{\mathrm{e}, \mathrm{B} 1}(\mathrm{~K})$ & 395.4 & 0.0051 & -0.12 & 0.2 \\
$T_{\mathrm{e}, \mathrm{B} 2}(\mathrm{~K})$ & 395.3 & 0.0051 & -0.12 & 0.2 \\
\hline$\dot{\boldsymbol{m}}(\mathbf{k g} / \mathbf{s})$ & $\mathbf{1 3 . 4 9}$ & & $\boldsymbol{u}_{\mathbf{c}} / \dot{\boldsymbol{m}}_{\mathrm{e}}=\mathbf{0 . 0 1 5}$ & \\
\hline
\end{tabular}

\subsubsection{Fuel Consumption Calorimetry (Natural Gas)}

The measurement uncertainty for heat release measured at NFRL's system of natural gas burners is presented in Figure 18. For the two large burners, $8 \mathrm{MW}$ and $20 \mathrm{MW}$, the expanded uncertainty estimate is essentially constant at $1.46 \%$. The small box burner, $0.5 \mathrm{MW}$, operates at the low end of the range of the natural gas flow meter and therefore has lower precision. The range of expanded uncertainty for this burner is $1.4 \%$ to $1.8 \%$. There is significant overlap of the operating range of the $8 \mathrm{MW}$ and $20 \mathrm{MW}$ burners. Either burner can be utilized with similar performance. 


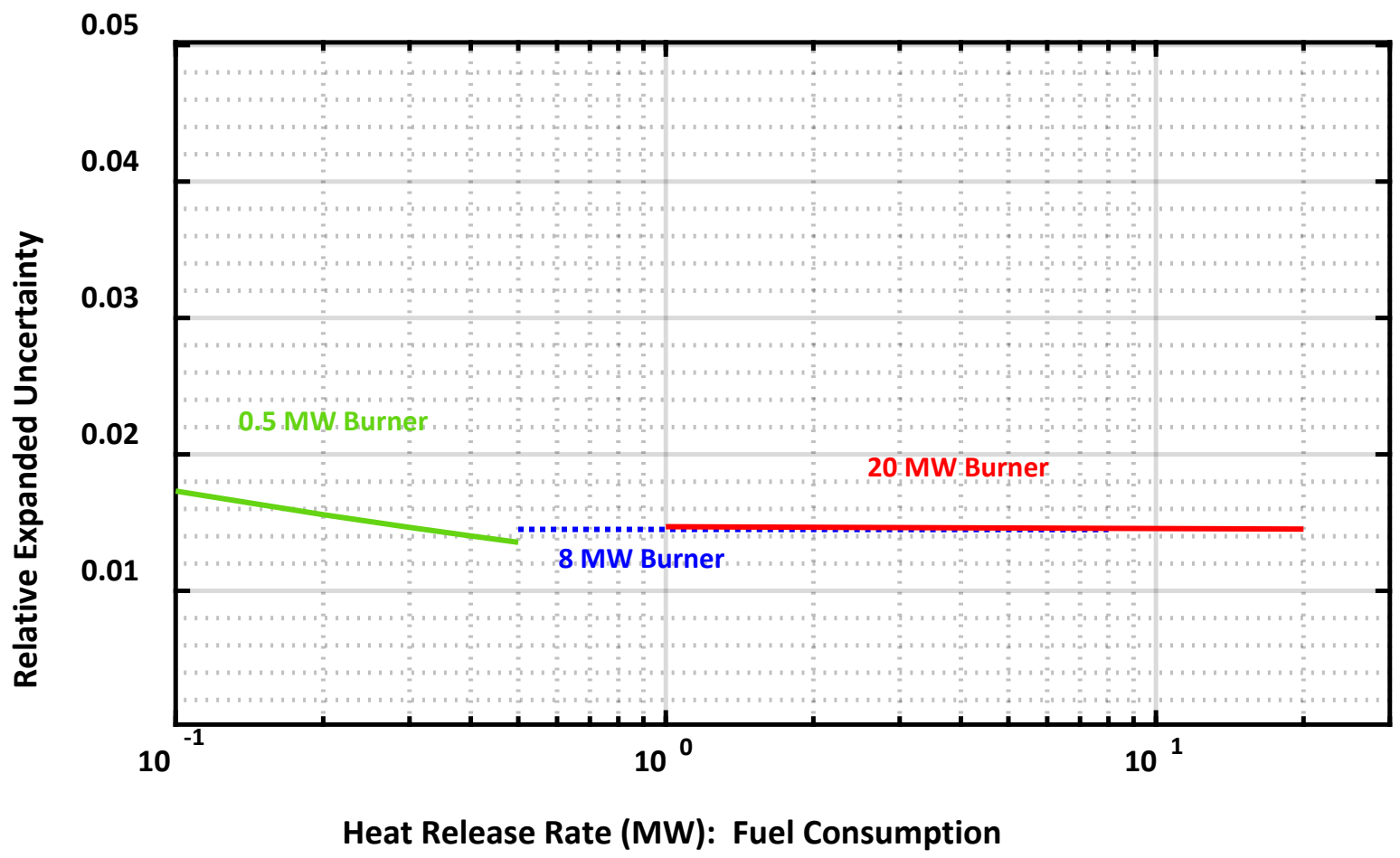

Figure 18 Estimated measurement uncertainty for heat release by fuel consumption for NFRL's natural gas burners. Expanded uncertainties are reported.

The uncertainty analysis utilizes the formulation of heat release based on fuel consumption, Eq. (26), as the measurement model, $y$. The analysis utilizes a model equation reduced to the independent component measurements to eliminate correlation among inputs. An uncertainty budget for heat release from the $8 \mathrm{MW}$ burner, Table 11, demonstrates the accounting of component uncertainty estimates and their contribution to the combined standard uncertainty. Major contributors to uncertainty are measurements of heat of combustion of the natural gas and flow meter pulse frequency. Significant effort has been applied to accurately measure natural gas flow and the heat content of the natural gas supply. The flow meter has been calibrated against a NIST primary flow standard and on-line analysis of the chemical content of natural gas has been implemented. Additional improvements such as increasing the pulse counting resolution has resulted in a high precision system for measuring heat release based on natural gas consumption. 
Table 11 Uncertainty budget for the measurement of heat release rate by fuel consumption at the $8 \mathrm{MW}$ natural gas burner.

\begin{tabular}{|c|c|c|c|c|}
\hline Measurement / Parameter, $x_{i}$ & Value & $u\left(x_{i}\right) / x_{i}$ & $s_{i}$ & $\begin{array}{r}\% \\
\text { Contribution }\end{array}$ \\
\hline$K_{\mathrm{m}}(-)$ & 508.00 & 0.00070 & -1.0 & 0.9 \\
\hline$f_{\mathrm{NG}}(\mathrm{Hz})$ & 15.070 & 0.0018 & 1.0 & 6.0 \\
\hline$P_{\mathrm{NG}}(\mathrm{Pa})$ & 202547 & 0.0016 & 1.0 & 4.9 \\
\hline$P_{\mathrm{NG}, \mathrm{bc}}(\mathrm{Pa})$ & 101325 & 0.0000 & -1.0 & 0.0 \\
\hline$T_{\mathrm{NG}}(\mathrm{K})$ & 304.33 & 0.0017 & -1.0 & 5.5 \\
\hline$T_{\mathrm{NG}, \mathrm{bc}}(\mathrm{K})$ & 288.7 & 0.0000 & 1.0 & 0.0 \\
\hline$\Delta_{\mathrm{c}} H_{\mathrm{NG}}^{\mathrm{id}}\left(\mathrm{MJ} / \mathrm{m}^{3}\right)$ & 34.69 & 0.0064 & 1.0 & 77.8 \\
\hline$\sqrt{\beta}_{\mathrm{NG}}(1 / \mathrm{psia})$ & 0.012020 & 0.0069 & 0.01 & 0.0 \\
\hline$\eta_{\mathrm{NG}}$ & 1.0000 & 0.0015 & 1.0 & 4.3 \\
\hline$\sigma_{\text {sys }}$ & - & 0.00053 & 1.0 & 0.5 \\
\hline$\dot{Q}_{\mathrm{FC}}(\mathrm{MW})$ & 1.959 & \multicolumn{3}{|c|}{$\begin{array}{c}u_{\mathrm{c}} / \dot{\boldsymbol{Q}}_{\mathrm{FC}}=0.0073 \\
U / \dot{Q}_{\mathrm{FC}}=0.0145\end{array}$} \\
\hline
\end{tabular}

\subsection{Measurement Confirmation}

NFRL's natural gas consumption system provides an accurate and precise source of chemical heat release as input into the facility's oxygen consumption calorimeters. Most important, the gas burners allow for a comparison of two independent measurements of heat release; one based on the principle of fuel consumption calorimetry, the other based on the principle of oxygen consumption calorimetry. This comparison is used for mutual confirmation of both measurements and not as a "calibration" of the oxygen consumption calorimetry. Procedural calibrations of instruments and the reduction of measurement bias through a detailed characterization of the system have eliminated the need for calibrating the system as a whole. [33] 


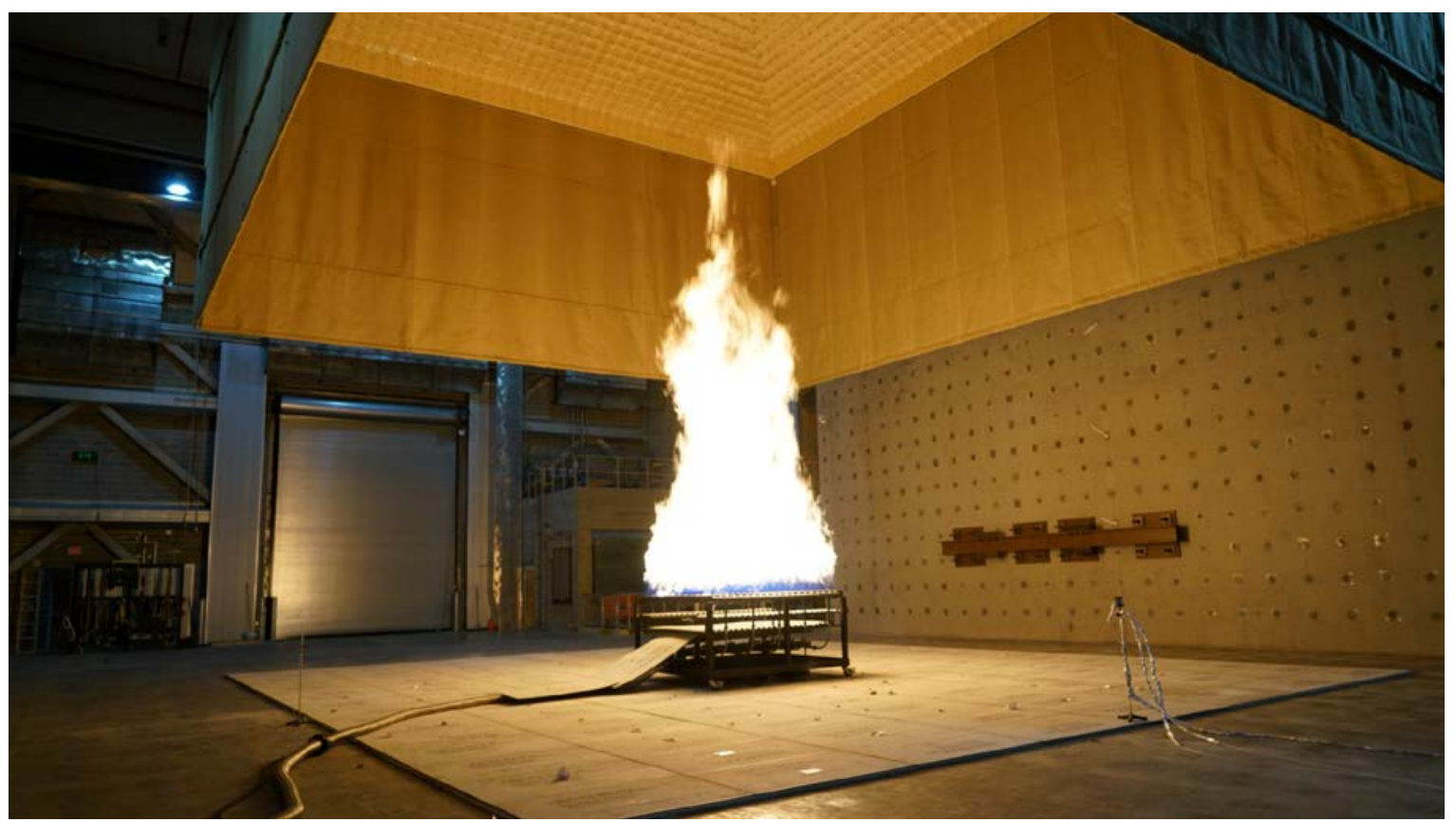

Figure 19 Confirmation burn at the 20 MW Calorimeter using the 20 MW natural gas burner.

Prior to a series of fire experiments at one of NFRL's calorimeters, it is routine procedure to perform an experiment using a natural gas burner to generate the full range of heat release anticipated for the test series, Figure 19. This experiment, referred to as a "confirmation burn," exercises all components of the calorimetry measurement and provides confirmation that the system is operating within its performance tolerances. The results of these confirmation measurements provide data to monitor the performance of the calorimetry measurement and establish quality controls to maintain performance levels. Figure 20 and Figure 21 are examples of "confirmation burns" for each of the calorimeters. These time history traces are used to confirm that the two independent measurements of heat release - fuel consumption and oxygen consumption calorimetry, agree within the estimated uncertainty limits. The traces also provide confirmation that proper delay times have been applied in the heat release computation by oxygen consumption.

41 

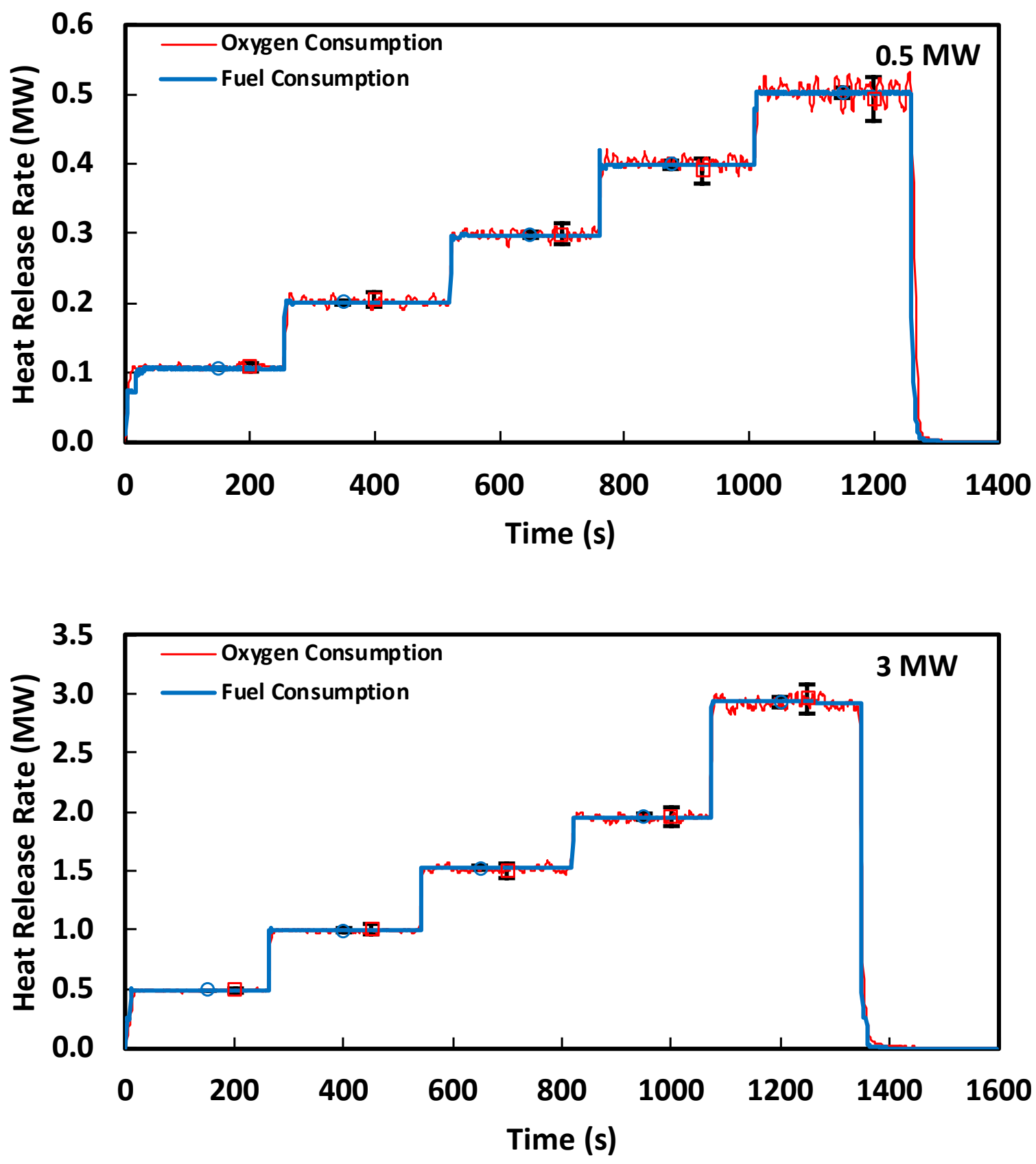

Figure 20 Time history traces of calorimetry confirmation experiments at the $0.5 \mathrm{MW}$ and 3 MW calorimeters. The natural gas reference burners were used to generate the prescribed fires. Uncertainty bars represent expanded uncertainties. 

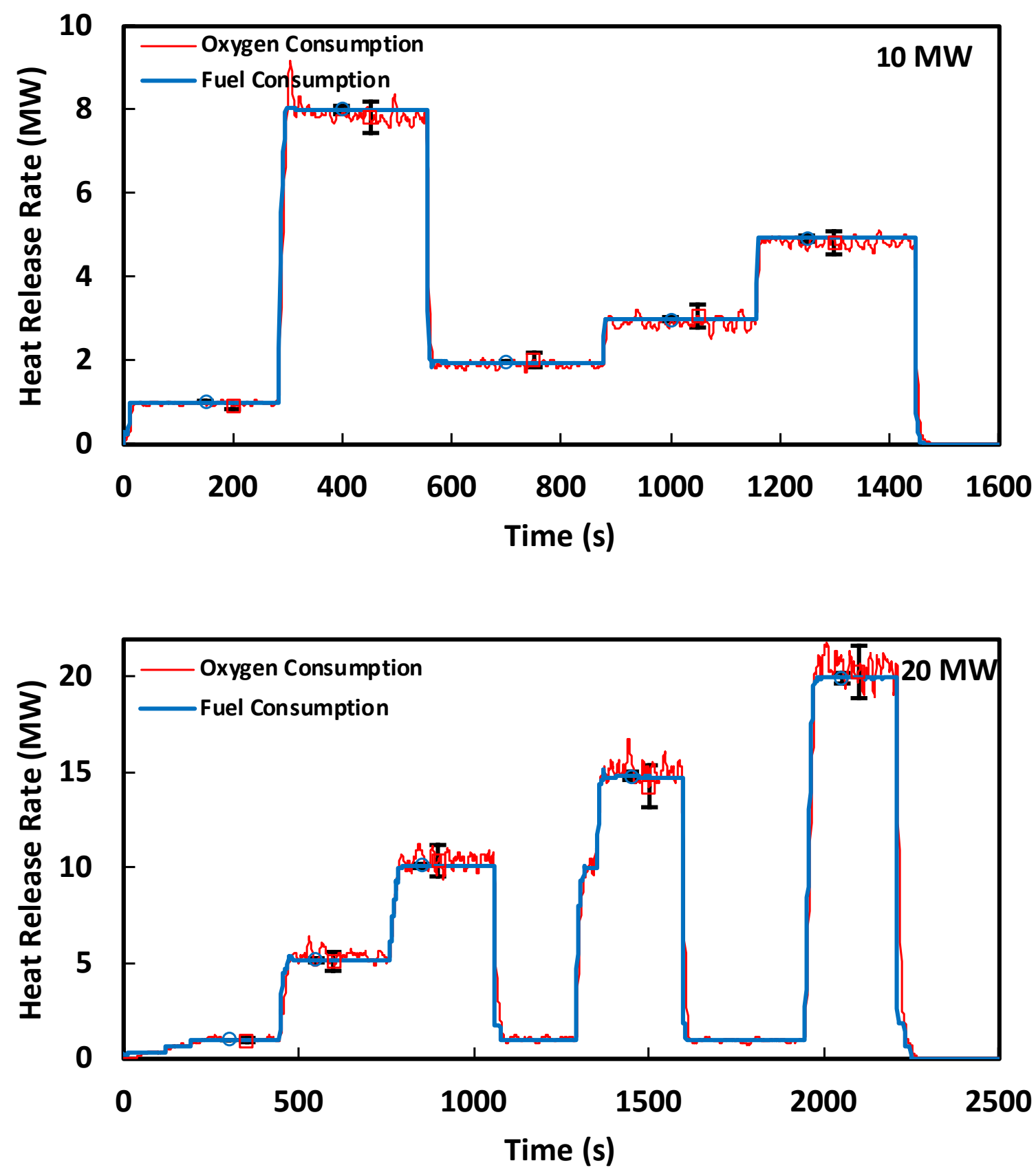

Figure 21 Time history traces of calorimetry confirmation experiments at the $10 \mathrm{MW}$ and $20 \mathrm{MW}$ calorimeters. The natural gas reference burners were used to generate the prescribed fires. Uncertainty bars represent expanded uncertainties. 
To conduct a detailed characterization of the performance of the calorimetry system, confirmation burns were conducted over the routine operating range of each calorimeter. This range of conditions also accounts for the various exhaust flow settings that are used to accommodate specific fire sizes and experiment requirements. Statistics were generated for the periods of steady burning to compare mean values of heat release. The ratio of the means for heat release measured by oxygen consumption (OC) and fuel consumption (FC) are plotted in Figure 22 and Figure 23. Ideally this ratio should be equal to 1.0, but if it falls within the uncertainty limits of the mean of the oxygen consumption calorimetry measurement the calorimeter is performing as anticipated. The relative expanded uncertainty for the mean calorimetry measurement by oxygen consumption is plotted as the dashed lines. The standard error of the mean, $\sigma_{\text {sys }} / \sqrt{N}$ (with $N=180$ ), replaces the repeatability in the uncertainty budget for the heat release rate measurement, Table 8 .

The $0.5 \mathrm{MW}, 3 \mathrm{MW}$, and $10 \mathrm{MW}$ calorimeters perform as anticipated over the full range of routine operating conditions. The $3 \mathrm{MW}$ and $10 \mathrm{MW}$ calorimeters perform slightly better when the exhaust flow is above $50 \%$ of full-scale (FS). There are mixed results for the largest calorimeter, $20 \mathrm{MW}$. Exhaust flow may have a more significant effect on the performance of the 20 MW calorimeter, as shown in Figure 23 where the performance is consistently better for fires less than $10 \mathrm{MW}$ and an exhaust flow of $50 \%$ of full-scale. For the case of $100 \%$ exhaust flow, the results are not as consistent. Since this is one of a few large-scale calorimeters in the world, more data is necessary to fully understand the role of each parameter on the performance of this size calorimeter. 

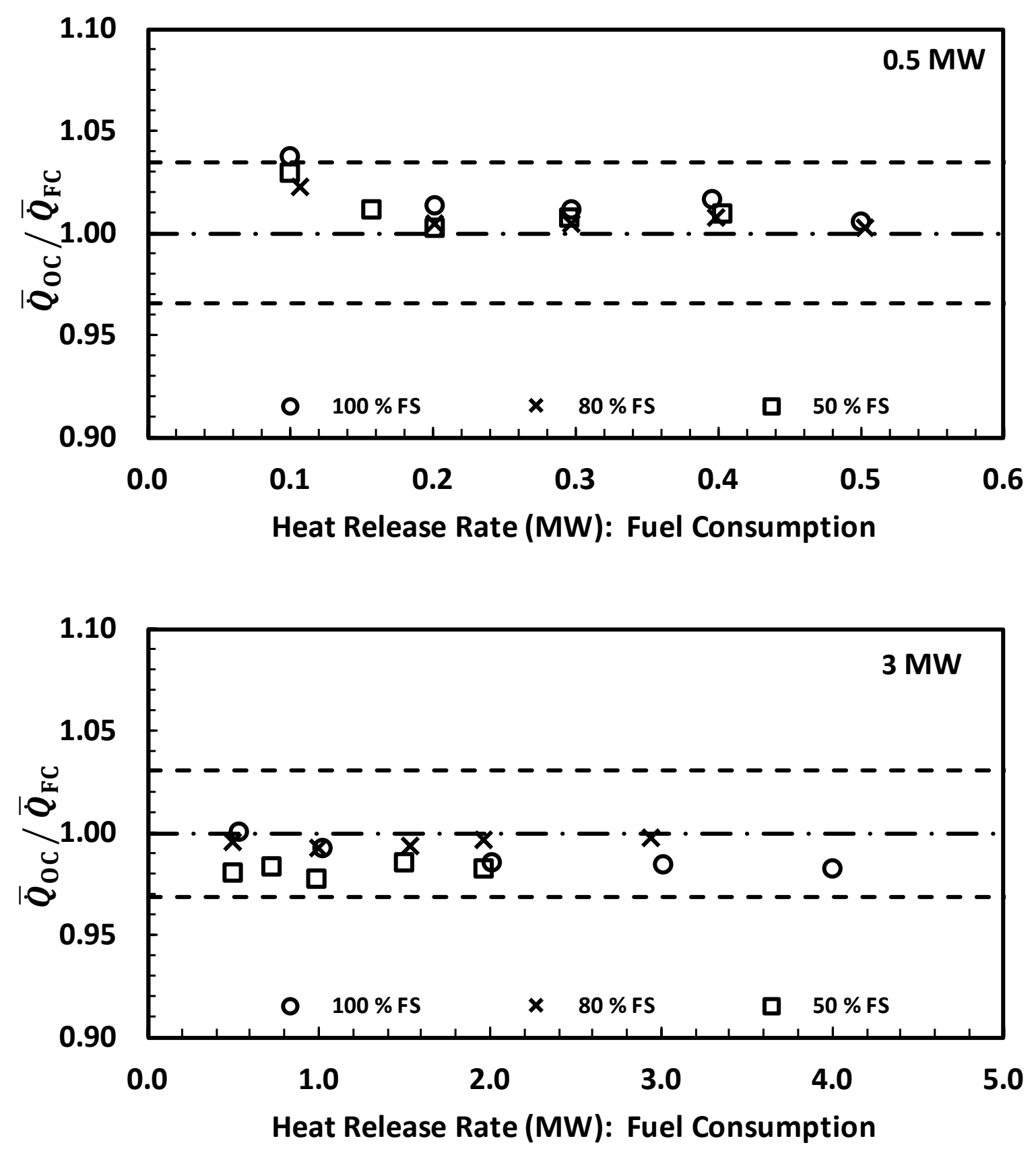

Figure 22 Comparison of mean values of independent heat release measurements for routine operating conditions at the $0.5 \mathrm{MW}$ and $3 \mathrm{MW}$ calorimeters. Symbols represent exhaust flow conditions, \% of full-scale (FS). Dashed lines represent relative expanded uncertainty of the mean calorimetry measurement by oxygen consumption. 

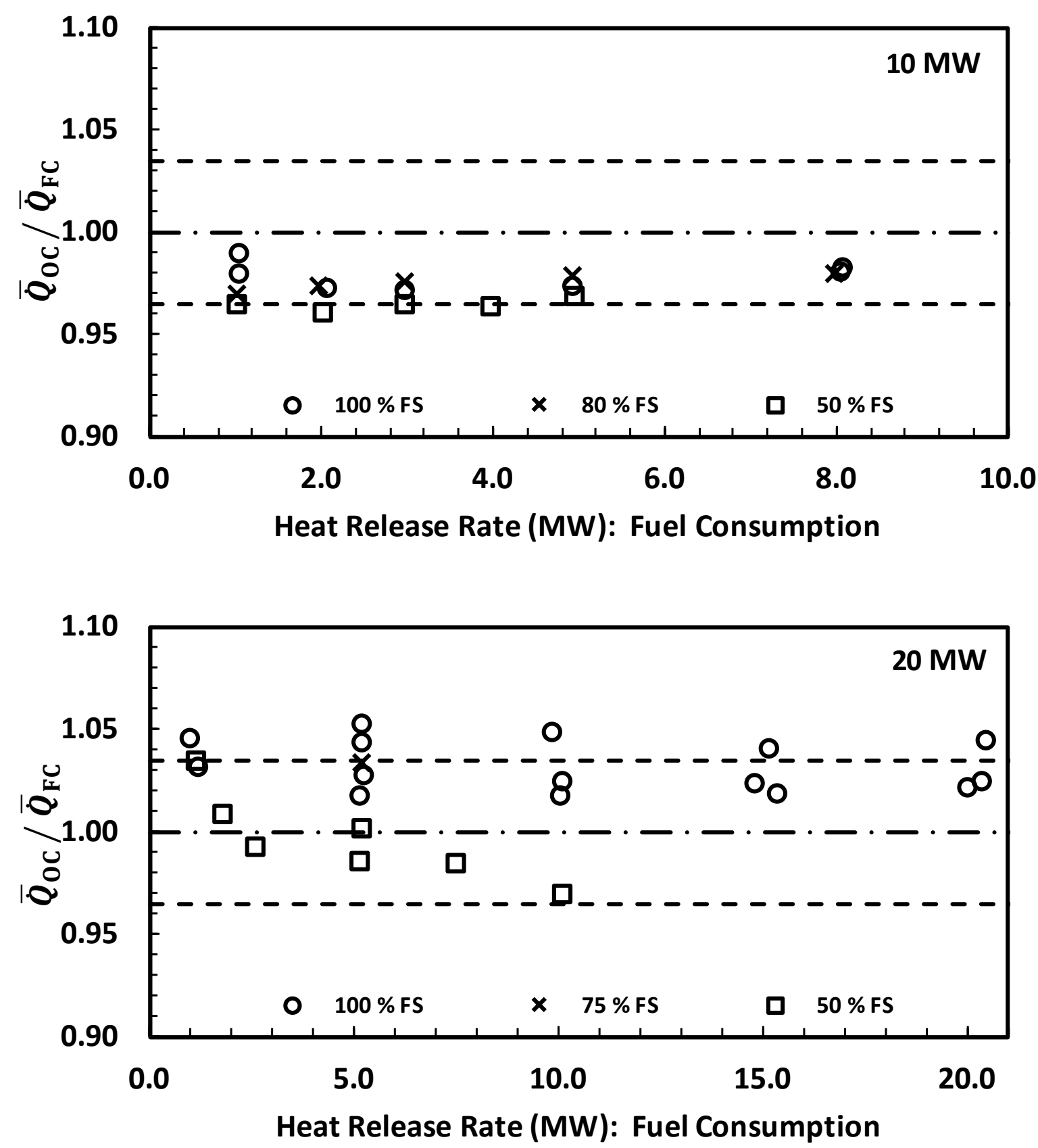

Figure 23 Comparison of mean values of independent heat release measurements for routine operating conditions at the $10 \mathrm{MW}$ and $20 \mathrm{MW}$ calorimeters. Symbols represent exhaust flow conditions, \% of full-scale (FS). Dashed lines represent relative expanded uncertainty of the mean calorimetry measurement by oxygen consumption. 


\subsection{Measurement Examples}

The previous sections provide evidence of NFRL's capability to measure heat release for largescale fires with quantitative estimates of measurement uncertainty. Two cases of fires from solid materials are also presented to further demonstrate the performance of NFRL's oxygen consumption calorimeters. The first case, Figure 24, is for a fully furnished apartment with structural members made from panels of cross laminated timber (CLT). [34] This is a case that fully exercises the facility's ability to accurately measure heat release from configurations of generic combustibles typical of residential buildings. The presence of large amounts of wood results in the generation of larger amounts of carbon monoxide compared to the natural gas fires. Uncertainty estimates were computed for this case involving increased carbon monoxide production and were unchanged from those estimates based on the natural gas fires (Figure 15), with approximately $9.0 \%$ expanded uncertainty.

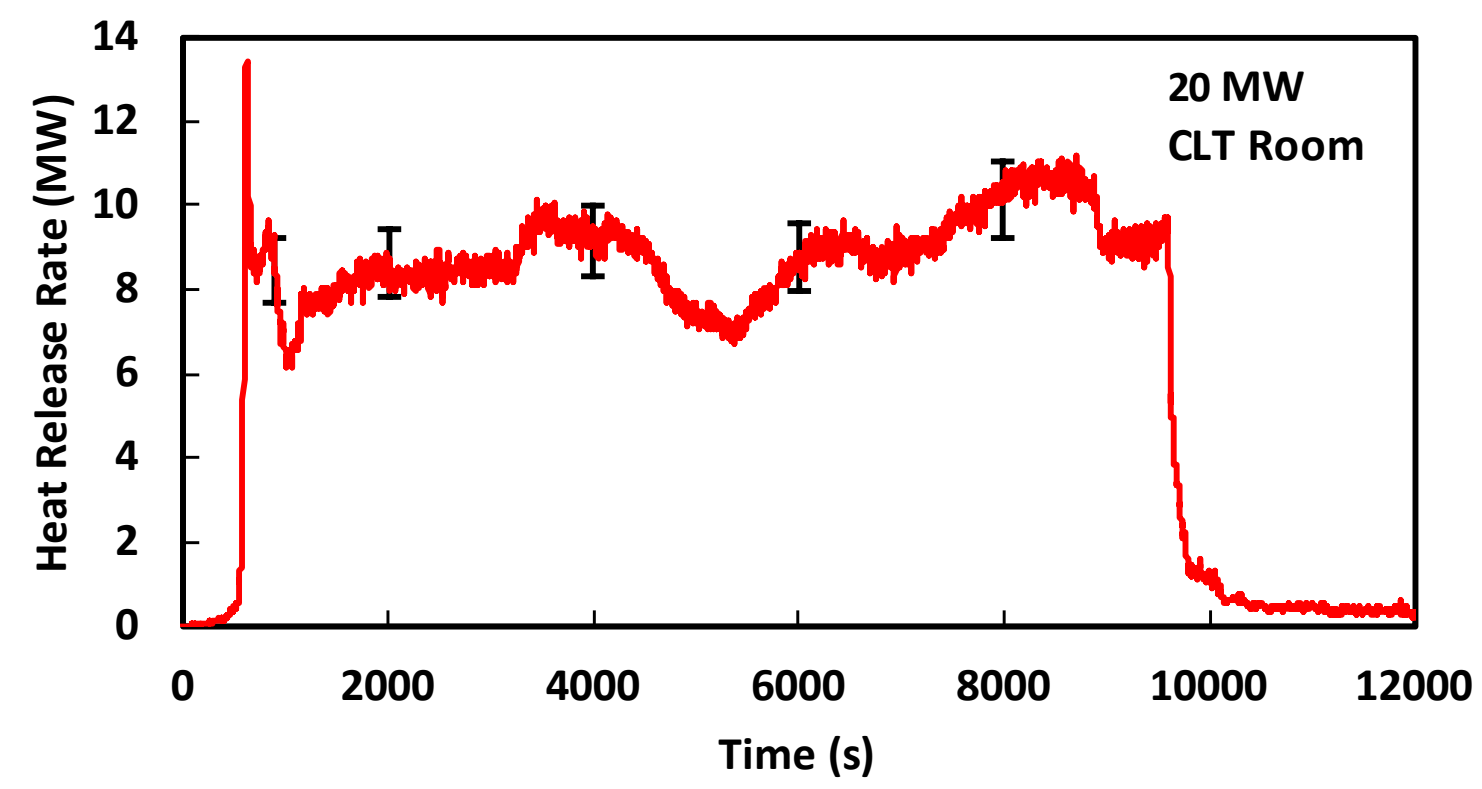

Figure 24 Time trace of heat release rate measured at the $20 \mathrm{MW}$ calorimeter for a fully-furnished apartment with exposed cross laminated timber structural members. Uncertainty bar represent expanded uncertainties.

For the second case, vertical panels of plexiglass or poly methyl methacrylate (PMMA) were burned in the $3 \mathrm{MW}$ calorimeter, Figure 25. The panels were weighed prior to the experiment and were totally consumed by the fire. Total heat release for the burn was computed by integrating the trace in Figure 26. Using this value and the heat of combustion for PMMA, total mass of fuel consumed by fire (mass loss) was computed and agreed with the mass of the panels determined during weighing. This example highlights the accuracy of the calorimeter when burning other than gaseous fuels. 


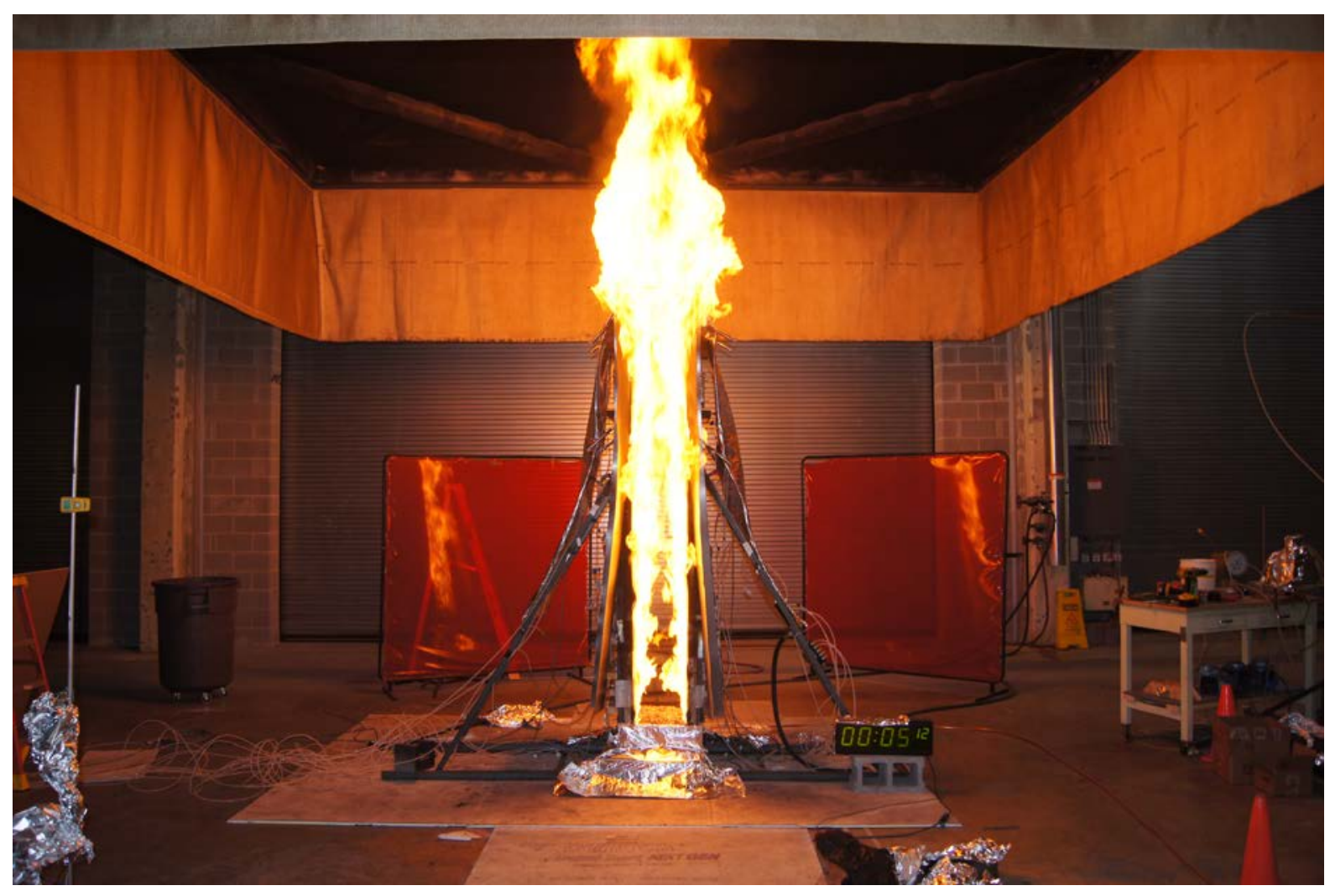

Figure 25 Opposing vertical panels of PMMA, burning at the $3 \mathrm{MW}$ calorimeter. The heat release rate at the time of the photograph was $1.85 \mathrm{MW}$

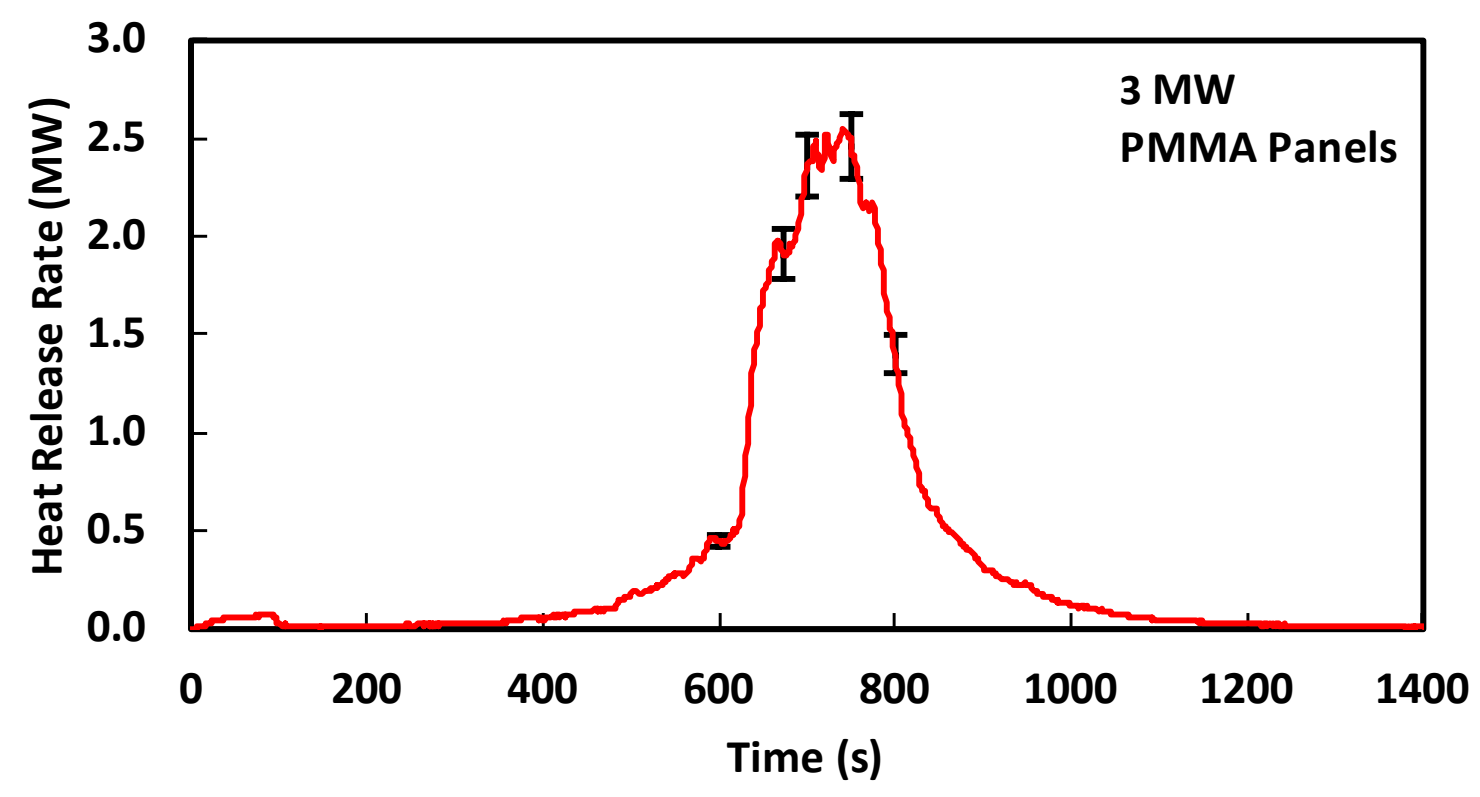

Figure 26 Time trace of heat release rate measured at the 3.0 MW calorimeter for verticallyoriented PMMA panels. Uncertainty bars represent expanded uncertainties. 


\subsection{Measurement Delays and Alignment}

The total delay time from the fire to the gas analyzers is composed of several components including the flow transport time from the test floor to the measurement locations in the exhaust ducts. The flow transport time is typically $2 \mathrm{~s}$ to $10 \mathrm{~s}$ and is affected by the exhaust flow, fire size, and height of the hood. The transport time for gases to travel from the sample tube to the duct sample pump is $3 \mathrm{~s}$ to $5 \mathrm{~s}$ depending on the sample tube length. The sample gas transport time from the dry sample pump inlet to the gas analyzers is approximately $12 \mathrm{~s}$. The delay times for a specific test configuration are determined using a step change in the natural gas burner fire size and typically range from $20 \mathrm{~s}$ to $30 \mathrm{~s}$.

A radiant heat flux gauge with a response time of less than $100 \mathrm{~ms}$ is used to identify a fire event at the test floor. Therefore, it is utilized as a reference signal to determine delay times. With the reference burner set to target fire size, steady-state signals are collected for a period of $180 \mathrm{~s}$ followed by a step change in fire size and a second steady period of $180 \mathrm{~s}$. The reference time is the time when the change in heat flux is greater than $10 \%$ of total change. For example, if the heat flux for the first steady period is $1.0 \mathrm{~kW} / \mathrm{m}^{2}$ and the heat flux for the second steady period is $2.0 \mathrm{~kW} / \mathrm{m}^{2}$, then the reference time (rounded to the nearest second) is the time when the heat flux increases above $1.1 \mathrm{~kW} / \mathrm{m}^{2}$. The $10 \%$ deflection time for each of the delayed signals is determined in a similar manner. The delay time is the difference between the deflection time and the reference time. This method is repeated for at least four different fire sizes to determine the average delay time for each signal at a given exhaust flow rate. The standard deviation of the delay time calculation using this method is typically less than $2 \mathrm{~s}$. Figure 27 displays an example case of determining the delay time for the signal from the oxygen analyzer. This example is for a step of $0.54 \mathrm{MW}$ to $1.02 \mathrm{MW}$ in heat release, using the natural gas burner, and conducted in the $3 \mathrm{MW}$ calorimeter. Figure 20 and Figure 21 show how the calorimeter and burner time traces are temporally aligned at the step transitions; demonstrating the effectiveness of this method for signal alignment. 


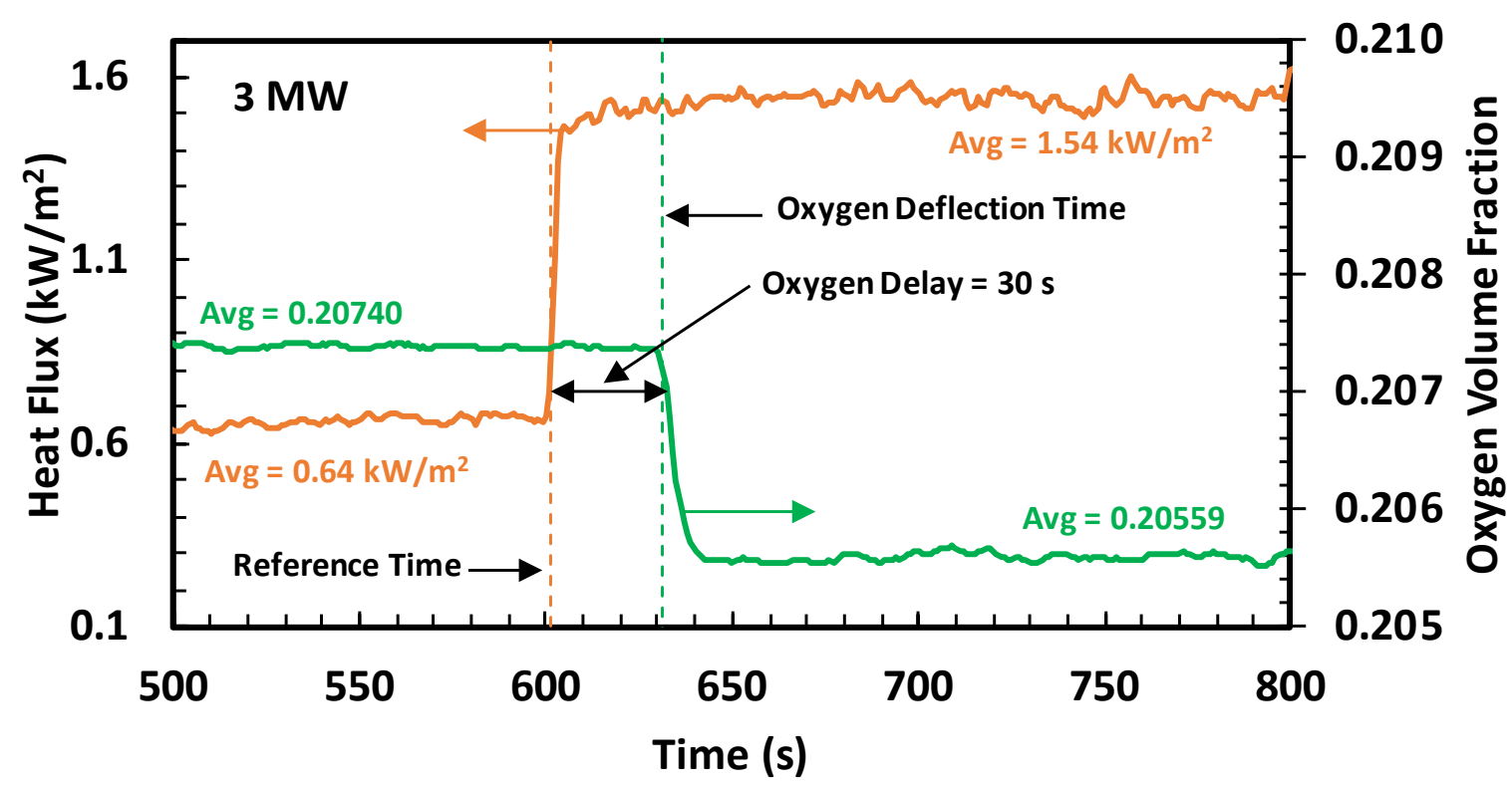

Figure 27 Example of data used for oxygen delay time calculation. The data was generated using the natural gas burner at the $3 \mathrm{MW}$ calorimeter and for a heat release step of $0.54 \mathrm{MW}$ to $1.02 \mathrm{MW}$.

\subsection{Measurement Time Response}

Experiments were conducted to estimate the time response of the $3 \mathrm{MW}$ calorimeter. Due to the precise control and fast response of the natural gas control valve it is possible to generate pulsing fires at the natural gas burners. A series of square wave pulses were provided to the control valve to create fires with different pulse widths. A square wave pulse is used to simulate peak heat release in a real fire, such as a single item of burning furniture. Multiple pulses provide repeat measurements at the same conditions. Since peak heat release rate is often a desired parameter from a fire test, it is useful to know how accurately the calorimeter can measure the peak. The results of preliminary experiments at the $3 \mathrm{MW}$ calorimeter are shown in Figure 28. They demonstrate that the amplitude of the calorimeter response is similar to the amplitude of the pulse train from the burner for pulse widths of $15 \mathrm{~s}$ or greater. The data suggest that the $3 \mathrm{MW}$ calorimeter can accurately resolve a fire event with a peak lasting more than $15 \mathrm{~s}$. Similar experiments were conducted at the $20 \mathrm{MW}$ calorimeter and results suggest that it can accurately resolve fire events lasting more than $20 \mathrm{~s}$. However, the results from the $20 \mathrm{MW}$ calorimeter also suggest that the ability to resolve fire events decreases with decreasing exhaust flow; further evidence for the need to tune exhaust flows to meet measurement requirements.

Signals are sampled at $1 \mathrm{~Hz}$ for each of the calorimeters. This sample rate provides enough temporal resolution for event identification during a fire experiment. Some users of the facility may wish to apply smoothing filters to the heat release data, however this procedure has limitations. Figure 26 demonstrates that when a moving average of $15 \mathrm{~s}$ is applied to the data, the ability to quantify the magnitude and the occurrence of events is reduced. Information about the dynamics of the fire is lost. In order to preserve as much information about the fire 
as possible, the window for moving averages should be less than the response time of the calorimeter. Figure 26 suggests that the response time of the $3 \mathrm{MW}$ calorimeter is $7 \mathrm{~s}$ to $8 \mathrm{~s}$, half the width of the pulse resolution. These results are preliminary and provide a starting point for a full characterization of the time response of NFRL's calorimeters. More data is necessary to generate quantitative estimates of response time.

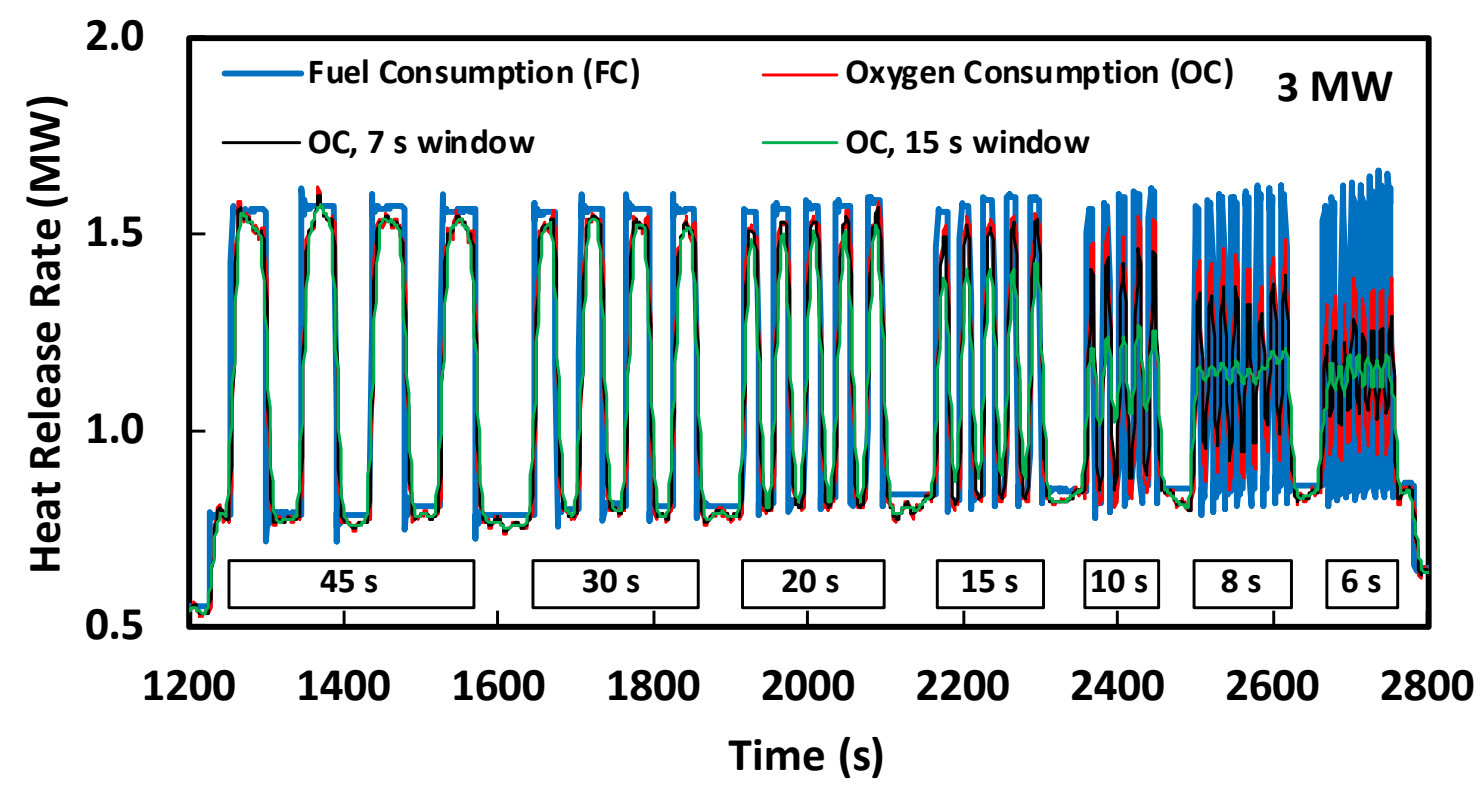

Figure 28 Dynamic response of the $3 \mathrm{MW}$ calorimeter to a pulsing natural gas fire. Pulse widths decrease left to right. Black and green traces are examples of moving averages applied to the data.

\subsection{Measurement Traceability}

The effort to assure accurate and defendable results for NFRL's large-scale heat release rate measurements has required a rigorous evaluation of the measurement process. Since this effort began in 2002 [32], improvements in measurement components, measurement methodology, and reductions in measurement uncertainty were implemented where possible. One such improvement has been creating in-house working standards (NFRL WSTD) and utilizing these working standards to recalibrate instruments or recertify commercially supplied materials (gas mixtures). The working standards are created from NIST reference standards (calibrations and SRMs) and therefore provide an easily traceable path to the primary standards. This has resulted in the reduction of uncertainty for measurement components previously identified as significant contributors. For example, the uncertainty of the span gas mixtures used to calibrate the oxygen analyzer has been reduced by a factor of 4.5 since beginning this effort. Measurements with a traceability path internal to NIST are summarized below in Table 12. 
Table 12 Summary of traceable measurements for NFRL's oxygen consumption and fuel (natural gas) consumption calorimetry systems.

\begin{tabular}{|c|c|c|c|c|}
\hline Measurement & $\begin{array}{c}\text { Input } \\
\text { Measurement }\end{array}$ & $\begin{array}{c}\text { Input } \\
\text { Measurement }\end{array}$ & $\begin{array}{l}\text { Working } \\
\text { Standard }\end{array}$ & $\begin{array}{c}\text { NIST Reference } \\
\text { Standard/Calibration }\end{array}$ \\
\hline \multirow{5}{*}{$\dot{Q}_{\text {oc }}$} & \multirow{2}{*}{$\dot{m}_{\mathrm{e}}$} & $C_{\mathrm{f}}$ & $\begin{array}{c}\text { NIST WGFS SN } \\
1857\end{array}$ & $\begin{array}{c}\text { NIST } 34 \text { L PVTt Primary Flow } \\
\text { Standard }\end{array}$ \\
\hline & & $\Delta P$ & $\begin{array}{l}\text { NFRL WSTD } \\
577967\end{array}$ & $\begin{array}{c}\text { NIST Calibration \# } 291256 \\
\text { V490 }\end{array}$ \\
\hline & $X_{\mathrm{O}_{2}}$ & & $\begin{array}{c}\text { NFRL WSTD } \\
012497\end{array}$ & NIST SRM 2659a \\
\hline & $X_{\mathrm{CO}_{2}}$ & & $\begin{array}{l}\text { NFRL WSTD } \\
\text { XA5254 }\end{array}$ & NIST SRM 2620a \\
\hline & $X_{\mathrm{CO}}$ & & $\begin{array}{l}\text { NFRL WSTD } \\
\text { CC104575 }\end{array}$ & NIST SRM 1681b \\
\hline \multirow[b]{2}{*}{$\dot{\boldsymbol{Q}}_{\mathrm{FC}}$} & $\dot{V}_{\mathrm{NG}, \mathrm{bc}}$ & $K_{\mathrm{m}}$ & & $\begin{array}{l}\text { NIST Calibration \# 836- } \\
\text { 280021-10 } \\
\end{array}$ \\
\hline & $\Delta_{\mathrm{c}} H_{\mathrm{NG}}^{\mathrm{id}}$ & $\begin{array}{c}X_{\mathrm{CH}_{4}}, X_{\mathrm{C}_{2} \mathrm{H}_{6}}, X_{\mathrm{C}_{3} \mathrm{H}} \\
, \ldots \ldots\end{array}$ & & $\begin{array}{c}\text { NIST SRM 16140; NIST SRM } \\
16154\end{array}$ \\
\hline
\end{tabular}




\section{Best Practices}

The NIST oxygen consumption calorimetry system for large-fire research has been refined and optimized over the past 20 years. It is the world's most well characterized and accurate measurement system of its kind and can serve as a model for other large-fire laboratories. Recognizing that every laboratory has unique physical constraints and performance objectives, several best practice recommendations have been compiled as guidance for laboratories seeking to optimize their measurement quality.

1) Canopy Hood and Floor Space: The overhead canopy hood should be designed to efficiently capture combustion products. [19] The walls of the facility should be far enough from the sides of the hood to allow uniform air entrainment and reduce the effects of radiative heat feedback to the fire. The hood size, shape, height and flow capacity should be designed based on the largest expected fire size. Air intakes close to the ceiling and far from the hood can minimize cross flow under the hood. Some fire experiments can be especially sensitive to cross flow air currents in the lab. Wind screens located near the edge of the exhaust hood can be used to minimize the effect of cross flow. It is important to control air currents in the lab when the experiment involves smoldering combustion or small flame ignition.

\section{2) Exhaust Flow Measurement:}

a. Most fire calorimeters have a measurement section in a horizontal or vertical section of the exhaust duct. It important to place the flow sensors in a straight section of the duct and as far as possible from the hood inlet and bends or turns. This is necessary to allow for a fully developed flow profile and to minimize the effect of fire plume position below the hood. A flow development length of at least 10 duct diameters is recommended, but one should be aware that most duct flows are not axisymmetric. Flow conditioning such as screens or tubes will help to reduce asymmetry, but at the cost of increased pressure drop and hence increased power requirements.

b. There are many different methods for determining the exhaust mass flow. Pressure based velocity methods are often used in fire applications because they can be used in harsh environments with soot particulates. Bi-directional probes are widely used to measure local velocities in fire doorway and exhaust ducts. [35] An averaging pitot probe provides a spatially integrated measurement from multiple points across the duct and can be used to determine an effective mean velocity. Two averaging pilot probes mounted on orthogonal chords are recommended to account for flow asymmetry.

c. The exhaust flow measurement is usually one of the largest sources of uncertainty and should be independently confirmed periodically using an alternative method such as tracer gas dilution or point flow mapping. [22, 36]

3) Gas Sampling: A perforated tube or multiple perforated tubes should be used for gas sampling. If the duct flow is highly turbulent and promotes good mixing and diffusion 
of exhaust gases, a single perforated tube may be used. A survey of the gas species distribution is recommended to confirm uniform distribution.

4) Gas Temperature: At least two temperature probes at different locations in the duct should be used to confirm uniformity of the exhaust temperature profile across the duct. The temperatures at two distinct locations should not vary by more than $1 \%$. Temperature probes with a response time of $1 \mathrm{~s}$ or less are essential for accurate characterization of flow transport and instrument delay times.

5) Calibrate the Instruments, Confirm the Calorimeter: It has been standard practice to calibrate each instrument in a calorimetry system and then to calibrate the entire calorimetry system by burning a gaseous fuel for which the heat release is known. [37] Doing so complicates the uncertainty analysis by coupling the uncertainty of the oxygen consumption calorimetry measurement to the fuel consumption calorimetry measurement. Section 4.2 of this document demonstrates that procedural calibrations of the system's instruments along with a detailed characterization of the system to reduce measurement bias can eliminate the need for calibrating the whole system. Fuel consumption calorimetry should first provide an independent confirmation of the oxygen consumption calorimetry. If the discrepancy between the two measurements is greater than the uncertainty of the oxygen consumption calorimetry measurement, then efforts to identify and reduce measurement bias should begin. If the measurement bias cannot be reduced and calibration against the fuel consumption measurement is the only option, then the uncertainty of the fuel consumption measurement must be included in the correction factor for the oxygen consumption calorimetry measurement. In this case, the oxygen consumption calorimetry is no longer independent of the fuel consumption calorimetry. As the practices described here have demonstrated, the oxygen consumption calorimetry and fuel (natural gas) consumption measurements are independent and so are their measurement uncertainties.

6) Water Removal: Water is a major product of combustion for fires. Additional sources of water include humidity in the ambient and water suppression used in fire experiments. It is important to condition the exhaust gas sample before it is analyzed. Water and soot must be removed from the sample stream to prevent potential damage to sensitive instrumentation. Drying the sample to a consistent moisture level will produce a more accurate measurement of oxygen and other exhaust gases. The detection limit of some high quality $\mathrm{O}_{2}$ sensors are better than $10 \mu \mathrm{L} / \mathrm{L}(10 \mathrm{ppmv})$. A highly efficient water removal system can dry the sample to dew points of less than $-45^{\circ} \mathrm{C}$ or less than $100 \mu \mathrm{L} / \mathrm{L}(100 \mathrm{ppmv})$. Water in the sample stream will bias the gas species measurements through dilution. Drying the sample to low level of water can reduce this bias. At water levels less than $200 \mu \mathrm{L} / \mathrm{L}$ (200 ppmv) the dilution effect on the oxygen measurement is negligible. The use of water dew point analyzers to measure moisture levels of the sample gas before and after the drying stage is recommended. Cold traps and desiccant tubes can be used to remove water from the 
sample stream, however these methods required the drying media to be frequently replaced and limit the test duration. Utilizing a Nafion membrane style tube dryer that can be operated continuously with no disposable drying media is recommended. In addition to the practical benefits of operation, the continuous tube dryer selectively removes water molecules and does not remove condensable organic compounds or acid gases. This allows quantification of these species if needed.

7) Confirm Stoichiometry: When burning pure gaseous fuels such as methane or propane as a free and open flame not impinging on any surfaces, it is possible to use the gas analysis measurements for the gas sample from the exhaust duct to confirm stoichiometry. The ratio of mole fraction of oxygen molecules consumed to the mole fraction of carbon dioxide molecules produced is determined by the fuel. For the case of methane, 2 oxygen molecules are consumed for every 1 carbon dioxide molecule produced, resulting in a ratio of 2.0. This ratio is 1.67 for the case of propane. For natural gas this ratio is $1.75 \pm 0.09$ depending on the composition of the natural gas. [24] Monitoring this ratio during confirmation burns with gaseous fuels provides a check of the quality of the calorimeter's gas analysis measurements. If this ratio does not agree with stoichiometry within reasonable limits, one should begin trouble shooting the system's gas analysis measurements. It is important that flame impingement on surfaces is avoided during this quality check as this will cause incomplete combustion due to soot deposition. 


\section{Summary}

Having the ability to quantitatively characterize the response of full-scale structural systems to realistic fire and mechanical loads establishes the National Fire Research Laboratory as one of the most unique fire research facilities in the world. The facility maintains an infrastructure of physical measurements necessary for conducting research to characterize the behavior of structures in a fire. This measurement infrastructure includes four oxygen consumption calorimeters - able to measure the heat release rate of fires ranging from $0.02 \mathrm{MW}$ to $20 \mathrm{MW}$, and a fuel (natural gas) consumption calorimetry system - utilized to generate precisely determined fires over the same range of heat release. The methodology, hardware, and performance of both systems has been described here, providing the technical background necessary to properly interpret the measurement results. With this system being the most highly characterized of its kind, this description is also intended to provide technical guidance to other laboratories with the mission of accurate large-scale fire testing. Best practice recommendations have been summarized with those laboratories in mind.

A rigorous evaluation of measurement uncertainty was conducted to assure accurate and defendable results for NFRL's large-scale heat release rate measurements. For the routine operating conditions of the facility, the measurement uncertainty for NFRL's oxygen consumption calorimeters ranges from $4 \%$ to $13 \%$; depending on which calorimeter is utilized as well as the fuel source for the fire. Overlap of the measurement ranges of the calorimeters offers some flexibility in choosing a calorimeter for a specific fire study to optimize measurement performance. Current uncertainty estimates for the $3 \mathrm{MW}$ calorimeter have improved by better than a factor of 2.5 when compared to previous estimates. The measurement uncertainty for NFRL's fuel (natural gas) consumption calorimetry system is better than $2.0 \%$. This system provides the capability to precisely generate natural gas fires for confirmation of the oxygen consumption system and to generate prescribed fires to simulate thermal loading on a structure. Measurement agreement between the two independent systems has been demonstrated; providing evidence that NFRL's systems of heat release rate measurements for large-scale fire research are the most accurate and highly characterized of their kind. 


\section{Acknowledgments}

The authors are grateful to several members of the NIST Fire Research Division for their valuable contributions to this work: Artur Chernovsky, who designed, integrated and maintained the data acquisition and control system for the NFRL; Laurean DeLauter, who coordinated the installation of exhaust duct measurement probes and gas sample transfer lines, assembled the natural gas fuel delivery system, and fabricated the $8 \mathrm{MW}$ burner; John Gross, who designed the $20 \mathrm{MW}$ burner; Anthony Hamins who designed the $8 \mathrm{MW}$ burner; Marco Fernandez, who served as data collection and control systems operator and provided installation and maintenance of instrumentation; Anthony Chakalis, who assembled the gas sample analysis and conditioning system; Brian Story, who provided scale drawings and acquired critical dimensions of the physical space; Christopher Smith, who assisted with the uncertainty analysis for the effective diameter measurement of the exhaust ducts; Gregory Fiola, who assisted with the data analysis for time response of the calorimetry system; and Matthew Hoehler and Kevin McGrattan, who provide editorial review. The entire team provided critical feedback and technical assistance to make the development of this measurement system possible. 


\section{References}

[1] Babrauskas V , Peacock RD (1992) Heat Release Rate - the Single Most Important Variable in Fire Hazard. Fire Safety Journal 18(3):255-272.

[2] Babrauskas V (2002) Heat Release Rates. The SFPE Handbook of Fire Protection Engineering, eds DiNenno PJ, Drysdale D, Beyler CL, \& Walton WD (National Fire Protection Association and The Society of Fire Protection Engineers, Quincy, MA), Chapter Section 3, Chap 1, 3rd Edition Ed., pp 1-37.

[3] Peacock RD, Forney GP, Reneke PA, Portier RW, Jones WW (1993) CFAST, The Consolidated Model of Fire Growth and Smoke Transport. (National Institute of Standards and Technology, Gaithersburg, MD), NIST Technical Note TN-1299.

[4] McGrattan K, Hostikka S, McDermott R, Floyd J, Vanella M (2019) Fire Dynamics Simulator Technical Reference Guide. (National Institute of Standards and Technology, Gaithersburg, MD), NIST Special Publication SP-1018-1. https://doi.org/http://dx.doi.org/10.6028/NIST.SP.1018

[5] Orloff L, Deris J, Delichatsios MA (1992) Radiation from Buoyant Turbulent Diffusion Flames. Combustion Science and Technology 84(1-6):177-186. https://doi.org/10.1080/00102209208951852

[6] Parker WJ , Long ME (1971) Development of a Heat Release Rate Calorimeter at NBS. Proceedings of the Symposium on Ignition, Heat Release, and Noncombustibility of Materials, (American Society for Testing and Materials, Philadelphia, PA), pp 135-151.

[7] Huggett C (1980) Estimation of Rate of Heat Release by Means of OxygenConsumption Measurements. Fire and Materials 4(2):61-65.

[8] Babrauskas V (1982) Development of the Cone Calorimeter - A Bench-Scale Heat Release Rate Apparatus Based on Oxygen Consumption. (National Bureau of Standards, Gaithersburg, MD), NBSIR 82-2611.

[9] Babrauskas V, Lawson R, Walton WD, Twilley W (1982) Upholstered Furniture Heat Release Rates Measured With a Furniture Calorimeter. (National Bureau of Standards, Gaithersburg, MD), NBSIR 82-2604.

[10] Bryant RA, Ohlemiller TJ, Johnsson EL, Hamins A, Grove BS, Guthrie WF, Maranghides A, Mulholland GW (2003) The NIST 3 MW Quantitative Heat Release Rate Facility - Description and Procedures. (National Institute of Standards and Technology, Gaithersburg, MD), NISTIR-7052.

[11] Newman JS, Wieczorek C, Troup J (2005) Application of Building-Scale Calorimetry. Fire Safety Science - Proceedings of the 8th International Symposium, pp 1425-1434. https://doi.org/doi:10.3801/IAFSS.FSS.8-1425

[12] Steckler KD (2002) The Bureau of Alcohol, Tobacco and Firearms (ATF) Fire Research Laboratory. Fire Safety Science - Proceedings of the 7th International Symposium, pp 109-110. https://doi.org/doi:10.3801/IAFSS.FSS.7-109

[13] Kerber S (2010) Impact of Ventilation on Fire Behavior in Legacy and Contemporary Residential Construction. (Underwriters Laboratories, Inc., Northbrook, IL).

[14] Yoo YH, Kim HY, Shin HJ (2008) The Study of Development and Calibration for the Real Scale Fire Test Facility. Journal of Korean Institute of Fire Science and Engineering 22(1):37-44. 
[15] Lee E (2006) Design of Large Cone Calorimeter for the Fire Study. Journal of Korean Institute of Fire Science and Engineering 20(4):65-71.

[16] Sensenig DL (1980) Oxygen Consumption Technique for Determining the Contribution of Interior Wall Finishes to Room Fires. (National Bureau of Standards, Gaithersburg, MD), NBSTN-1128.

[17] Parker WJ (1984) Calculations of the Heat Release Rate by Oxygen-Consumption for Various Applications. Journal of Fire Sciences 2(5):380-395.

[18] Parker WJ , Janssens ML (1992) Oxygen Consumption Calorimetry. Heat Release in Fires, eds Babrauskas V \& Grayson SJ (Elsevier Applied Science, New York), Chapter Chap 3 pp 31-59.

[19] Cooper LY (1994) Some Factors Affecting the Design of a Calorimeter Hood and Exhaust. Journal of Fire Protection Engineering 6(3):99-112.

[20] Heskestad G (2002) Fire Plumes, Flame Height and Air Entrainment. The SFPE Handbook of Fire Protection Engineering, eds DiNenno PJ, Drysdale D, Beyler CL, \& Walton WD (National Fire Protection Association and The Society of Fire Protection Engineers, Quincy, MA), Chapter Section 2, Chap 1, 3rd Edition Ed., pp 117.

[21] Rosemount (2006) Rosemount 485 Annubar Flow Handbook. (Rosemount Incorporated, Chanhassen, MN), Reference Manual 00809-0100-1191, RevCB.

[22] ASTM (1999) Standard Test Method for Volumetric and Mass Flow Rate Measurement in a Duct Using Tracer Gas Dilution. (ASTM International, West Conshohocken, PA), ASTM E 2029-99.

[23] Bryant RA (2018) Uncertainty estimates of tracer gas dilution flow measurements in large-scale exhaust ducts. Flow Meas Instrum 61:1-8. https://doi.org/10.1016/j.flowmeasinst.2018.03.004

[24] Bryant R, Bundy M, Zong RW (2015) Evaluating measurements of carbon dioxide emissions using a precision sourceA natural gas burner. Journal of the Air \& Waste Management Association 65(7):863-870. https://doi.org/10.1080/10962247.2015.1031294

[25] Borthwick R , Bundy M (2011) Quantification of a Precision Point Source for Generating Carbon Dioxide Emissions. EPRI CEM User Group Conference and Exhibit, (Electric Power Research Institute, Palo Alto, Ca).

[26] ASTM (2003) Standard Practice for Calculating Heat Value, Compressibility Factor, and Relative Density of Gaseous Fuels. (ASTM International, West Conshohocken, PA), ASTM D 3588-98.

[27] GPA (2014) Calculation of Gross Heating Value, Relative Density, Compressibility and Theoretical Hydrocarbon Liquid Content for Natural Gas Mixtures for Custody Transfer. (Gas Processors Association, Washington, DC), GPA Standard 2172-14.

[28] GPA (2009) Table of Physical Properties for Hydrocarbons and Other Compounds of Interest to the Natural Gas and Natural Gas Liquids Industries. (Gas Processors Association, Washington, DC), GPA Standard 2145-09.

[29] Lemmon EW, Bell IH, Huber ML, McLinden MO (2018) NIST Standard Reference Database 23: Reference Fluid Thermodynamic and Transport Properties-REFPROP. (NIST, Gaithersburg, MD). 
[30] ISO (2008) Evaluation of Measurement Data - Guide to the Expression of Uncertainty in Measurement. (International Organization for Standardization, Switzerland), JCGM 100:2008.

[31] Lafarge T , Possolo A (2015) The NIST Uncertainty Machine. NCSLI Measure 10(3):20-27. https://doi.org/10.1080/19315775.2015.11721732

[32] Bryant RA, Ohlemiller TJ, Johnsson EL, Hamins A, Grove BS, Guthrie WF, Maranghides A, Mulholland GW (2003) The NIST 3 Megawatt Quantitative Heat Release Rate Facility. (National Institute of Standards and Technology, Gaithersburg, MD), NISTSP-1007.

[33] Bryant RA , Mulholland GW (2008) A guide to characterizing heat release rate measurement uncertainty for full-scale fire tests. Fire and Materials 32(3):121-139. https://doi.org/10.1002/fam.959

[34] Su J, Lafrance PS, Hoehler M, Bundy M (2018) Fire Safety Challenges of Tall Wood Buildings - Phase 2: Task $2 \& 3$ - Cross Laminated Timber Compartment Fire Tests. (Fire Protection Research Foundation, Quincy, MA), FPRF-2018-01.

[35] McCaffrey BJ , Heskestad G (1976) Robust Bidirectional Low-Velocity Probe for Flame and Fire Application. Combustion and Flame 26(1):125-127.

[36] ASTM (2006) Standard Test Method for Average Velocity in a Duct (Pitot Tube Method). (ASTM International, West Conshohocken, PA), ASTM D 3154-00.

[37] ASTM (2015) Standard Practice for Full-Scale Oxygen Consumption Calorimetry Fire Tests. (ASTM International, West Conshohocken, PA), ASTM E 2067-15. 


\section{Appendix}

\subsection{Nomenclature}

$\begin{array}{ll}B & \text { blockage factor for averaging pitot probes } \\ C_{\mathrm{f}} & \text { calibrated correction factor for exhaust flow measurement } \\ C_{\Delta \mathrm{P}} & \text { calibrated correction factor for differential pressure transducer } \\ D & \text { inner diameter of exhaust duct } \\ f & \text { pulse frequency of gas flow meter } \\ \Delta_{\mathrm{c}} H & \text { net heat of combustion; lower heating value (LHV) } \\ k & \text { coverage factor } \\ K_{\mathrm{a}} & \text { flow coefficient for averaging pitot probe } \\ K_{\mathrm{m}} & \text { calibrated frequency factor for natural gas flow meter } \\ \dot{m} & \text { mass flow; rate of fuel consumption } \\ M & \text { molecular weight } \\ n_{\mathrm{C}} & \text { number of carbon atoms } \\ P & \text { absolute pressure } \\ \Delta P & \text { differential pressure } \\ \dot{Q} & \text { heat release rate } \\ R & \text { universal gas constant } \\ S & \text { non dimensional sensitivity coefficient } \\ T & \text { temperature } \\ u & \text { standard uncertainty } \\ U & \text { expanded uncertainty (95 \% confidence interval, } k=2.0) \\ V & \text { gas velocity } \\ \dot{V} & \text { volume flow } \\ V & \text { instrument voltage response } \\ x & \text { input quantity for measurement model } \\ X & \text { gas species volume fraction } \\ y & \text { output quantity of measurement model } \\ Z & \text { gas compressibility factor }\end{array}$

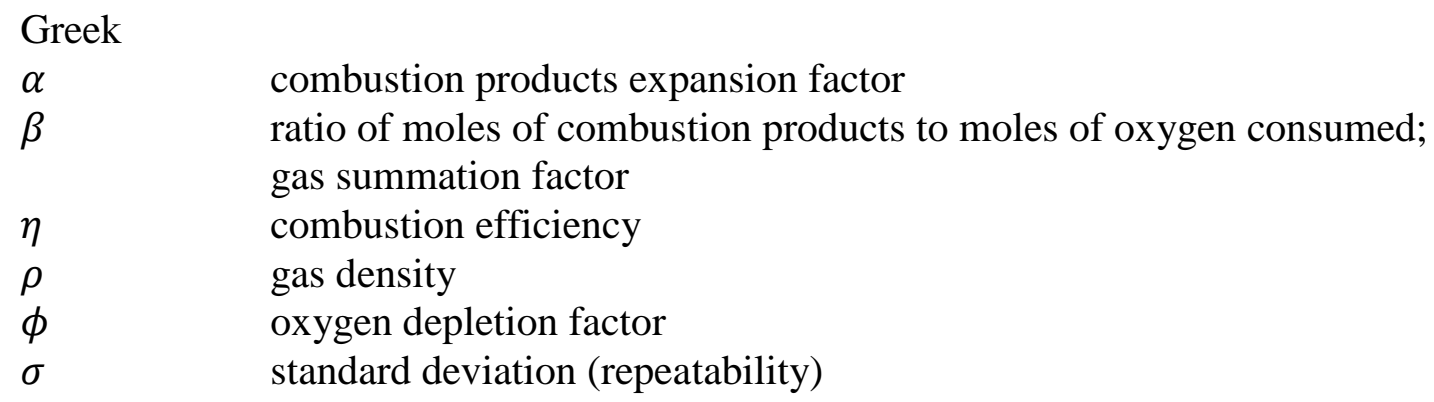
$\sigma \quad$ standard deviation (repeatability)

combustion products expansion factor ratio of moles of combustion products to moles of oxygen consumed; gas summation factor combustion efficiency gas density

Subscripts bc base conditions c

combustion or combined 


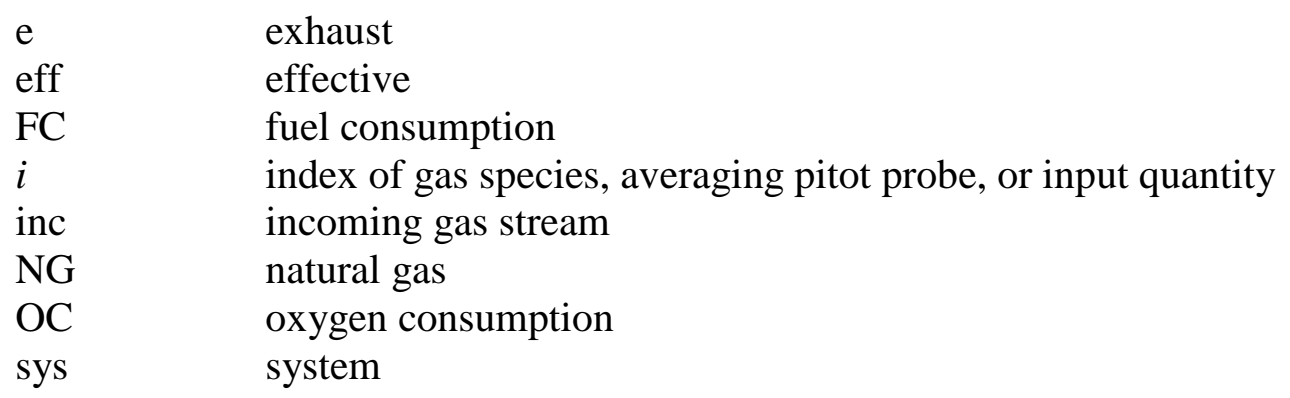




\subsection{Data Acquisition and Control Hardware}

Two types of data acquisition (DAQ) hardware are used to record or generate analog transducer signals. The ethernet based National Instruments (NI) cDAQ-9188 chassis are installed at four locations in the lab. These devices are populated with the following I/O-Modules: NI-9215 (voltage) NI-9211 (temperature), and NI-9219 (resistance). The NI-9265 module was used for $0 \mathrm{~mA}$ to $20 \mathrm{~mA}$ analog output control of the burner gas valve. The NI 9472 module was used for digital output control (relays and solenoid values).

A PXI based DAQ system is used to acquire signals from the gas analyzers and sample conditioning rack. A NI PCIe-6251 multifunction DAQ card in installed in a personal computer (PC) motherboard and connected to a SCXI-1000 chassis. Three NI-SCXI-1102B voltage input modules are installed in this chassis. Each module is connected to a rack mounted TC2095 signal conditioning and terminal block for voltage and thermocouple signal inputs.

An in-house software application, developed in LabVIEW ${ }^{\mathrm{TM}}$, was used to allocate channels and control data acquisition. Data is sampled at $200 \mathrm{~Hz}$ and recorded at $1 \mathrm{~Hz}$ along with the standard deviations from the averaging process. 
7.3. Rotational Distribution of Chord Measurements in NFRL's Exhaust Ducts

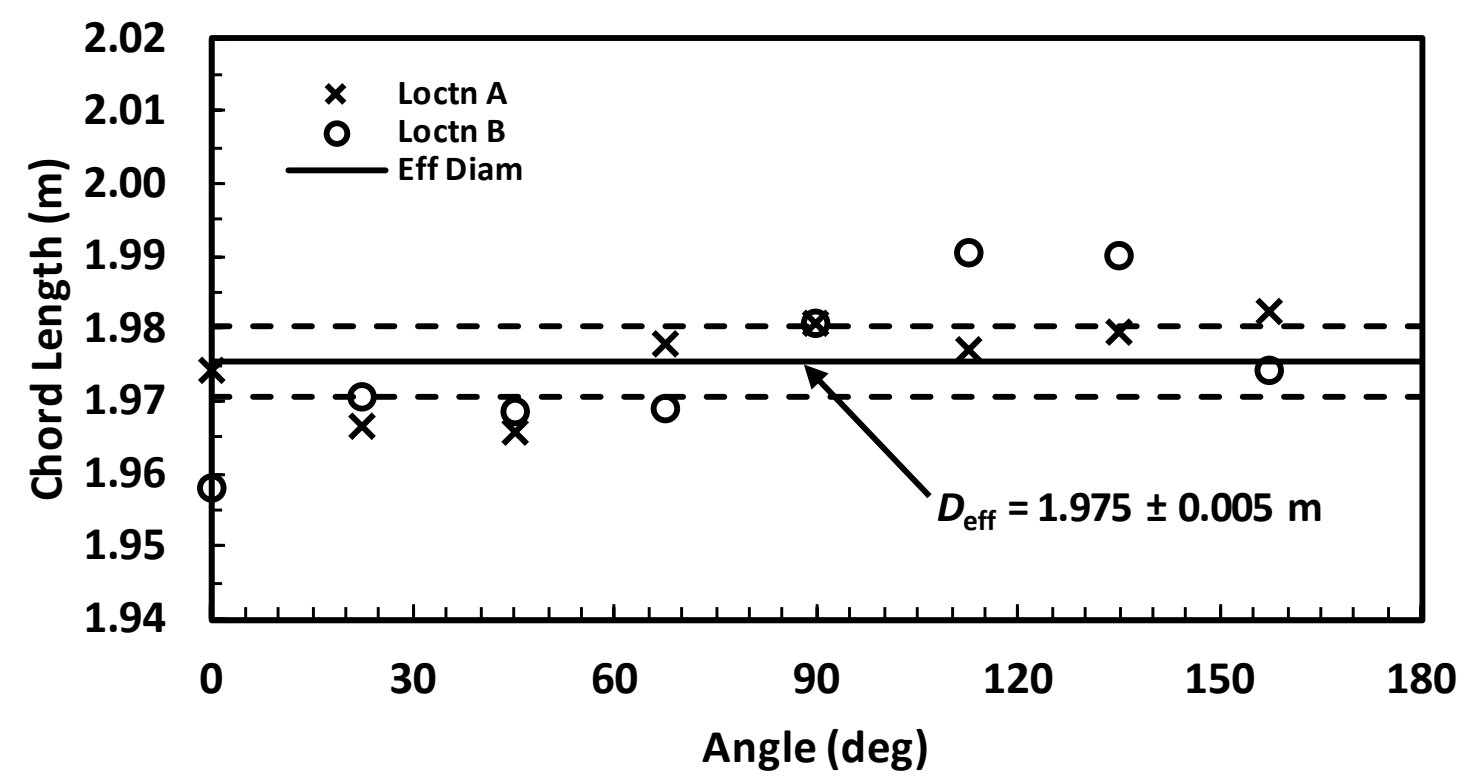

Figure 29 Chord length measurements at the measurement stations of the averaging pitot probes for the $3 \mathrm{MW}$ and the $10 \mathrm{MW}$ calorimeters. Dashed lines represent expanded uncertainties.

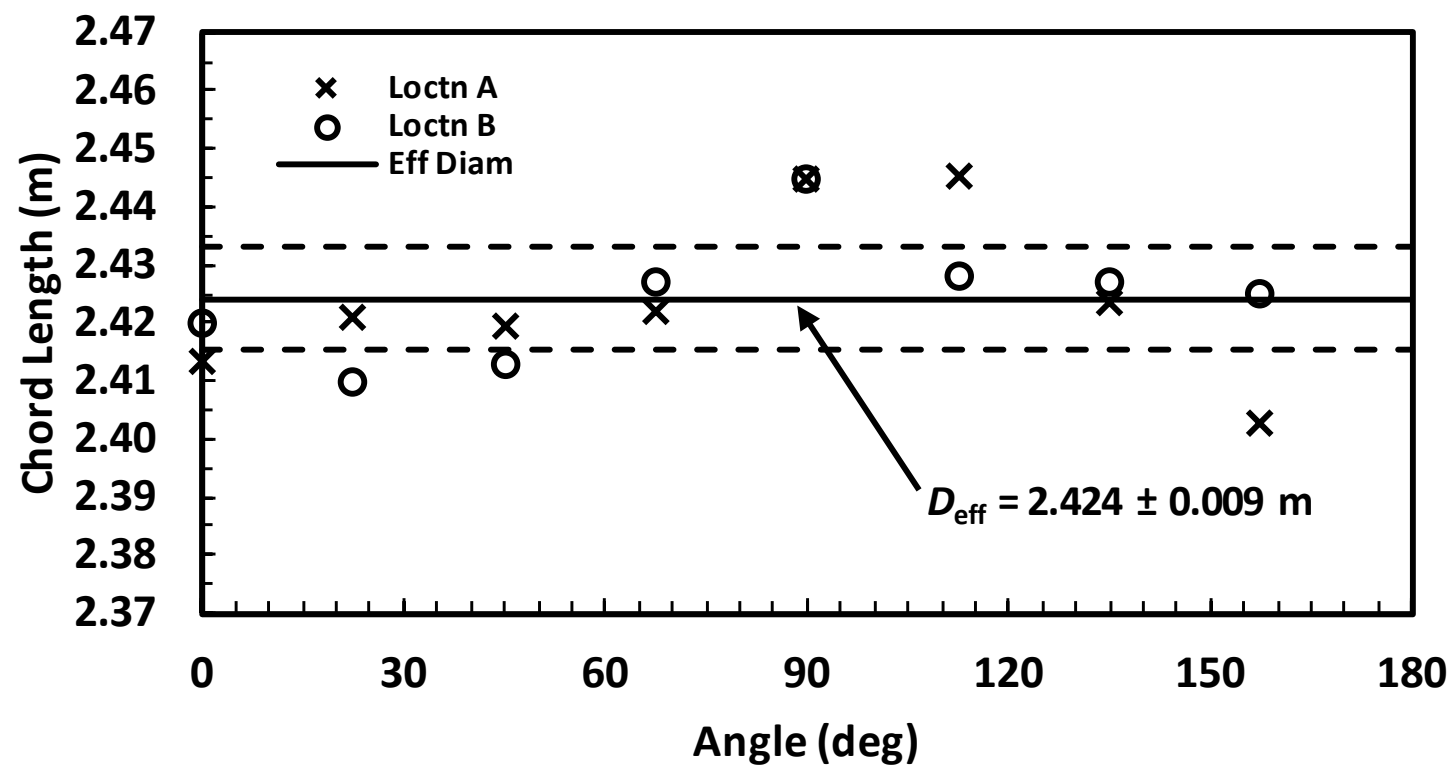

Figure 30 Chord length measurements at the measurement stations of the averaging pitot probes for the $20 \mathrm{MW}$ calorimeter. Dashed lines represent expanded uncertainties. 


\subsection{Uncertainty Budgets for Select Measurement Components}

Table 13 Uncertainty budget for the oxygen volume fraction measurement in the exhaust gas.

\begin{tabular}{lcccr}
\hline Measurement Component, $\boldsymbol{x}_{\boldsymbol{i}}$ & Value & $\boldsymbol{u}\left(\boldsymbol{x}_{\boldsymbol{i}}\right) / \boldsymbol{x}_{\boldsymbol{i}}$ & $\boldsymbol{s}_{\boldsymbol{i}}$ & $\begin{array}{r}\text { \% } \\
\text { Contribution }\end{array}$ \\
\hline$X_{\mathrm{O}_{2}}^{\text {span }}(\mathrm{L} / \mathrm{L})$ & 0.21259 & 0.00052 & 1.0 & 99.6 \\
$V_{\mathrm{O}_{2}}^{\text {span }}$ (volts) & 4.19228 & 0.000024 & -1.0 & 0.2 \\
$V_{\mathrm{O}_{2}}^{\text {zero }}$ (volts) & 0.00886 & 0.014 & 0.0 & 0.0 \\
$V_{\mathrm{O}_{2}}($ volts $)$ & 3.94290 & 0.000025 & 1.0 \\
\hline $\boldsymbol{X}_{\mathbf{O}_{\mathbf{2}}}(\mathbf{L} / \mathbf{L})$ & $\mathbf{0 . 1 9 9} \mathbf{9 2}$ & $\boldsymbol{u}_{\mathbf{c}} / \boldsymbol{X}_{\mathbf{O}_{2}}=\mathbf{0 . 0 0 0} 52$ \\
\hline
\end{tabular}

Table 14 Uncertainty budget for the carbon dioxide volume fraction measurement in the exhaust gas.

\begin{tabular}{lcccr}
\hline Measurement Component, $\boldsymbol{x}_{\boldsymbol{i}}$ & Value & $\mathbf{u}\left(\boldsymbol{x}_{\boldsymbol{i}}\right) / \boldsymbol{x}_{\boldsymbol{i}}$ & $\boldsymbol{s}_{\boldsymbol{i}}$ & $\begin{array}{r}\text { \% } \\
\text { Contribution }\end{array}$ \\
\hline$X_{\mathrm{CO}_{2}}^{\mathrm{Span}}(\mathrm{L} / \mathrm{L})$ & 0.010223 & 0.0012 & 1.0 & 96.5 \\
$V_{\mathrm{CO}_{2}}^{\mathrm{span}}$ (volts) & 1.70399 & 0.00011 & -1.0 & 0.8 \\
$V_{\mathrm{CO}_{2}}^{\text {zero }}$ (volts) & -0.00184 & 0.051 & 0.0 & 0.1 \\
$V_{\mathrm{CO}_{2}}$ (volts) & 0.95344 & 0.00020 & 1.0 & 2.6 \\
\hline $\boldsymbol{X}_{\mathrm{CO}_{2}}(\mathbf{L} / \mathbf{L})$ & $\mathbf{0 . 0 0 5 7 2 5}$ & $\boldsymbol{u}_{\mathbf{c}} / \boldsymbol{X}_{\mathrm{CO}_{2}}=\mathbf{0 . 0 0 1 2}$ \\
\hline
\end{tabular}


Table 15 Uncertainty budget for the measurement of carbon monoxide volume fraction in the exhaust gas.

\begin{tabular}{|c|c|c|c|c|}
\hline Measurement Component, $x_{i}$ & Value & $u\left(x_{i}\right) / x_{i}$ & $s_{i}$ & $\begin{array}{r}\% \\
\text { Contribution }\end{array}$ \\
\hline$X_{\mathrm{CO}}^{\text {span }}(\mathrm{L} / \mathrm{L})$ & 0.001005 & 0.0010 & 1.0 & 3.6 \\
\hline$V_{\text {CO }}^{\text {span }}$ (volts) & 1.44334 & 0.00035 & -1.0 & 0.5 \\
\hline$V_{\mathrm{CO}}^{\text {zero }}$ (volts) & 0.01983 & 0.021 & -0.1 & 33.6 \\
\hline$V_{\mathrm{CO}}$ (volts) & 0.14355 & 0.0036 & 1.2 & 62.3 \\
\hline$X_{\text {Co }}(\mathrm{L} / \mathrm{L})$ & $000873^{*}$ & & $0=$ & 0052 \\
\hline
\end{tabular}

*For the case of a fire in a furnished room with structural walls made from cross laminated timber. 
Table 16 Uncertainty budget for the measurement of effective gas velocity by the averaging pitot probes in the exhaust duct.

\begin{tabular}{lrrrr}
\hline Measurement / Parameter, $\boldsymbol{x}_{\boldsymbol{i}}$ & Value & $\boldsymbol{u}\left(\boldsymbol{x}_{\boldsymbol{i}}\right) / \boldsymbol{x}_{\boldsymbol{i}}$ & $\boldsymbol{s}_{\boldsymbol{i}}$ & $\begin{array}{r}\text { \% } \\
\text { Contribution }\end{array}$ \\
\hline$C_{\mathrm{f}}(-)$ & 1.028 & 0.014 & 1.0 & 90.9 \\
$K_{\mathrm{a}}(-)$ & 0.6271 & 0.0038 & 1.0 & 6.4 \\
$R(\mathrm{~J} / \mathrm{kmol} \mathrm{K})$ & 8314.47 & 0.0000 & 0.5 & 0.0 \\
$M_{\mathrm{air}}(\mathrm{kg} / \mathrm{kmol})$ & 28.97 & 0.0035 & -0.5 & 1.4 \\
$P_{\mathrm{amb}}(\mathrm{Pa})$ & 100762 & 0.00051 & -0.5 & 0.0 \\
$\Delta P_{\mathrm{A}}(\mathrm{Pa})$ & 27.162 & 0.0030 & 0.25 & 0.3 \\
$\Delta P_{\mathrm{B}}(\mathrm{Pa})$ & 25.442 & 0.0030 & 0.25 & 0.2 \\
$T_{\mathrm{e}, \mathrm{A} 1}(\mathrm{~K})$ & 396.8 & 0.0051 & 0.13 & 0.2 \\
$T_{\mathrm{e}, \mathrm{A} 2}(\mathrm{~K})$ & 396.6 & 0.0051 & 0.13 & 0.2 \\
$T_{\mathrm{e}, \mathrm{B} 1}(\mathrm{~K})$ & 395.4 & 0.0051 & 0.12 & 0.2 \\
$T_{\mathrm{e}, \mathrm{B} 2}(\mathrm{~K})$ & 395.3 & 0.0051 & 0.12 & 0.2 \\
\hline $\boldsymbol{V}_{\mathrm{eff}}(\mathbf{m} / \mathbf{s})$ & 4.965 & & $\boldsymbol{u}_{\mathbf{c}} / \boldsymbol{V}_{\text {eff }}=\mathbf{0 . 0 1 4 8}$ & \\
\hline
\end{tabular}


Table 17 Uncertainty budget for the natural gas heat of combustion computed from micro gas chromatograph measurements.

\begin{tabular}{|c|c|c|c|c|}
\hline $\begin{array}{l}\text { Measurement / Parameter, } \\
x_{i} \text { (Units) }\end{array}$ & Value & $u\left(x_{i}\right) / x_{i}$ & $s_{i}$ & $\%$ Contribution \\
\hline$\Delta_{c} H_{\mathrm{CH}_{4}}^{i d}\left(\mathrm{MJ} / \mathrm{m}^{3}\right)$ & 33.883 & 0.0005 & 0.94 & 0.6 \\
\hline$\Delta_{c} H_{\mathrm{C}_{2} \mathrm{H}_{6}}^{i d}\left(\mathrm{MJ} / \mathrm{m}^{3}\right)$ & 60.311 & 0.0005 & 0.0483 & 0.0 \\
\hline$\Delta_{c} H_{\mathrm{C}_{3} \mathrm{H}_{8}}^{i d}\left(\mathrm{MJ} / \mathrm{m}^{3}\right)$ & 86.251 & 0.0005 & 0.0036 & 0.0 \\
\hline$\Delta_{c} H_{\mathrm{C}_{4} \mathrm{H}_{10}}^{i d}\left(\mathrm{MJ} / \mathrm{m}^{3}\right)$ & 111.792 & 0.0005 & 0.0002 & 0.0 \\
\hline$\Delta_{c} H_{\mathrm{C}_{4} \mathrm{H}_{10}}^{i d}\left(\mathrm{MJ} / \mathrm{m}^{3}\right)$ & 112.179 & 0.0005 & 0.0004 & 0.0 \\
\hline$\Delta_{c} H_{\mathrm{C}_{5} \mathrm{H}_{10}}^{i d}\left(\mathrm{MJ} / \mathrm{m}^{3}\right)$ & 137.821 & 0.0005 & 0.0001 & 0.0 \\
\hline$\Delta_{c} H_{\mathrm{C}_{5} \mathrm{H}_{10}}^{i d}\left(\mathrm{MJ} / \mathrm{m}^{3}\right)$ & 138.003 & 0.0005 & 0.0000 & 0.0 \\
\hline$\Delta_{c} H_{\mathrm{C}_{6+}}^{i d}\left(\mathrm{MJ} / \mathrm{m}^{3}\right)$ & 177.055 & 0.0005 & 0.0037 & 0.0 \\
\hline$\Delta_{c} H_{\mathrm{N}_{2}}^{i d}\left(\mathrm{MJ} / \mathrm{m}^{3}\right)$ & 0.000 & 0.0005 & 0.00 & 0.0 \\
\hline$\Delta_{c} H_{\mathrm{CO}_{2}}^{i d}\left(\mathrm{MJ} / \mathrm{m}^{3}\right)$ & 0.000 & 0.0005 & 0.00 & 0.0 \\
\hline$X_{\mathrm{CH}_{4}}(\mathrm{~L} / \mathrm{L})$ & 0.9661 & 0.0054 & 0.94 & 65.6 \\
\hline$X_{\mathrm{C}_{2} \mathrm{H}_{6}}(\mathrm{~L} / \mathrm{L})$ & 0.0278 & 0.063 & 0.0483 & 23.6 \\
\hline$X_{\mathrm{C}_{3} \mathrm{H}_{8}}(\mathrm{~L} / \mathrm{L})$ & 0.00147 & 0.175 & 0.0036 & 1.0 \\
\hline$X_{\mathrm{C}_{4} \mathrm{H}_{10}}(\mathrm{~L} / \mathrm{L})$ & 0.000077 & 0.29 & 0.0002 & 0.0 \\
\hline$X_{\mathrm{C}_{4} \mathrm{H}_{10}}(\mathrm{~L} / \mathrm{L})$ & 0.000129 & 0.25 & 0.0004 & 0.0 \\
\hline$X_{\mathrm{C}_{5} \mathrm{H}_{12}}(\mathrm{~L} / \mathrm{L})$ & 0.0000128 & 0.85 & 0.0001 & 0.0 \\
\hline$X_{\mathrm{C}_{5} \mathrm{H}_{12}}(\mathrm{~L} / \mathrm{L})$ & 0.0000041 & 1.59 & 0.0000 & 0.0 \\
\hline$X_{\mathrm{C}_{6+}}(\mathrm{L} / \mathrm{L})$ & 0.00072 & 0.52 & 0.0037 & 9.1 \\
\hline$X_{\mathrm{N}_{2}}(\mathrm{~L} / \mathrm{L})$ & 0.002583 & 0.007 & 0.00 & 0.0 \\
\hline$X_{\mathrm{CO}_{2}}(\mathrm{~L} / \mathrm{L})$ & 0.00112 & 0.19 & 0.00 & 0.0 \\
\hline$\Delta_{c} H_{N G}^{i d}\left(\mathbf{M J} / \mathbf{m}^{3}\right)$ & 34.69 & & $\Delta_{c} H_{N G}^{i d}$ & 0.0063 \\
\hline
\end{tabular}

